\title{
The good, the bad, and the bubbly: Textural controls on secondary vesiculation of silicic magma through thermal heating
}

\author{
By \\ Calvin Michael Jones \\ A thesis submitted to Victoria University of Wellington in partial \\ fulfilment of requirements for the degree Master of Science in \\ Geology
}

\section{Geology Department}

School of Geography, Environment, and Earth Sciences

Victoria University of Wellington 


\section{Abstract}

Volcanic eruptions are driven by magma buoyancy caused by volatiles exsolving to form a separate gas phase. Gas overpressurization within the melt and subsequent fragmentation determines whether an eruption will be explosive (fragmentation) or effusive (no fragmentation). Therefore, a thorough understanding of factors which affect the ability of a melt to exsolve and retain or lose these volatiles effectively is required. Bubble nucleation and subsequent growth are the processes by which volatiles exsolve from the melt into an exsolved gas phase. As continued vesiculation occurs, bubbles may begin to interact and coalesce at a point called the percolation threshold, permeable pathways through the melt will then form until the permeability threshold is reached allowing volatiles to outgas, reducing overpressure. Currently, research has focused on the effects that pressure, temperature, and composition have on volatile solubility and eventual vesiculation. However, erupted bombs consisting of assemblages of heterogenous pyroclasts that were subsequently sintered and welded into a conduit-forming plug during the Cordón Caulle 2011-2012 eruption display vesiculation trends within naturally occurring obsidian pyroclasts formed by sintering of particles or quenched melt that cannot be resolved by volatile solubility effects alone. The erupted products have consistently low volatile contents with little variability present across erupted samples (0.07-0.32 wt. \% $\left.\mathrm{H}_{2} \mathrm{O}\right)$. Within these pyroclasts, the heterogeneity of internal textures is visible when viewed using backscattered electron (BSE) imaging or X-ray computed tomography (XCT) as clear borders exist between regions that are of a clastogenic (sintered) origin, of a quenched melt origin, or formed by variable forms of vesiculation. The heterogeneity of internal textures present within even a obsidian pyroclastic domain led to the hypothesis that foaming discrepancies observed within individual clasts were due to pre-existing textures promoting or inhibiting secondary vesiculation in the shallow conduit. This secondary vesiculation occurs through near isobaric temperature increases

in the shallow conduit, following primary vesiculation and volatile exsolution associated with isothermal decompression from storage at depth. To test this hypothesis, obsidian samples of $1 \mathrm{~cm} \times 1-2 \mathrm{~cm} \times 1-3 \mathrm{~cm}$ were heated above their glass transition temperature $\left(T_{\mathrm{g}}\right)$, between $850-$ 
$910^{\circ} \mathrm{C}$, to allow obsidians to vesiculate as the melt would have in the conduit. The textures of the samples were characterised before and after heating using $\mathrm{x}$-ray computed tomography. The results show that within the slightly volatile supersaturated samples variable foaming was observed for each independent texture within obsidian pyroclasts, with foaming preferentially occurring within regions that contained pre-existing, isolated bubbles. These experiments show that limited thermally driven in situ foaming of relatively dense clasts containing small isolated bubbles, can increase overpressure if the domain doesn't expand as bubbles form without increasing permeability leading to gas overpressure within this smaller region and localised explosions in order to clear this blockage, explaining the hybrid effusive-explosive eruptions observed at Cordón Caulle. 


\section{Acknowledgements}

I first have to thank my supervisor, lan Schipper: he has guided me through my thesis with numerous helpful insights, and a willingness to make time for a discussion on how my work is going. Although things did not always go to plan, especially being amid a global pandemic, you always had a plan B that we could follow to finish the project. Thank you taking me on as a student and aiding me in achieving this mammoth task of finishing a thesis, you truly were invaluable.

Secondly, I would like to thank my parents, Vicki and Richard, and my sister, Kelsey, for putting up with me throughout my entire time at uni. Your ability to be a sounding board and help my ideas come out in the writing, as well as being my second line grammar checker, was always appreciated although sometimes unspoken.

Ben Kennedy, Alex Nichols, Jonathan Davidson, and all the Canterbury University geology team that helped me during my heating experiments and FTIR work down in Christchurch. Your insights and technical know-how were evident, and my thesis work could not have gone ahead without you all. Also, the numerous ideas and questions asked generated many areas of discussion throughout this thesis.

I must also acknowledge all my other master and PhD thesis survivors; Abbie, Matt, Pip, Maia, Laura, Steph, Steve, Marco, Nick, Brenton, Josh, Carmen, Olivia, Sam, Alistair, Emily, Theo, Stu, Harry, and Yaas, we all were going through the same situations and getting a coffee or talking through ideas with each other was incredible. I believe all our work benefited from our group sessions, and the extra-curricular hang outs were just as helpful.

Last but far from least is all my friends, new and old, that helped me get through this year, and my entire time at uni. I know I continuously said no to hanging out a lot of the time but thanks for sticking with me for all this time. I am sorry I cannot name you all as there is just so many of you all and you all do mean the world to me. Your friendship and help over the years have shaped me and kept me sane over the years, as well as showing me I am capable of doing this. 


\section{Table of Contents}

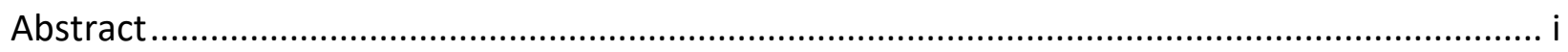

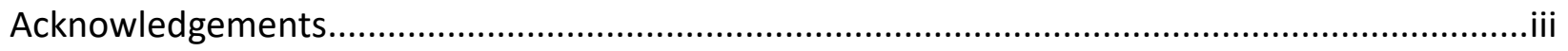

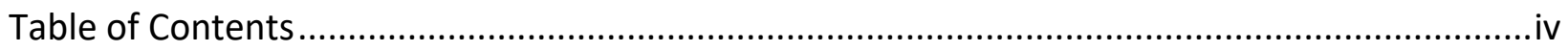

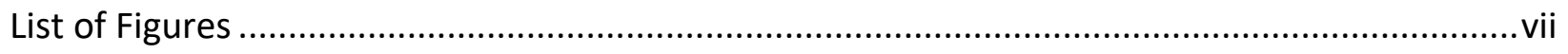

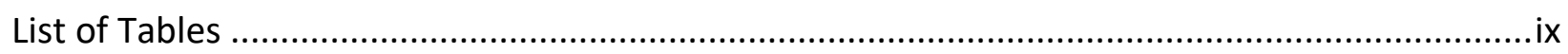

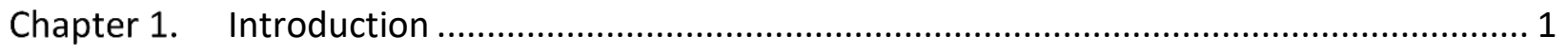

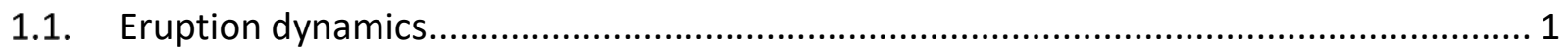

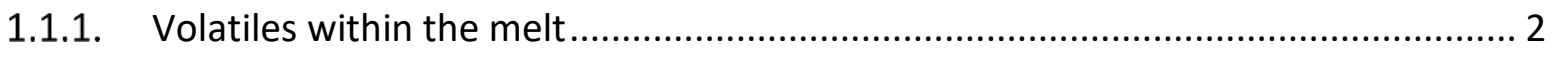

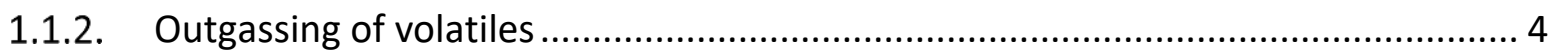

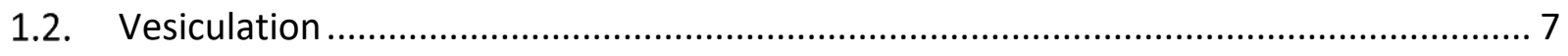

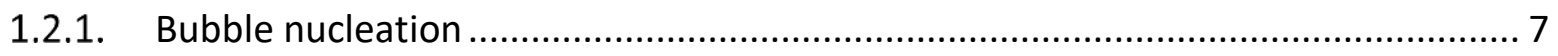

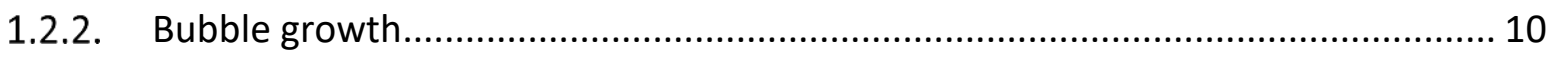

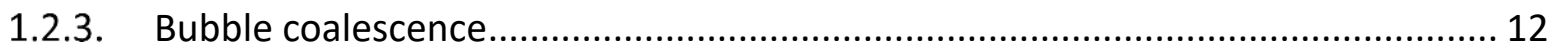

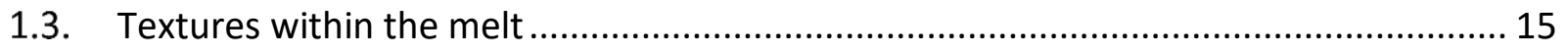

1.3.1. Investigating internal textures ............................................................ 15

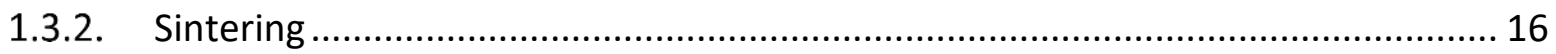

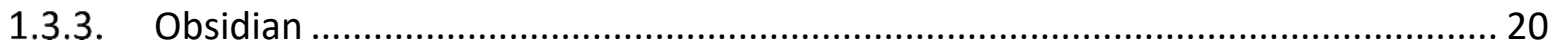

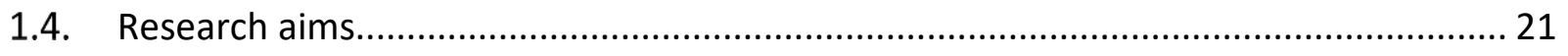

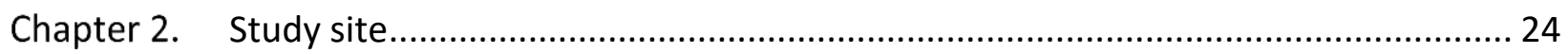




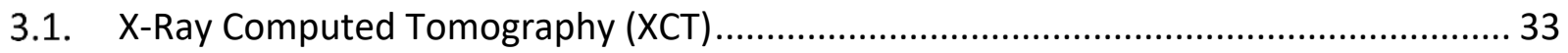

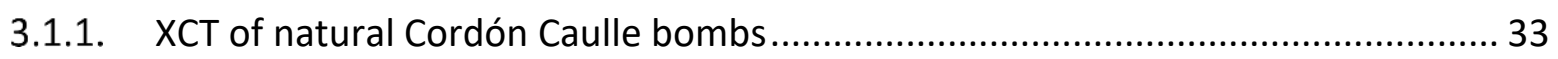

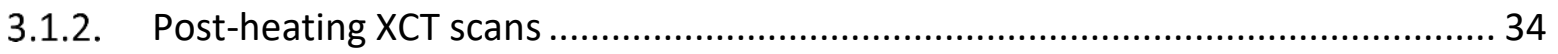

3.2. Fourier Transform Infrared Spectroscopy (FTIR) ............................................... 35

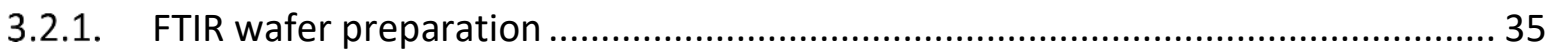

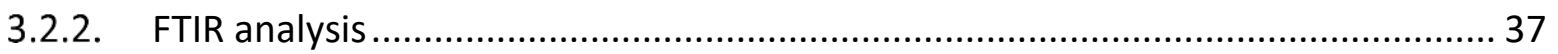

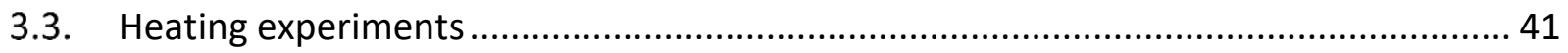

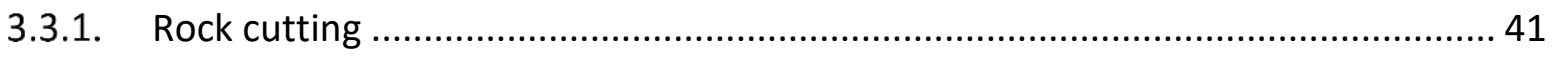

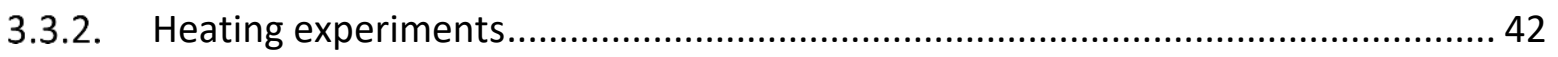

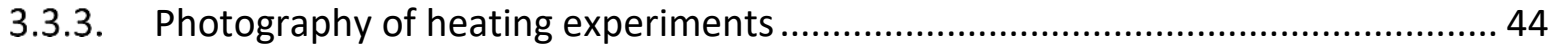

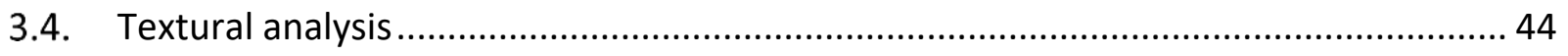

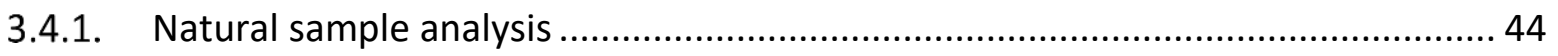

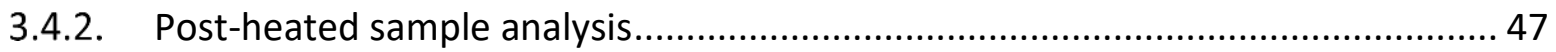

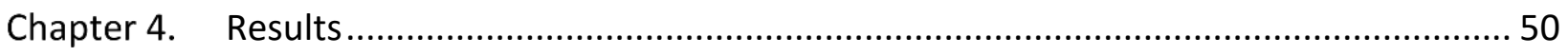

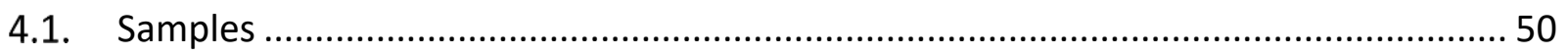

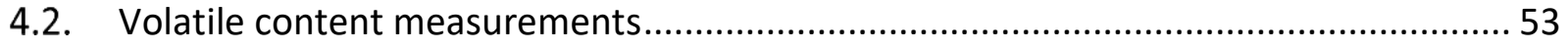

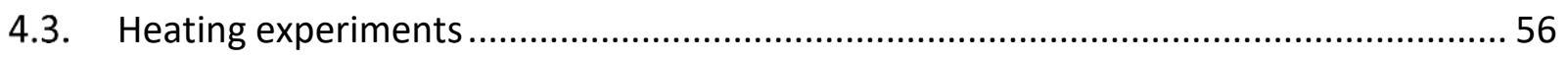

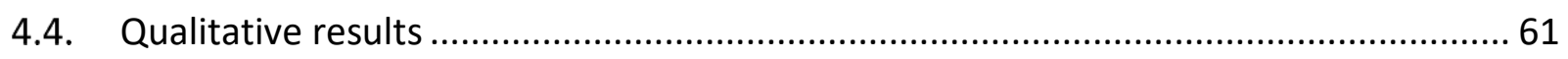

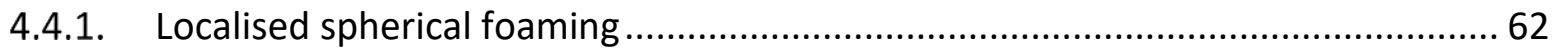

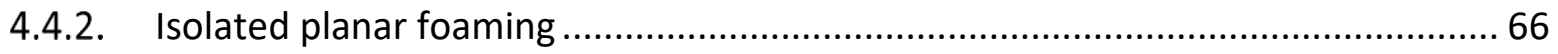

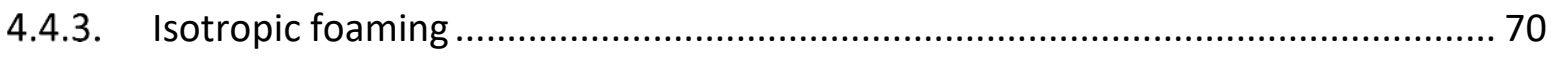

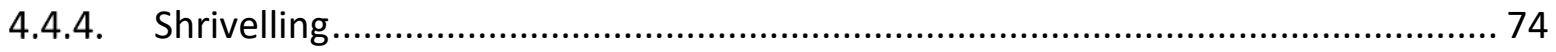




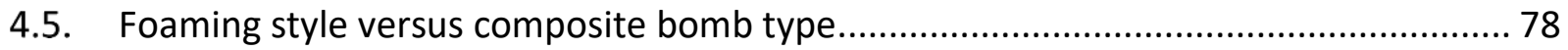

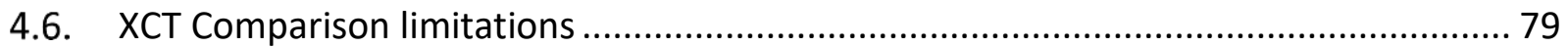

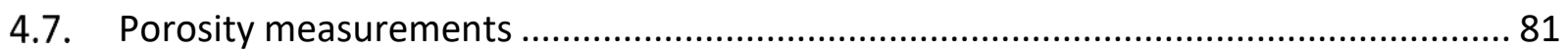

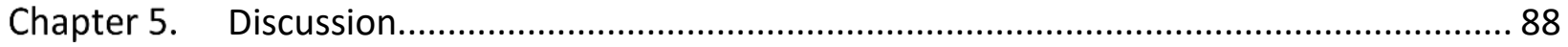

5.1. Textural representation of scanned heated samples ............................................. 88

5.2. The effect of volatile contents on porosity change ............................................ 92

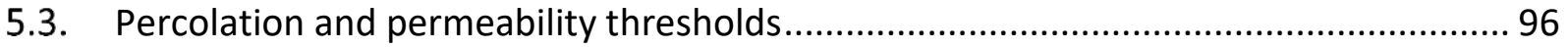

5.4. Differing vesiculation styles within a singular texture........................................ 100

5.5. Vesiculation processes in slightly supersaturated melt ......................................... 104

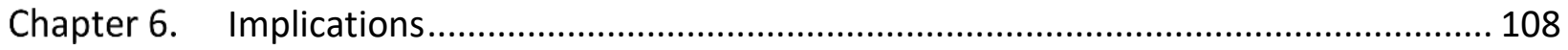

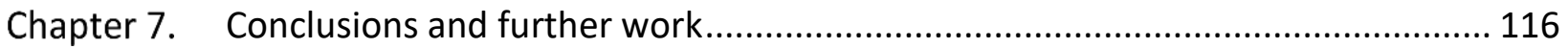

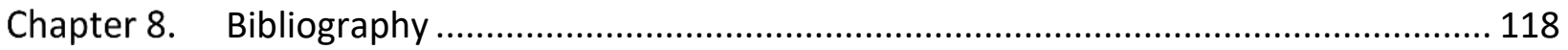

Appendix 1: All Data Collected During Heating Experiments of Samples .............................. 124

Appendix 2: FTIR measured and averaged data ............................................................. 128 


\section{List of Figures}

Figure 1.1 Effect of pressure and temperature on the solubility of $\mathrm{CO}_{2}$ and $\mathrm{H}_{2} \mathrm{O}$ in Cordón Caulle

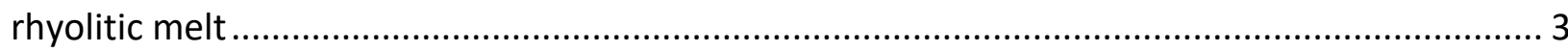

Figure 1.2 Schematic of typical effusive open system (A) and explosive closed system (B)

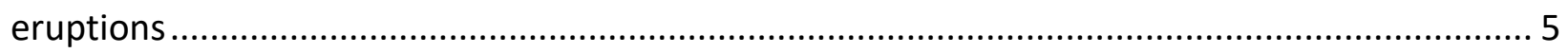

Figure 1.3 Schematic of diffusion occurring within a melt, required to both nucleate and grow

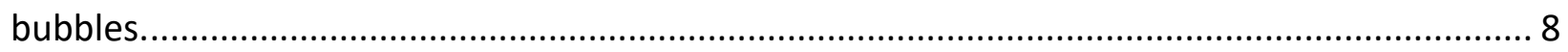

Figure 1.4 Schematic of bubble coalescence within a melt................................................... 12

Figure 1.5 Sintering of ash to form coherent melt and retain clastogenic textures. .................. 19

Figure 2.1 Cordón Caulle eruption with location where composite bomb samples were obtained

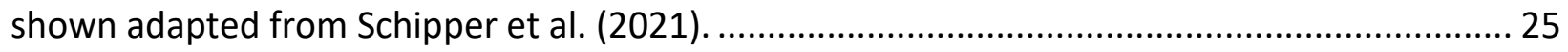

Figure 2.2 Composite bombs erupted from Cordón Caulle showing the variability in appearance

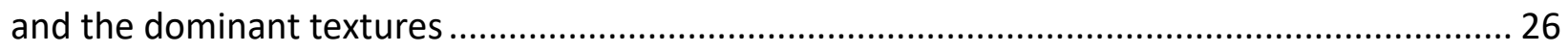

Figure 2.3 Internal textural variations within individual obsidian pyroclasts within composite

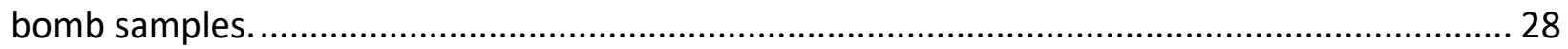

Figure 2.4 Vesiculation variability of obsidians within a composite bomb sample. ................. 30

Figure 2.5 Differences and variability of water contents measured in obsidian pyroclasts of

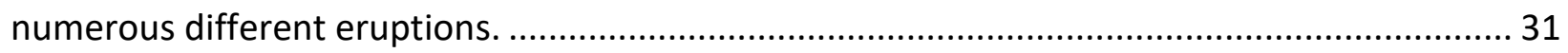

Figure 3.1 Schematic diagram of the set up used during the heating experiments. ................. 42

Figure 4.1 Histogram of obsidian water contents grouped by texture of composite bomb samples

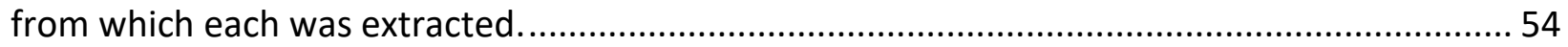

Figure 4.2 Isolated spherical foaming in two different obsidian samplesError! Bookmark not defined.

Figure 4.3 Isolated spherical foaming of two samples comparing the textural change of the

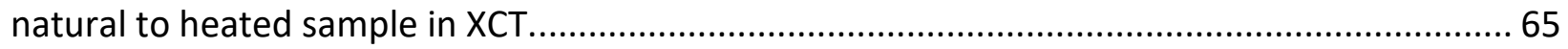

Figure 4.4 Isolated planar foaming within two composite bomb samples, from the B21_AS23

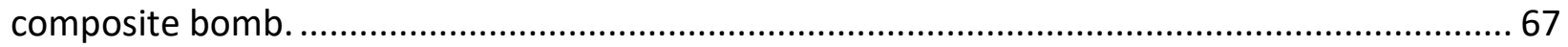

Figure 4.5 Isolated planar foaming displayed in XCT within two B21_AS23 samples ................. 69 
Figure 4.6 Isotropic foaming occurring within obsidians at the start and the end of the heating

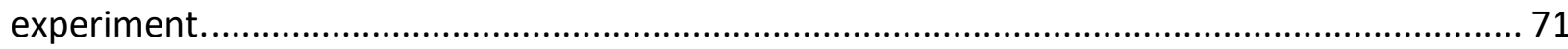

Figure 4.7 Isotropic expansion within obsidian samples in XCT ......................................... 73 Figure 4.8 Shrivelling and decrease in volume of pumice and obsidian regions within composite

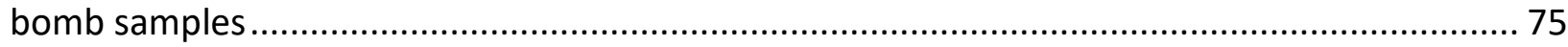

Figure 4.9 Shrivelling observed in XCT within pumice and obsidian regions of composite bombs. 77

Figure 4.10 Histogram of foaming observed throughout the heating experiments per composite

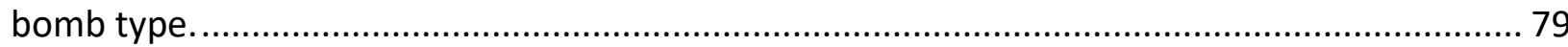

Figure 4.11 Comparison of XCT scans of a natural and heated sample. ................................. 81

Figure 4.12 Porosity changes during the heating of natural obsidians. ................................... 83

Figure 5.1 Areas of foaming within composite bomb samples' ........................................... 90

Figure 5.2 Effect of initial volatile contents on the porosity changes during heating experiments.

Figure 5.3 Differences in secondary vesiculation in response to pre-existing textures and

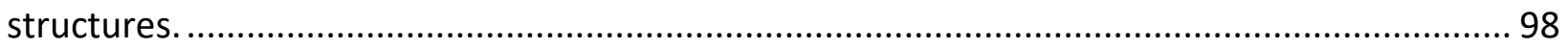

Figure 5.4 Coalescence and collapse of structures that decreases porosity.......................... 102 Figure 5.5 Spherical isolated foaming showing the structural reorganisation associated with this foaming. 107

Figure 6.1 Cartoon cross-section from NW to SE of the Cordón Caulle 2011-2012 vent, with proposed effects of textures had on the eruption dynamics observed during the effusiveexplosive hybrid eruption 114 


\section{List of Tables}

Table 4.1 Composite bomb classes and alterations made for our experiments...................... 52 Table 4.2 Water contents of obsidian samples, grouped into composite bomb types from which

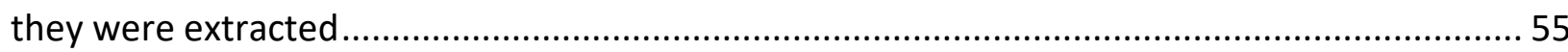

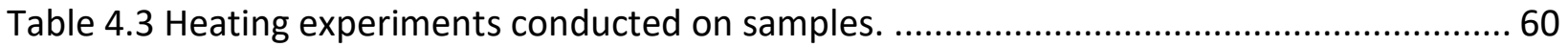

Table 4.4 Porosity and volume change from natural to heated samples observed for specific

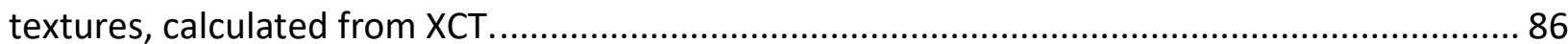




\section{Chapter 1. Introduction}

Volcanic eruptions are some of the most hazardous natural events on Earth, however the hazard associated with a given eruption are dependent on its overall eruption dynamics. Numerous different features can affect the eruption dynamics, including vesiculation, which is the exsolution of dissolved volatiles into a separate gas phase. The effect that internal textures within the magma have on secondary vesiculation (late-stage isobaric heating in the shallow conduit, as opposed to isothermal decompression from depth) and consequent eruption dynamics is unknown. The aim of this thesis is to determine how these internal textures within the magma body can affect the vesiculation process and will focus on how the effect of temperature on solubility of a melt mildly and variably oversaturated at near-atmospheric pressures. Due to vesiculation impacting additional processes prior to the overall effect on eruption dynamics, a background of eruption dynamics, how vesiculation affects this, and pre-existing knowledge will be given prior to research aims at the end of this section. This allows for the previous gaps in knowledge to be highlighted and a context for why these research aims were selected. Following this, selection of 2011-2012 Cordón Caulle erupted samples will be justified and shown to be ideal for representing the textural controls on secondary vesiculation, and methods used to determine the textural controls on secondary vesiculation explained. This is followed by a presentation of the data acquired using the prior methods and a discussion of the representative nature of the textures selected, trends observed which promoted or limited vesiculation, and what this implies for eruption dynamics - especially effusive-explosive hybrid eruptions. Through this thesis the textural controls on vesiculation will be shown and the potential impacts to eruption dynamics explained.

\subsection{Eruption dynamics}

Volcanic eruptions are driven by gas overpressure within the conduit as volatiles exsolve from an ascending melt (Eichelberger and Westrich 1981), and have end-member dynamics ranging from effusive to explosive (Newhall and Self 1982; Schipper et al. 2013; Cassidy et al. 2018). Effusive eruptions are typified by lava flow emplacement with a relatively minor impact to the local 
surroundings, and are thought to be associated with the development of effective permeable pathways through which exsolved volatiles can be removed from the melt (Gonnermann and Manga 2003; Gonnermann 2015). Explosive volcanic eruptions have higher impact to surrounding areas with wide dispersal of pyroclastic material that is erupted quickly and violently. Explosive eruptions are typically associated with exsolved volatiles being retained within the melt, building internal pressure that leads to violent eruptions.

Although gas overpressure within the conduit is the major control on volcanic eruptions, numerous additional factors affect the ability of the melt to exsolve volatiles and then outgas the resulting gases from the conduit. It is primarily melt composition and rheology, decompression rates, temperature, and fluid dynamics within the conduit that control the fate of exsolved volatiles, and thus eruption dynamics (Newhall and Self 1982; Polacci et al. 2009; Bryan et al. 2010). Additional processes can impact the eruption dynamics such as conduit geometry and the external assimilation of ground or surface water, although to a lesser extent (Cassidy et al. 2018).

\subsubsection{Volatiles within the melt}

A volcanic eruption is driven by the exsolution of volatiles from the liquid melt (Eichelberger and Westrich 1981). These volatiles are dominantly $\mathrm{H}_{2} \mathrm{O}$ with $\mathrm{CO}_{2}$ being in a lesser abundance within the melt, and even lower concentration of other volatiles elements (e.g. S, Cl, F) (Wallace 2005; Zhang et al. 2010). Solubility laws determine the amount of volatiles that can be contained within the melt at any certain pressure and temperature (Eichelberger and Westrich 1981). Within shallower magma systems the exsolution of water drives volcanic eruptions as it is the most abundant volatile and relatively soluble to low pressures compared to other major volatile species (Wallace 2005). When the volatiles dissolved within the melt reach their solubility limits, the melt is referred to as being saturated, and equilibrium saturation curves for $\mathrm{H}_{2} \mathrm{O}$ and $\mathrm{CO}_{2}$ at different temperatures are displayed on Figure 1.1. If any perturbations should occur within this system, such as a decrease in pressure or increase in temperature, volatiles within the melt will exceed the saturation point, and the melt becomes supersaturated. When a melt enters this state of supersaturation it requires volatile exsolution to then regain equilibrium with the melt (Ericson et al. 1975; Toramaru 1989). 


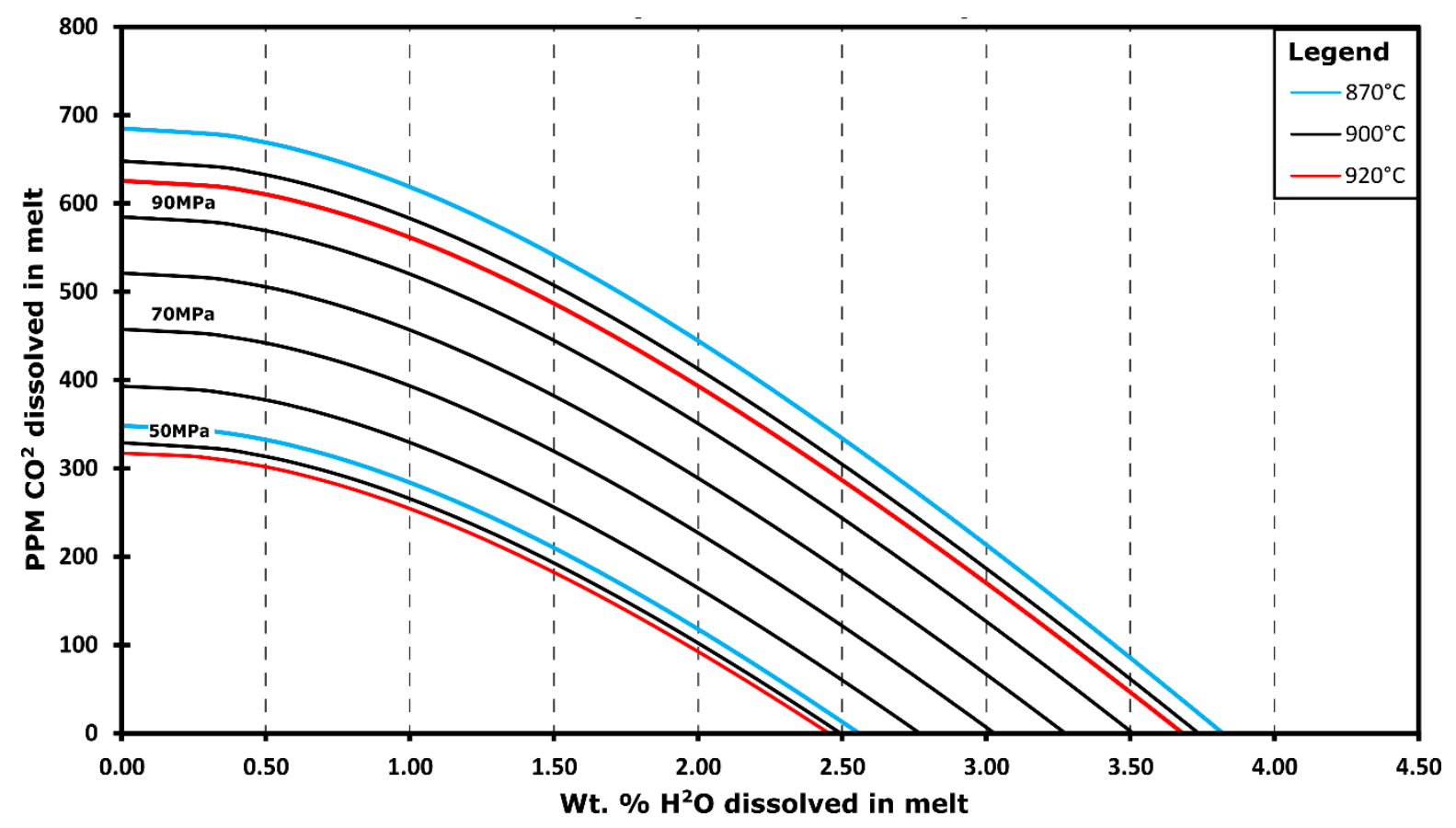

Figure 1.1 Effect of pressure and temperature on the solubility of $\mathrm{CO}_{2}$ and $\mathrm{H}_{2} \mathrm{O}$ in Cordón Caulle rhyolitic melt, obtained using compositions given by Castro et al. (2014) and the VolatileCalc program by Newman and Lowenstern (2002). Each solid black line within this image defines 10MPa changes to pressure with the lowest being 50MPa and the highest being $100 \mathrm{MPa}$ at a temperature of $900^{\circ} \mathrm{C}$, the red lines show the effect of increasing the temperature by $20^{\circ} \mathrm{C}$ at $50 \mathrm{MPa}$ and $100 \mathrm{MPa}$. The blue line shows the effect of cooling the melt by $30^{\circ} \mathrm{C}$ at $50 \mathrm{MPa}$ and $100 \mathrm{MPa}$.

Figure 1.1 demonstrates the relationship between the solubility limits of weight percentage (wt. \%) of $\mathrm{H}_{2} \mathrm{O}$ and of $\mathrm{CO}_{2}$ in parts per million (ppm) within a rhyolitic melt (Cordón Caulle) at given pressure and temperatures using the software VolatileCalc by Newman and Lowenstern (2002). Decreasing the pressure of the melt has the greatest impact on solubility (Fig. 1.1), as this depressurization during magma ascent creates a positive feedback loop (Martel and Schmidt 2003; Polacci et al. 2009; Edmonds and Woods 2018). As pressure decreases the melt will exsolve volatiles to regain equilibrium by creating a low-density fluid phase. If this fluid is not removed from the melt, it will increase the buoyancy of the melt, causing the magma to further ascend, lowering pressure and driving further volatile exsolution in a feedback loop (Martel and Schmidt 2003; Polacci et al. 2009; Edmonds and Woods 2018).

Although pressure most strongly controls volatile solubility, heating a melt can also drive exsolution by causing the melt to reach solubility limits (Fig. 1.1), as shown by Lavallée et al. (2015) for the 2012 Santiaguito volcanic eruption. Although this heating can affect and cause 
eruptions, especially within shallow vent or stalled melts within the conduit, it is a less dominant factor due to the lack of this feedback loop. Also as a melt rises through the conduit to generally lower temperatures controlled by the earth geothermal gradient, the temperature of the melt may slightly lower through heat conduction to the conduit walls, however this is not significant compared to the dominant effect of depressurisation and competes with the heating effects of viscous or frictional heating (Edmonds 2008; Lavallée et al. 2015; Edmonds and Woods 2018).

The last important feature for volatile exsolution within a melt is the initial melt composition. Basaltic and rhyolitic melts have different melt solubilities (Stevenson et al. 1997; Newman and Lowenstern 2002; Liu et al. 2005; Wallace 2005). Additionally, the volatile content of the magma (e.g. CO2, F, Cl etc) will in turn affect the solubility of water (Tuffen et al. 2013; Castro et al. 2014; Forte and Castro 2019). Therefore, melt evolution, magma mixing or gas fluxing can all locally affect solubility, drive vesiculation and eventual eruption (Pallister et al. 1992; Kress 1997; Forte and Castro 2019). However, the focus of all these previous studies has been on how fluctuations to the solubility of volatiles can affect the vesiculation of the melt.

\subsubsection{Outgassing of volatiles}

Gas removal from within a volcanic system has one of the highest impacts on eruption dynamics. The process is in two stages; "degassing" is used to describe volatile exsolution from melt into a bubble; and the term "outgassing" is used here to describe the removal of bubbles from the magma (Eichelberger et al. 1986; Gonnermann and Manga 2003; Gonnermann 2015). As outgassing refers to the removal of exsolved volatiles from within the melt it is the key feature of open system (Fig. 1.2 A), as opposed to closed system (Fig. 1.2 B) degassing. Outgassing occurs when exsolved volatile gases are vented upwards or into the conduit walls along permeable pathways (Bagdassarov and Dingwell 1992; Gonnermann 2015; Cassidy et al. 2018). Such an open system (Fig. 1.2 A) allows for these volatile gases to be outgassed from the magma effectively, lowering the internal pressure and typically leading to an effusive eruption. Closed system degassing (Fig. 1.2 B) cannot outgas the exsolved volatile gases from within the magma, meaning these remain within the system and produce overpressure as well as the development of 
buoyancy, which can lead to the positive feedback loop discussed earlier and an explosive eruption (Edmonds 2008; Gonnermann 2015; Wallace et al. 2015).
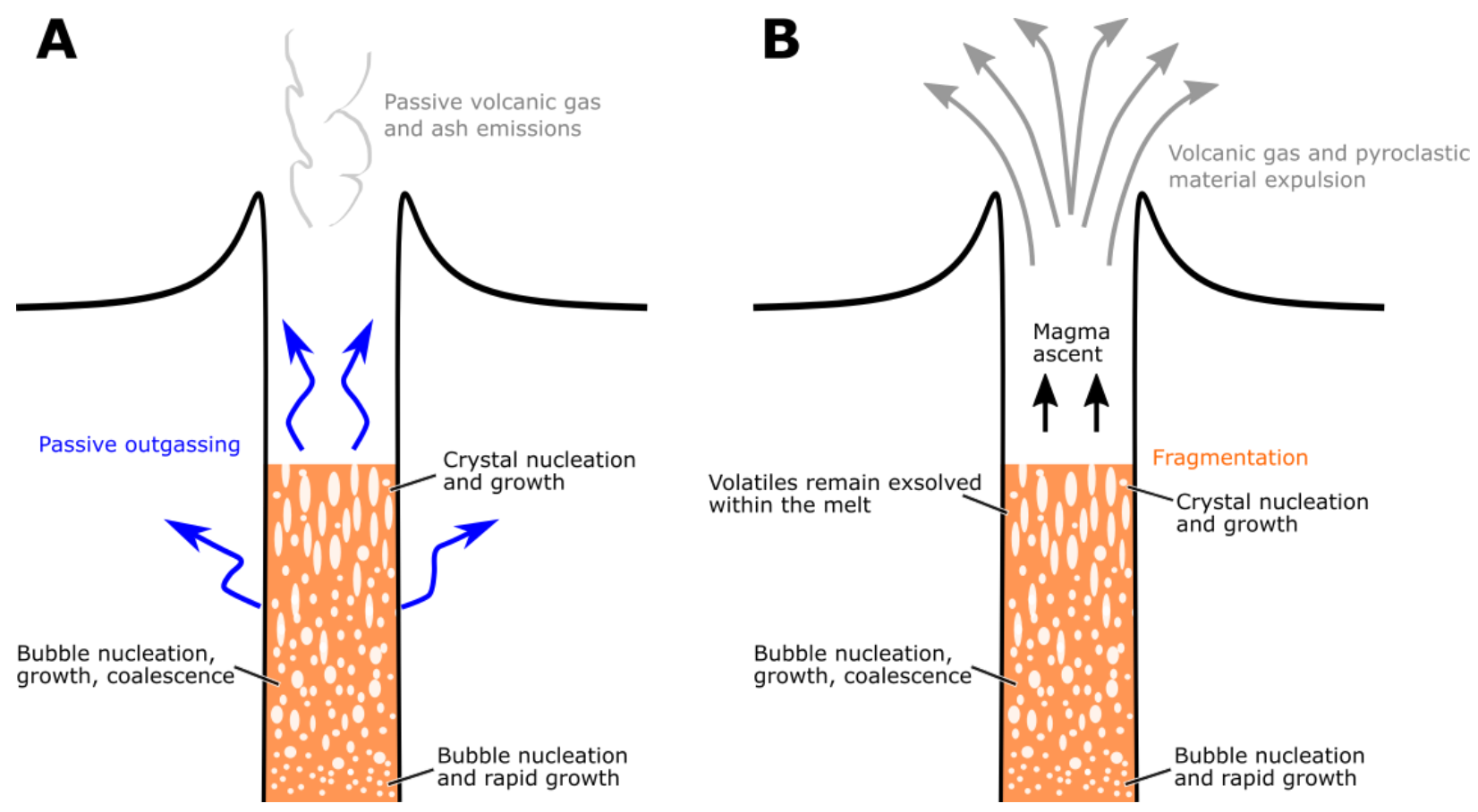

Figure 1.2 Schematic of typical effusive open system (A) and explosive closed system (B) eruptions adapted from Gonnermann (2015) and Whattam (2019). A typical open system degassing scenario, where bubble nucleation, growth, and coalescence occurs throughout the conduit. Volatiles can be outgassed effectively through either the conduit vent or through the conduit walls resulting in passive volcanic gas emissions from the vent (top of $\boldsymbol{A}$ ) or geothermal activity if the gases are removed through the conduit walls. B typical closed system degassing where bubble nucleation and growth occur throughout the conduit as volatiles are exsolved, but the lack of effective outgassing pathways results in volatile retention within the magma. This then causes the magma to ascend throughout the conduit, begin to fragment near surface, and lead to volcanic gas and pyroclastic material being erupted in a violent, explosive eruption.

Degassing via diffusion and outgassing via viscous bubble migration both depend upon the viscosity of the melt (Castro et al. 2014; Gonnermann 2015; Gardner et al. 2018). Viscosity is the ability for the melt to resist flow, so at higher viscosities the exsolved gaseous volatiles will be unable to move easily throughout the melt and can be associated with a closed system (Fig. 1.2 B). If the viscosity is low (e.g., in basaltic systems) the converse will happen, where the exsolved gas volatiles can easily move through the melt, be more likely to be removed readily and form an open system (Eichelberger and Westrich 1981; Cassidy et al. 2018). 
Outgassing of the melt can also be achieved via the formation of effective outgassing pathways, for example a high-viscosity silicic melt can be an open system and allow gas to be removed from the melt through cracks or connected bubble networks (Fig. 1.2 A) (Eichelberger and Westrich 1981; Sparks 2003; Gonnermann 2015; Kennedy et al. 2016; Gardner et al. 2018; Wadsworth et al. 2020). However, if these fractures and outgassing pathways suddenly close and can no longer effectively outgas, the system can switch from being open to closed, build pressure and transition from an effusive to explosive eruption (Schipper et al. 2013; Cassidy et al. 2018; Wadsworth et al. 2020).

Lastly, the melt composition and volatile exsolution will also affect the outgassing of the melt. If the resulting volatiles within the melt are high and exsolution is occurring at a rate that these cannot be effectively removed, through either a high viscosity, regardless of the viscosity or outgassing pathways present. This can be due to magma ascent occurring quicker then bubble migration or the viscosity of the melt inhibiting bubble migration (Eichelberger and Westrich 1981; Sparks 2003; Gonnermann 2015; Kennedy et al. 2016; Gardner et al. 2018; Wadsworth et al. 2020). This will then lead to an effectively closed system due to the inability to outgas, gas overpressure arising and typically explosive volcanism (Forte and Castro 2019). Viscosity, outgassing pathways and volatile exsolution of the melt can fluctuate dramatically, and build overpressure changing an eruption from being effusive to explosive quickly, demonstrating their importance as well as that of the process that produces the volatile exsolution.

The ability for the melt to be able to outgas exsolved volatiles ultimately affects the volcanic eruption dynamics. If passive outgassing through fractures in the upper conduit and conduit walls occurs then the eruption will be effusive, with the converse of exsolved volatile retention in the magma causing overpressure and an explosive eruption (Eichelberger and Westrich 1981; Gonnermann and Manga 2003; Gonnermann 2015; Wadsworth et al. 2020). Therefore, there is the potential that previous outgassing pathways, especially within the central conduit, be filled by impermeable material and cause localised explosive conditions and a hybrid effusive-explosive eruption (Gardner et al. 2017; Cassidy et al. 2018; Gardner et al. 2018; Wadsworth et al. 2020; Schipper et al. 2021). 


\subsection{Vesiculation}

Vesiculation is the primary method for volatile exsolution from the melt and encompasses the nucleation, growth, and coalescence of bubbles within the melt. Ultimately, without volatile exsolution and vesiculation taking place within a melt an eruption will stall within a conduit as no outgassing and buoyancy will be created. However, typically once vesiculation begins within a melt it will continue to occur and lead to a volcanic eruption, either effusive or explosive (Eichelberger and Westrich 1981; Navon and Lyakhovsky 1998; Herbert and Andrew 2002; Polacci et al. 2009). These vesiculation processes are primarily controlled by viscosity and volatile saturation of the melt, but additional factors necessary for bubble nucleation, bubble growth, and bubble coalescence make each of these processes more prevalent under specific conditions (Prousevitch et al. 1993; Hurwitz and Navon 1994; Navon and Lyakhovsky 1998; Proussevitch and Sahagian 1998). In this thesis, secondary vesiculation will be used to investigate the textural response. This means that the vesiculation response is due to temperature fluctuations within the melt or conduit under near-isobaric conditions, close to the surface in the shallow conduit. This would follow from primary vesiculation associated with isothermal decompression during magma ascent. Relict bubble networks generated during primary vesiculation can, however strongly influence volatile exsolution during any subsequent secondary vesiculation.

\subsubsection{Bubble nucleation}

Bubble nucleation is the term used to describe the formation of a bubble within the melt where no bubble previously existed. Bubble nucleation includes; 1) the transition of dissolved to exsolved volatiles, 2) diffusion of volatiles to the bubble nuclei localities, 3) breaking of kinetic barriers to the collection of volatile molecules into nuclei, and 4) overcoming of surface tension in the melt (Hurwitz and Navon 1994). If any of these processes do not occur a bubble will either not form and be redissolved into the melt.

Bubble nucleation is kinematically difficult requiring enough energy and internal pressure of the nucleated bubbles to initially break network-forming bonds within the melt, and combat surface tension. The energy required to overcome these kinematic barriers is substantial, and typically 
requires the melt to be strongly supersaturated in volatiles before it can occur (Navon and Lyakhovsky 1998). Surface tension is a major force that must be overcome for nuclei to form (Toramaru 1989). This force drives surface area minimization, which needs to be overcome in the initial formation of a bubble nucleus and requires elevated internal pressure of the nucleated bubble. The other main kinematic barrier is the attraction of bonds between molecules within the melt, which is dictated by the viscosity of the melt (Eichelberger and Westrich 1981). High viscosity melts have a higher resistance to movement and make nucleation more difficult, meaning that a higher degree of supersaturation is required to allow nucleation to occur.

Figure 1.3 Schematic of diffusion occurring within a melt, required to both nucleate and grow bubbles. The blue circle represents the bubble-melt interface. The black circles represent volatiles suspended within the melt which must diffuse to reach the undersaturated region at the periphery of the bubble. The double ended blue arrows show the incorporation of these volatiles into the bubble at the bubble-melt interface (white head of the arrow) and resultant growth of the bubble once these volatiles are incorporated (blue head of arrow).

Bubble nucleation is also separated into two categories, homogenous and heterogenous. Homogenous nucleation is the classic nucleation theory which assumes that the thermodynamic properties (energy, pressure, temperature, melt composition, etc.) are constant throughout the melt, bubbles form spherically and have an equal probability of forming anywhere within the melt (Eichelberger and Westrich 1981; Bagdassarov and Dingwell 1992; Toramaru 1995; Proussevitch and Sahagian 1998). This theory requires free energy, supplied by high amounts of supersaturation within the melt, to exceed the surface tension, pressure, and viscosity within the melt prior to nucleation occurring (Toramaru 1995). Homogenous nucleation assumes the formation of these bubbles be statistically random within the melt and allows for estimations to be made of these required energies for nucleation (Toramaru 1995; Navon and Lyakhovsky 1998; Polacci et al. 2009).

Heterogenous nucleation is the alternate theory used for bubble nucleation. This theory acknowledges the heterogeneity of the natural system and sometimes crystals within the melt can act as catalysts, allowing the system to require lower free energy to nucleate bubbles 
compared to homogenous nucleation (Eichelberger and Westrich 1981). This will allow bubble nucleation to occur at lower supersaturations. Zircon, biotite, and Fe-Ti oxides all promote heterogeneous bubble nucleation (Navon and Lyakhovsky 1998). Due to this, care must be taken when investigating nucleation histories of a melt and be accounted for in any vesiculation comparison.

Lastly, each bubble must grow to a size where the internal pressure within the bubble is equalor-greater to the restrictive force of the surface tension of the melt. This point where the bubble is stable and no longer likely to dissolve into the melt is referred to as the critical nucleus (Hurwitz and Navon 1994; Navon and Lyakhovsky 1998). This critical nucleus requires the internal pressure within the bubble be equal to the combined pressure of surface tension and the ambient pressure of the melt (Toramaru 1989; Hurwitz and Navon 1994). If the critical nucleus is to be reached it requires rapid growth to reach this point and overcome these forces. Although this could be classified as bubble growth, it is crucial for survival of bubble nuclei, and is more closely associated to the process of bubble nucleation than bubble growth (Toramaru 1995; Navon and Lyakhovsky 1998; Proussevitch and Sahagian 1998). Any additional growth once this critical nucleus has been reached will be controlled by diffusion of additional volatiles into the stable bubble. 


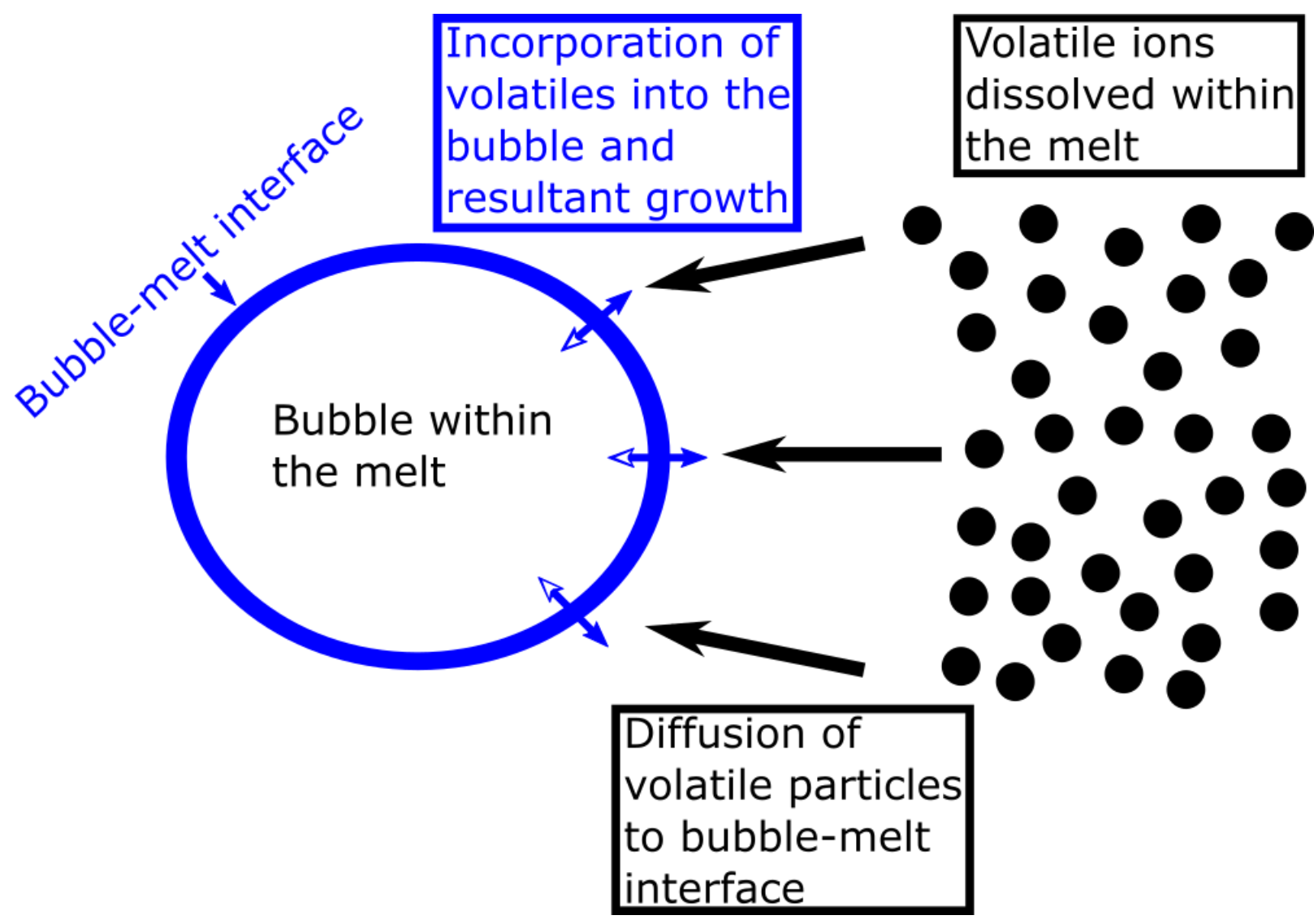

\subsubsection{Bubble growth}

Once bubbles have nucleated and reached their critical nuclei, growth of these bubbles can take place. Due to the pre-existence of these bubble-melt interfaces combined with the networkforming bonds within the melt being pre-broken, lower amounts of supersaturation and free energy are required for bubble growth compared to bubble nucleation (Toramaru 1989). Therefore, bubble growth is limited by the diffusion of volatiles to the pre-existing bubble structure, viscosity of the melt and again saturation of the melt.

Surrounding any bubble is a region of the melt that is less saturated in volatiles than the overall bulk saturation of the melt. This is due to the bubble's diffusively scavenging volatiles from the region directly surrounding the bubbles (Proussevitch and Sahagian 1998). To allow for bubble growth to occur volatiles are required to be transported through the melt to these undersaturated regions surrounding the bubble and to the bubble-melt interface (Navon and Lyakhovsky 1998). For volatiles to reach these undersaturated regions and the bubble-melt 
interface, diffusion is required (Fig. 1.3). Diffusion is affected by the saturation of the melt and the viscosity of the melt. Diffusion is the random process by which volatiles move throughout the melt, from more concentrated to less concentrated regions, and is the method of volatile transport to these undersaturated regions. The level of supersaturation dictates the overall quantity of volatiles within the melt that can be exsolved and the higher the viscosity of the melt the more restrictive to the flow of the volatiles through the melt (Zhang et al. 2010).

Melt viscosity affects diffusion by restricting the movement of volatiles through the melt, but it also affects the surface tension exerted on the bubble. The higher the viscosity of the melt the thicker and more resistant to the flow of the volatiles, resulting in volatiles diffusing through the melt more slowly and requiring higher degrees of supersaturation to allow for enough volatile diffusion through the melt for bubble growth (Navon and Lyakhovsky 1998; Zhang et al. 2010). Higher viscosities also can have higher surface tensions that resist the growth of the bubble (Ericson et al. 1975). Higher melt surface tension means a higher internal pressure is required to sustain the bubble, which can restrict bubble growth, especially in highly viscous melts, and ultimately limit the size these bubbles can grow to (Toramaru 1989; Toramaru 1995; Navon and Lyakhovsky 1998). As the bubbles grow this internal pressure must either exceed or equal these external pressures otherwise the bubble will become unstable and dissolve into the melt. This ultimately determines the overall size a bubble can grow to, no matter the supersaturation of the melt (Prousevitch et al. 1993; Navon and Lyakhovsky 1998).

Lastly, the supersaturation of melt affects bubble growth as this is ultimately the supply of volatiles for the growth of the bubbles. Although bubble growth may proceed at a lower saturation, not requiring significant supersaturation due to pre-established bubble-melt interfaces. This means that if a melt is only slightly supersaturated then regions that typically have a higher porosity will be more likely to vesiculate further (Prousevitch et al. 1993; Toramaru 1995; Navon and Lyakhovsky 1998). This ability of bubble growth to proceed at saturation means that internal textures and pre-existing bubble structures can affect the subsequent additional vesiculation of a melt, especially if the melt is only slightly supersaturated. 


\subsubsection{Bubble coalescence}

The last of the key vesiculation processes is that of bubble coalescence (Fig. 1.4). This occurs when bubbles interact within the melt, resulting in multiple bubbles amalgamating into a singular bubble (Eichelberger and Westrich 1981; Navon and Lyakhovsky 1998). This coalescence occurs irrespective of supersaturation but requires relatively dense bubble populations within the melt. However, prior to bubble coalescence occurring, the bubbles require a thinning of bubble walls, these bubble wall interacting, and failure of a melt film resulting in these bubbles coalescing (Castro et al. 2012). The main factors dictating bubble coalescence are the viscosity of the melt, supersaturation combined with porosity of the melt, and how these bubbles interact with one another.

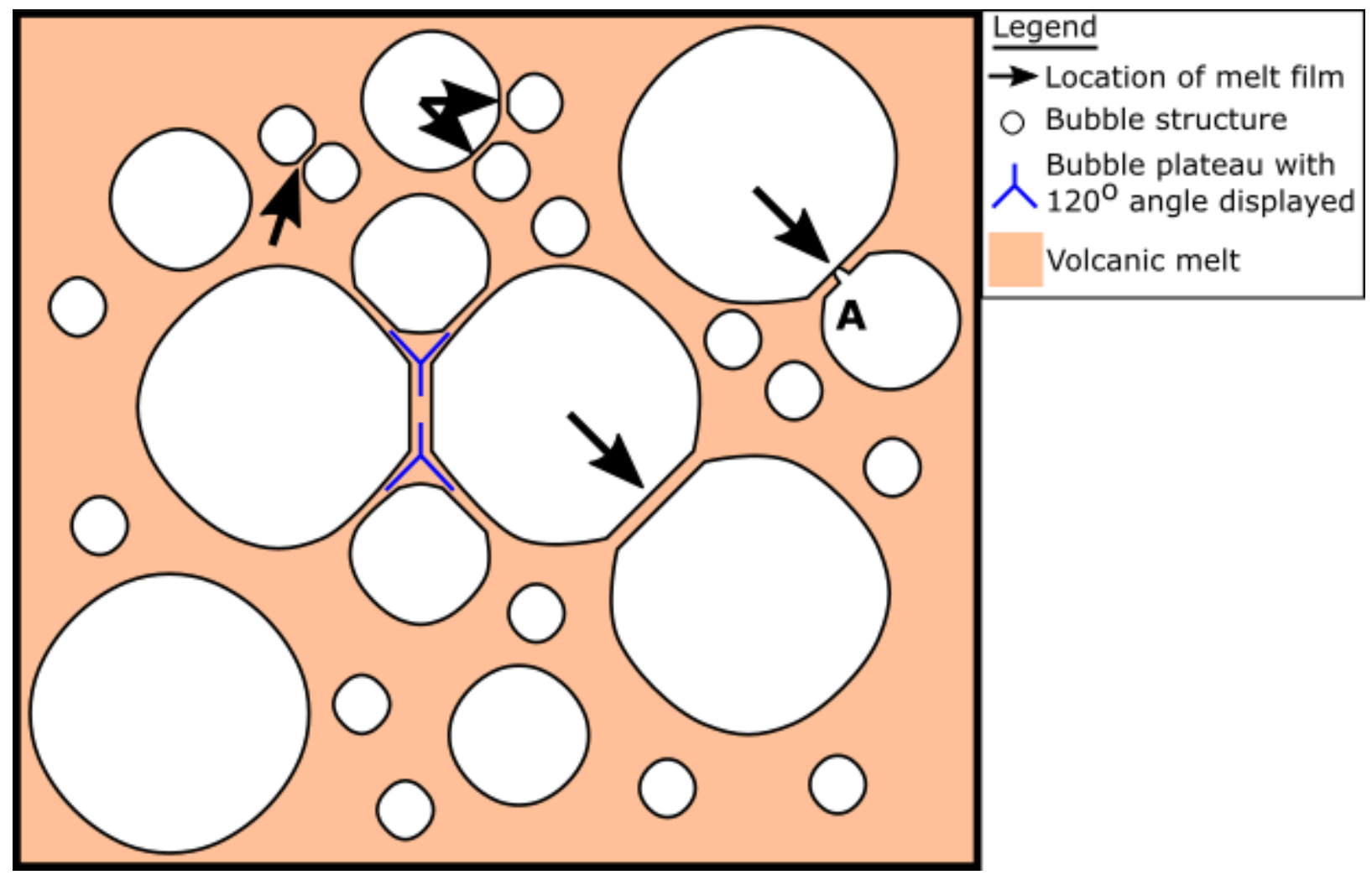

Figure 1.4 Schematic of bubble coalescence within a melt. Melt films between two bubbles are highlighted by black arrows and blue lines highlight the plateau borders forming with the $120^{\circ}$ angle at which they form. $\boldsymbol{A}$ shows the eventual failure of the melt film and the formation of a dimple like syringe along inter-bubble pressure gradients (smaller bubble to larger bubble). 
One factor that limits the coalescence and interaction of these bubbles within the melt is the development and failure of a melt film (Fig. 1.4). The melt film is a small area of melt that separates two bubbles where they are interacting (Stevenson et al. 1997; Castro et al. 2012). As these bubbles get closer together the film becomes thinner before it eventually fails, causing the bubble walls to retract (Stevenson et al. 1997). Film failure is therefore required before coalescence can occur otherwise bubble walls will not begin to interact and cause the coalescence of these bubbles (Stevenson et al. 1997; Castro et al. 2012). Film failure becomes increasingly more difficult at higher viscosities, due to the resistance to movement mentioned earlier, requiring more time until failure which has been noted to be the controlling factor of bubble coalescence (Eichelberger and Westrich 1981; Hurwitz and Navon 1994).

The development of bubble plateau borders and thinning of the walls at these film margins is also needed to allow bubbles to coalesce (Fig. 1.4). Plateau borders are the intersection regions of 3 bubbles where the angles out of this equal $120^{\circ}$ (Fig.1.4). These regions have lower capillary pressures due to the surrounding curvature surfaces and as such, larger bubbles make these regions more unstable (Proussevitch et al. 1993). This means that within low viscosity melts, where large bubbles are numerous, these plateau borders will dictate the ability for these bubbles to coalesce easily. There also requires a thinning of these bubble walls to allow for the transmission of gaseous volatiles from one bubble to another (Toramaru 1989). This occurs in two ways; the bubble walls naturally thin during bubble growth, and as the bubbles interact the walls thin at the point of interaction (Hurwitz and Navon 1994; Navon and Lyakhovsky 1998; Castro et al. 2012). Both these processes take time, and depend on the initial thickness of these walls, size of bubbles/the area over which these bubbles are interacting (Proussevitch and Sahagian 1998). However, once these walls have thinned to the point where diffusion of gaseous volatiles from bubble to bubble can occur the trend is to follow the pressure difference, with the lowest internal pressure bubble moving to the highest internal pressure bubble, in a dimple or syringe like movement (Fig. 1.4 A) (Navon and Lyakhovsky 1998; Castro et al. 2012). Once the gaseous volatile exchange has been completed the coalesced bubble will then strive for a 
spherical shape, as this shape is the lowest energy shape within a melt if no shear deformation is enacting on it. 


\section{3. $\quad$ Textures within the melt}

Internal textures define structural, density, crystallography, porosity, and chemical differences and gradients between one region of a melt/material and another region of a melt/material (Castro et al. 2014; Schipper and White 2016). Internal structures are present within the melt due to the wide range of processes occurring in different regions of the magma leading to irregularities across these regions. However, there is a lack of research into how these texturally different domains can affect the overall behaviour of a magma body that is subjected to different conditions. Over the past few decades there have been advances in experimental and analytical techniques that have made investigation of these heterogeneities possible (Mees et al. 2003; Rust and Cashman 2004; Wadsworth et al. 2016). However, no studies have investigated how pre-existing heterogeneity of textures may affect subsequent secondary vesiculation through isobaric heating in shallow conduits, and the resulting effects on eruption dynamics.

\subsubsection{Investigating internal textures}

Current imaging techniques permit investigation of changes in the morphology of rocks. Scanning electron microscopy (SEM), and photomicrography can be used to get high-definition images of polished surfaces, and $\mathrm{x}$-ray computed tomography (XCT) can permit volumes of a sample to be investigated in 3D (Shea et al. 2010; Cashman and Sparks 2013; Schipper et al. 2021). SEM imagery provides very high resolution surface imagery by scanning the surface of the material with a focused electron beam, these then interact with the surface atoms producing various signals making the image that is produced (Desbois et al. 2011). Photomicrographs are photographs of thin sections of rocks in transmitted light taken at high resolution (Fig. 1.5 A, B, D, E) which highlight certain regions as they would appear to your eye (Wadsworth et al. 2014). However, these images are 2D surface images and do not provide information about the internal structures in 3D. To visualise the internal structures of a material, this typically requires the use of XCT. Other techniques like scanning transmission electron microscope (STEM) could be used but due to their requirement of thin material (usually nanometre to micrometre in size), this makes them inadequate and unrepresentative of bubbly melts. XCT can also be of high resolution 
(of micron or sub-micron scale) creating accurate and representative scans (Ketcham and Carlson 2001). Due to their ability to produce high resolution scans of internal structures in a nondestructive manner. XCT has been used in numerous textural studies of volcanic material as well as petrological and sedimentological material (Mees et al. 2003; Cnudde et al. 2006). The advantage that XCT has over other techniques is its ability to obtain and render non-destructive three-dimensional (3D) volumes of samples, whereas the other techniques only produce twodimensional (2D) images of a surface, typically requiring destruction of samples to obtain (Schipper et al. 2013; Castro et al. 2014; Schipper et al. 2015).

XCT can and has been used to observe changes within vesiculation of rocks, with investigation of rocks occurring within four-dimensional (4D, which is 3D plus time) providing scans with time variables to produce video files of time sequences of evolving textures (Pankhurst et al. 2014; Wadsworth et al. 2016; Baker et al. 2018; Heenan et al. 2018). These studies highlight the advantages to using XCT, especially highly accurate micro-tomography, to investigate textural, permeability and vesiculation changes during heating (Jerram and Higgins 2007; Zandomeneghi et al. 2010; Desbois et al. 2011). However, the affect that internal textures have on the vesiculation process has not yet been investigated. In this thesis, using XCT measurements, the affect that these textures could potentially have on the secondary vesiculation of a melt and of sintered material (explained below) will be investigated and applied to the effusive-explosive transition (Rust and Cashman 2004; Forte and Castro 2019; Whattam 2019).

\subsection{2. $\quad$ Sintering}

During volcanic eruptions, permeable pathways of cracks within lava flows or volcanic conduits may allow volcanic gas to outgas from the system. As this gas passes through these pathways it heats up the surrounding material with the added possibility of depositing ash within these newly formed pathways (Wadsworth et al. 2020). This temperature influx into the veins with the addition of pre-existing and newly deposited ash can cause the material to begin to compact forming a new solid within these regions, in an evolution from a dilute ash suspension to a low porosity melt with negligible permeability, and is referred to as 'sintering' (Rust and Cashman 
2004; Cashman and Sparks 2013; Gardner et al. 2017; Gardner et al. 2018; Gardner et al. 2019). This sintering can happen at varying timescales from minutes to tens of hours and change the outgassing capacity of the melt completely. It is one explanation for volcanoes going through effusive-explosive transitions within eruption sequences (Rust and Cashman 2004; Cashman and Sparks 2013; Wadsworth et al. 2020; Schipper et al. 2021). When these pathways are filled with sintered ash and preserved within a rock they are commonly referred to as tuffisites (Schipper et al. 2015; Cassidy et al. 2018; Paisley et al. 2019; Whattam 2019). These sintered materials also produce independent textures and specific regions that need to be identified and differentiated from regions of quenched melt (e.g., melt that has never fragmented).

Due to their clastogenic nature, sintered regions can evolve to have numerous different textures. Sintering can even form obsidian if the particles are heated for a long enough time (Wadsworth et al. 2016; Gardner et al. 2017; Gardner et al. 2018; Gardner et al. 2019; Schipper et al. 2021). To form these obsidians through sintering, the material must be continuously and extensively heated, with this depending on the composition of the vein material (Wadsworth et al. 2014; Gardner et al. 2018). Although sintering can form obsidians, the newly formed obsidians retain distinctive clastogenic textures (Fig. 1.5) unless pressure is high enough to allow compaction and reabsorption of bubbles within the obsidian to form a homogenous texture (Rust and Cashman 2004; Wadsworth et al. 2014; Schipper et al. 2021). As the material progressively sinters, porosity decreases (Fig. 1.5 A, C to B, D respectively) however, some distinguishing features of the original material can persist, especially when viewed in cross-polarized light, indicating a clastogenic origin (Fig. 1.5 C to D). These clastogenic textures can also be viewed using either backscatter electron (BSE) images or x-ray computed tomographic (XCT) scans. For a clastogenic obsidian to become a homogenous obsidian, there needs to be pressure-driven compaction of the melt (Rust and Cashman 2004; Cashman and Sparks 2013; Wadsworth et al. 2014; Gardner et al. 2018).

Sintering, and the degree to which it progresses, can have large implications for how a magma body behaves if re-heated and caused to vesiculate, especially in clastogenic obsidian. If the obsidian retains clastogenic structures, it has a lower permeability threshold due to their preexisting voids at the original boundaries of the particles that sintered to form this glass (Gardner 
et al. 2018). The permeability threshold relates to the relative porosity at which a material begins or ceases to become permeable, controlling future vesiculation of the material (Rust and Cashman 2004). The percolation threshold is closely related to this and is the porosity at which individual bubble clasts begin interacting with one-another. This percolation threshold occurs at $\sim 30 \%$ porosity for vesiculating non-clastogenic melts (although varies between $20-70 \%$ porosity), but is much lower - only $\sim 3 \%$ porosity - in clastogenic melts (Wadsworth et al. 2016). This means that intuitively, obsidian of clastogenic origin should, when heated or decompressed, vesiculate to a lesser extent than the homogenous obsidians due to them retaining significant permeability even at a low porosity (Rust and Cashman 2004; Wadsworth et al. 2016). Additionally, if the obsidians are sintered and compacted into the formation of a dense, homogenous obsidian then this percolation threshold will be higher meaning more vesiculation will be able to occur (Rust and Cashman 2004). From this the hypothesis emerges that the internal textures might affect the eruptive behaviour of an eruption, but care must be taken to determine whether an obsidian is clastogenic or homogenous. 


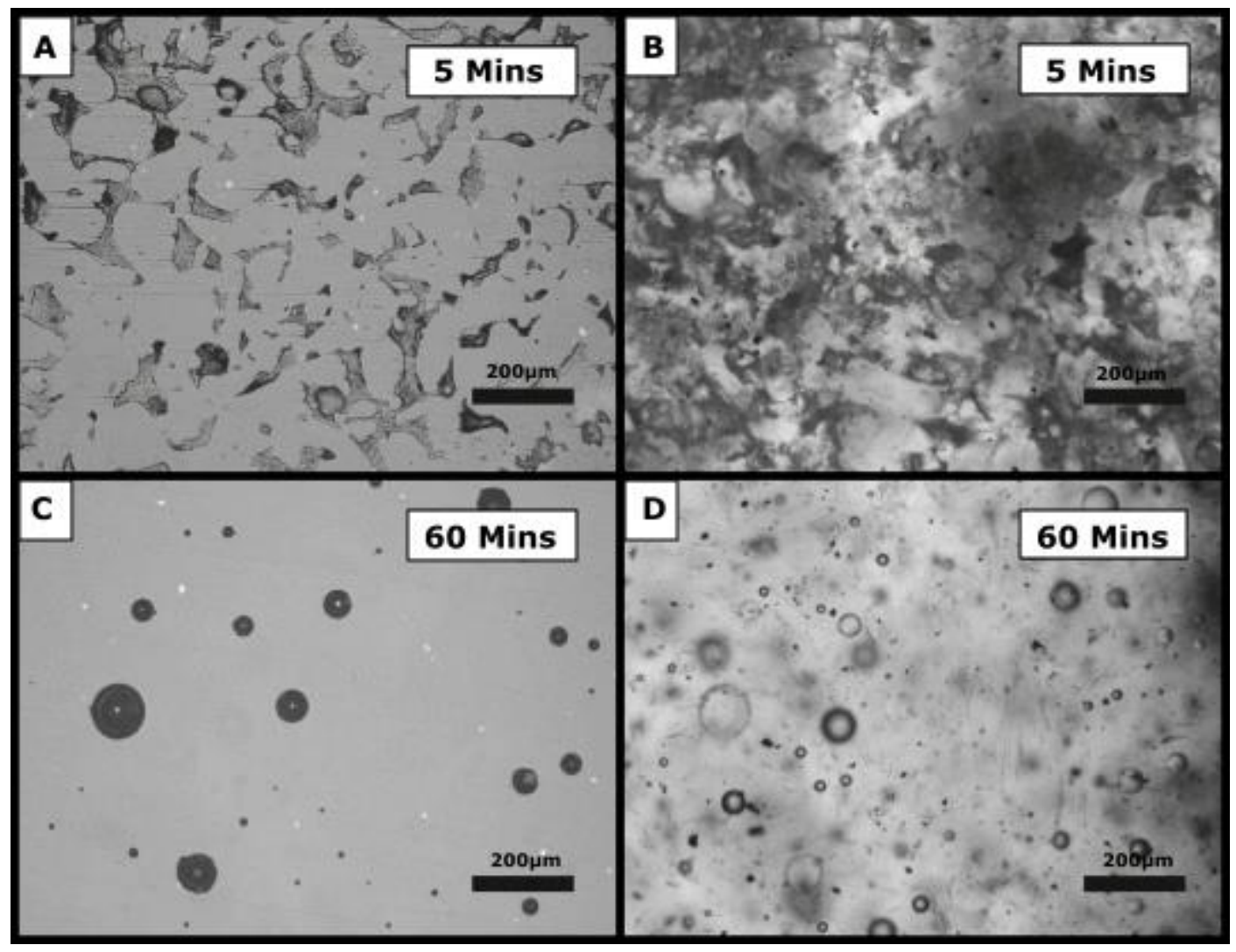

Figure 1.5 Sintering of ash to form coherent melt and retain clastogenic textures. A, B, C and D are taken from Wadsworth et al. (2016) which using microphotographs to show un-sintered ash in reflected light (A) and transmitted light (B) after 5 minutes heating at $800^{\circ} \mathrm{C}$ becoming dense glass after 60 minutes of heating again in reflected $(\boldsymbol{C})$ and transmitted light $(\boldsymbol{D})$. This shows the change from being separated ash $(\boldsymbol{A}$ and $\boldsymbol{B})$ to being a dense glass after sintering $(\boldsymbol{C}$ and D). 


\subsubsection{Obsidian}

Obsidian is a volcanic glass formed when melt is rapidly cooled after a volcanic eruption, or by the sintering of ash particles to one another (Ericson et al. 1975; Rust and Cashman 2004; Wadsworth et al. 2014). When the obsidians form from cooled liquid melt material, it can be assumed that this will then be representative of the melt at the time of eruption (Ericson et al. 1975). However, it will not represent the entire melt body, as it has already experienced many evolutionary processes (such as fracturing, crystal fractionation, volatile exsolution) prior to quenching (Stevenson et al. 1997; Proussevitch and Sahagian 1998). Still, obsidian formed at approximately the time of the eruption can provide insight into the immediate state of the volcanic melt at eruption (Castro et al. 2014; Forte and Castro 2019). Due to the rapid quenching of obsidian, it provides information about the links between gas overpressure, volcanic eruption dynamics and certain pre-eruptive textures as seen preserved within the pre-eruptive melt (Jerram and Higgins 2007; Schipper et al. 2013; Schipper et al. 2021).

All pyroclastic material erupted from the volcanic conduit during eruptions can inform about preeruptive conditions, but obsidian in particular is analytically useful, being a dense volcanic glass (Ericson et al. 1975). The glassy state of obsidian lends itself well to analysis of residual volatile concentrations by Fourier transform infrared spectroscopy (FTIR) (von Aulock et al. 2014). Thin (10-200 $\mu \mathrm{m}$ thick) glass wafers analysed by FTIR give insight into water $\left(+/-\mathrm{CO}_{2}\right)$ contents of erupted melt (Stevenson et al. 1997; Nichols and Wysoczanski 2007; von Aulock et al. 2014), allowing determination of the volatile variability in various products from a given volcanic eruption (Castro et al. 2014; Forte and Castro 2019). Also, when glassy obsidian is heated above the glass transition temperature $\left(T_{\mathrm{g}}\right)$ it is free to physically react to stress, and to vesiculate, as the original melts would (Ericson et al. 1975; Eichelberger and Westrich 1981; Toramaru 1989). The glass transition is the point where the obsidian will no longer behave as a solid, but a viscous melt, able to deform as well as vesiculate. Typically, $T_{g}$ depends on the viscosity and water content of the obsidian/pre-eruptive melt with numerous studies heating obsidians above the $T_{g}$ to investigate eruption dynamics in terms of vesiculation and gas exsolution (Eichelberger and 
Westrich 1981; Newman et al. 1986; Nichols and Wysoczanski 2007; Castro et al. 2014; Forte and Castro 2019).

Natural obsidians have been extensively used as a proxy for investigating syn-eruptive melt conditions (Ericson et al. 1975; Eichelberger and Westrich 1981; Eichelberger et al. 1986; Toramaru 1989; Hurwitz and Navon 1994; Toramaru 1995; Proussevitch and Sahagian 1998). Obsidians have also been experimentally decompressed and heated in studies that focusses on how perturbations to the solubility curve cause the obsidians to react, and then infer how these perturbations will affect the melt as a whole (Martel and Schmidt 2003; Edmonds 2008; Polacci et al. 2009; Lavallée et al. 2015; Forte and Castro 2019). However, due to their formation, natural obsidians are "mostly" glass, but do contain multiple textural elements such as crystals, bubbles, and flow bands (Shea et al. 2010; Wadsworth et al. 2016; Schipper et al. 2021). As of yet, no study has investigated how these pre-existing textures might influence subsequent textural response once the temperature exceeds the $\mathrm{T}_{\mathrm{g}}$ and the solubility factors such as $\mathrm{H}_{2} \mathrm{O}$ concentration, pressure and temperature are constant (Martel and Schmidt 2003; Lavallée et al. 2015; Whattam 2019).

\subsection{Research aims}

The overall research question addressed in this thesis is how pre-existing textures within obsidians can affect the vesiculation response during heating, and the resulting effect on the eruption dynamics. This thesis aims to evaluate the textural response to secondary vesiculation by: 1) determining the precursory textures within both obsidian pyroclasts and composite bomb samples, 2) identification of vesiculation trends of each precursory texture determined and the resultant impact this texture has on the subsequent vesiculation process, 3 ) examination of the role the percolation and permeability thresholds have on secondary vesiculation, 4) exploration of the implications for thermally driven secondary vesiculation on greater eruption dynamics, such as hybrid effusive-explosive volcanism. To ensure textural effects are isolated during this work on secondary vesiculation, other controls on vesiculation must be accounted for, primarily the initial water contents of the samples, with the remainder (pressure and temperature constrained during heating experiments) controlled by chosen experimental conditions. This 
requires the water content within the obsidians be characterised to ensure that volatile content variability does not control vesiculation behaviour. The internal textures of samples will also be determined through XCT scans of both natural and heated samples to visually represent and show vesiculation change across the sample textures. The next section will highlight how the erupted products from the 2011-2012 Cordón Caulle volcanic eruption are ideal for determining the textural controls on secondary vesiculation, with the added benefit of highlighting the overall research problem. 


\section{Chapter 2. Study site}

The 2011-2012 Puyehue-Cordón Caulle eruption lasted from 4 June 2011 to 21 April 2012, and provided ideally heterogenous products for investigating textural controls on secondary vesiculation within silicic melts. The eruption was rhyolitic, occurring within the Cordón Caulle fissure, part of the larger Puyehue-Cordón Caulle volcanic complex, Southern Chile, at $\sim 40.5^{\circ} \mathrm{S}$ and $\sim 72.1^{\circ} \mathrm{W}$ (Parejas et al. 2012; Schipper et al. 2013). The eruption itself had both explosive and effusive phases, with an extended transitional period between these two eruption styles, which included simultaneous "hybrid" eruption of effusive and explosive material (Castro et al. 2013; Tuffen et al. 2013). The eruption began with a large Plinian explosive phase on 4 June 2011. As the eruption continued the explosive behaviour changed from being a sustained ash column to discrete Vulcanian expulsions of bombs and ash. On 7 June 2012, the emergence of a visible obsidian lava flow occurred, just prior to the onset of hybrid activity (Fig. 2.1 A, B, C) consisting of explosive blasts and ash emission and synchronous lava effusion (Parejas et al. 2012; Castro et al. 2013). The bombs produced during the explosive-effusive transition hybrid eruptions are ideal for investigating vesiculation processes as they consist of variably vesicular clasts and underwent sintering/welding in the upper volcanic conduit while effusive volcanism was also occurring (Polacci et al. 2009; Pistolesi et al. 2015; Forte and Castro 2019; Paisley et al. 2019).

The bombs erupted just prior to and during the effusion of the obsidian lava consisted of numerous different clasts and textures welded together with a fine grained matrix (Castro et al. 2014; Pistolesi et al. 2015; Schipper et al. 2015; Paisley et al. 2019; Whattam 2019; Schipper et al. 2021). These welded assemblages formed in Vulcanian blasts, by the fragmentation of the melt due to gas overpressure (Gonnermann and Manga 2003; Gonnermann 2015). This fragmentation of the melt makes them good analogues for the pre-eruptive melt as once erupted they quenched rapidly and retained many of the melt characteristics (Schipper et al. 2015). These bombs also display signs of heterogeneity between samples (Fig. 2.2) with respect to the internal textures, and the relative abundances of larger clasts and the fine grained matrix. The extreme heterogeneity has led to them broadly being described as "composite bombs" (Schipper et al. 2013; Pistolesi et al. 2015; Schipper et al. 2015; Schipper et al. 2021). The material investigated 
here is extracted from $12 \sim 1$ metre diameter composite bombs, as these display variation in textures and clasts within them, and previous textural work on these samples provides a scientific context for the significance of these same bombs (Schipper et al. 2013; Pistolesi et al. 2015; Schipper et al. 2015; Whattam 2019; Schipper et al. 2021)

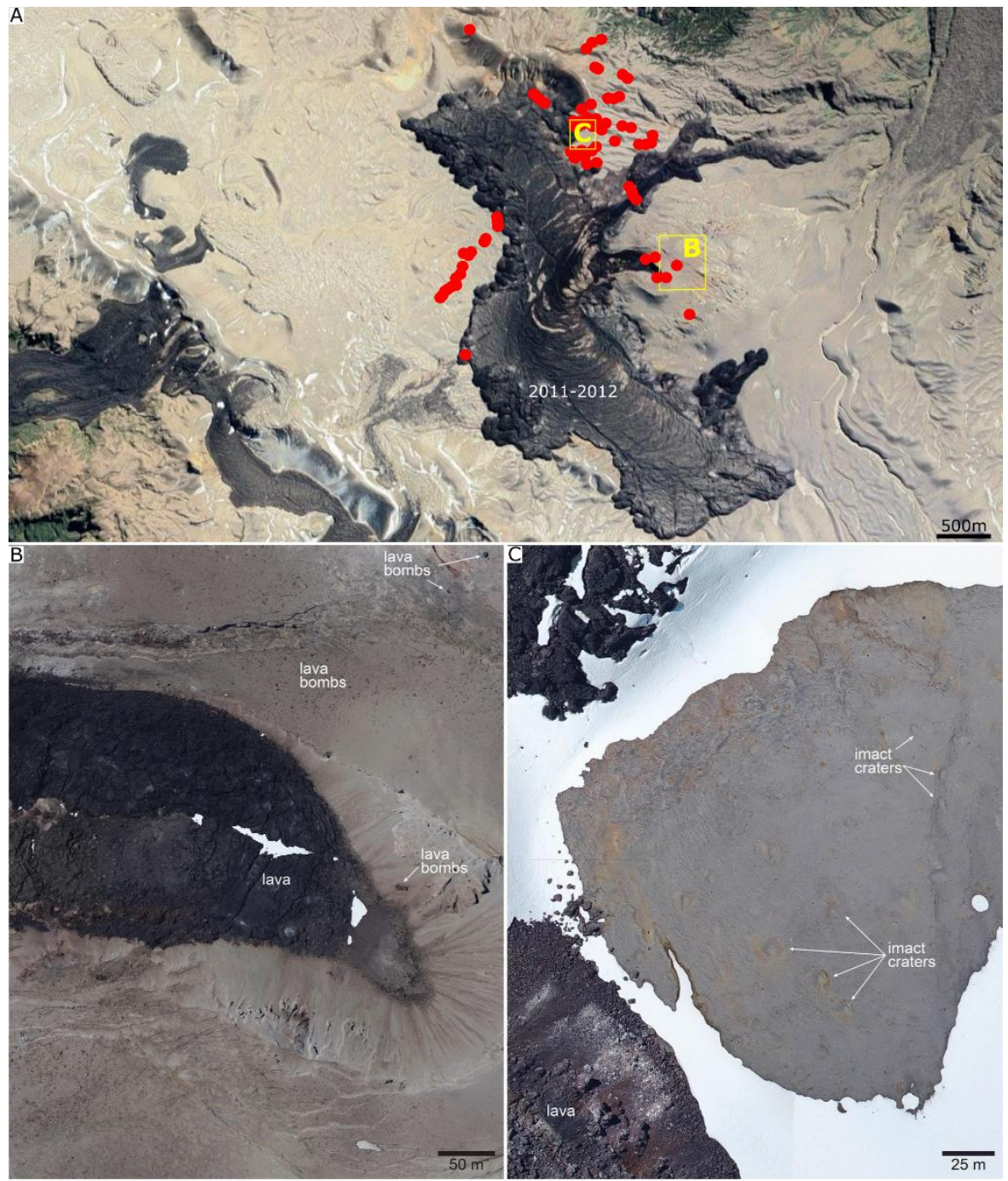

Figure 2.1 Cordón Caulle eruption with location where composite bomb samples were obtained shown adapted from Schipper et al. (2021). A extent of the 2011-2012 obsidian lava flow with composite bombs sampled locations marked by red dots and the locations of the images taken at $\mathbf{B}$ and $\mathbf{C}$ (Google Earth image taken on 26 March, 2018 by Maxar Technologies, 2021). B and C are orthographic images shown in Schipper et al. (2021) taken during a 2017 overflight of Cordón Caulle highlighting lava bombs and impact craters made by composite bombs landing. 
Although the composite bombs all contain clasts and matrix, there is variability in the dominant texture or type of domain that makes up each composite bomb, as well as internally within clasts. The Cordón Caulle composite bombs are separated into 3 composite bomb types; obsidian dominated (Fig. 2.2 D), pumice dominated (Fig. 2.2 A, B), and matrix dominated (Fig. 2.2 C) (Schipper et al. 2021). Specific textural or compositional definitions can be added to these samples such as pumice-fiamme dominated composite bomb or dense obsidian dominated composite bomb (Fig. 2.2 A), to further separate and define these composite bombs (Schipper et al. 2021). These extra separations provide additional information on the composite bombs described and show that although these bombs are similar cosmetically and compositionally, they can vary vastly in texture, specifically overall vesicularity and vesicularity distribution (Sánchez et al. 2009; Schipper et al. 2021).
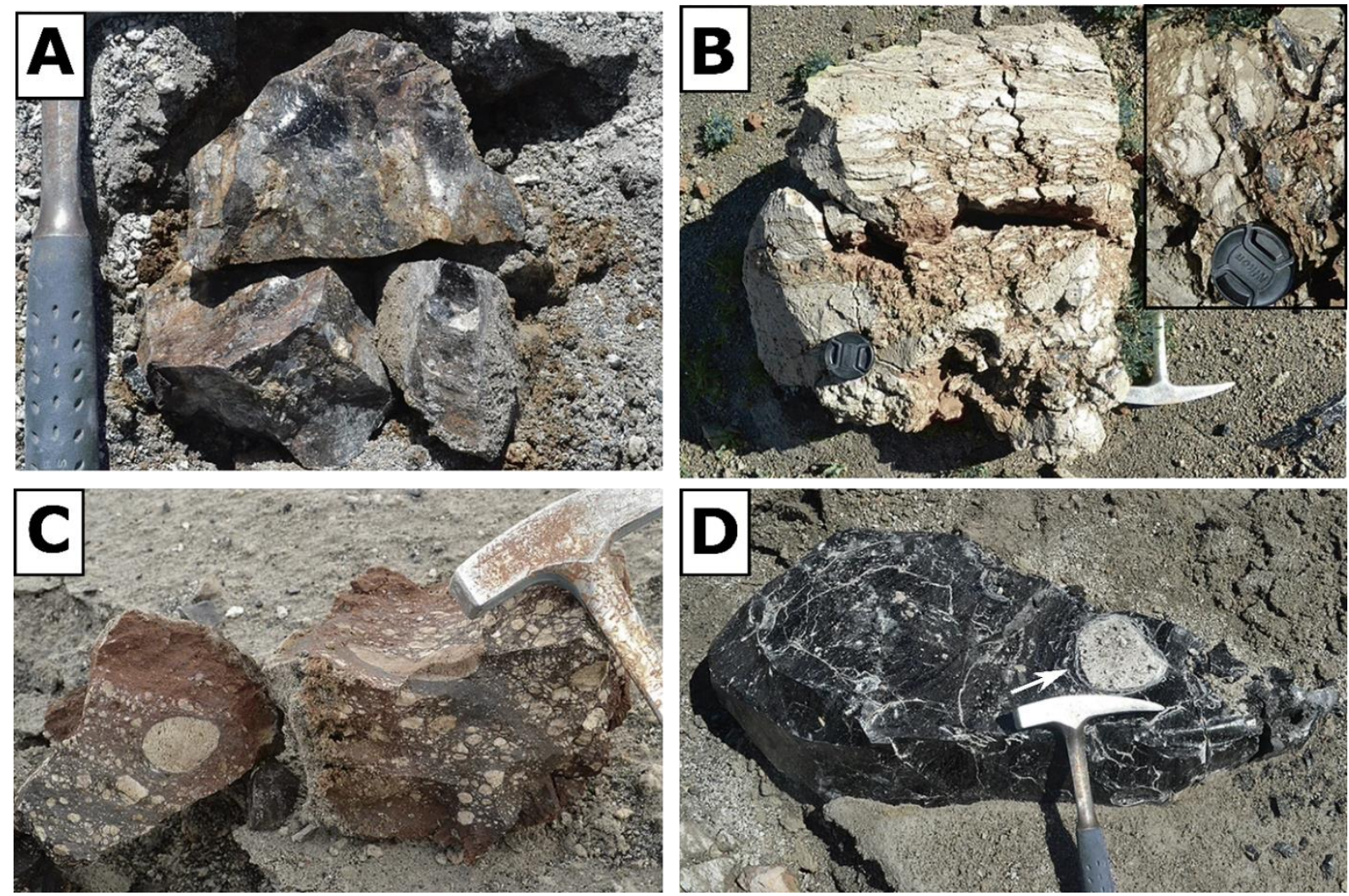

Figure 2.2 Composite bombs erupted from Cordón Caulle showing the variability in appearance and the dominant textures, adapted from Schipper et al. (2021). A dense pumice composite bomb with large 3-4 cm clasts of obsidian within. $\boldsymbol{B}$ low density pumice dominated composite bomb with the dominant pumice clasts, obsidian clast and matrix shown in the box in the upper right corner. $\mathbf{C}$ matrix dominated composite bomb with variable pumice clasts sizes visible within the composite bomb. $\boldsymbol{D}$ obsidian composite bomb lacking any obvious matrix within but there is the presence of a pumice clasts (highlighted by the arrow) showing it is still composite. 
There is also variation seen within the internal textures of individual clasts within the composite bombs, showing different histories of formation, with some regions appearing to have evolved from unfragmented melt, and others of a clastic origin (Schipper et al. 2021). These regions are separated by clear borders within the pyroclast, although they can usually only be discerned using techniques such as backscatter electron (BSE) imaging (Fig. 2.3 A) on thin sections, or micron-level XCT (Fig. 2.3 B) (Castro et al. 2014; Whattam 2019; Schipper et al. 2021). XCT can be exceptionally useful when investigating samples which appear to consist of solely one texture, but then distinctly different regions are revealed within (Schipper et al. 2021). This is particularly true for the obsidian clasts within the composite samples, with areas of homogenous, hypocrystalline obsidians (homogenous obsidian Fig. 2.3) being representative of the main melt, directly adjacent to areas of a clastic origin (clastogenic obsidian Fig. 2.3) likely formed by the sintering of particles (Wadsworth et al. 2020; Schipper et al. 2021). These textural differences, especially within the obsidians, are important to note as they can impact on whether the secondary vesiculation of that region is typical of the melt or of these clastic materials, although both are of interest with respect to outgassing pathways. These prior observations then aids in providing context for how certain textures were formed, the variable textures within single clasts and composite bombs, and how these can influence vesiculation of the melt. 

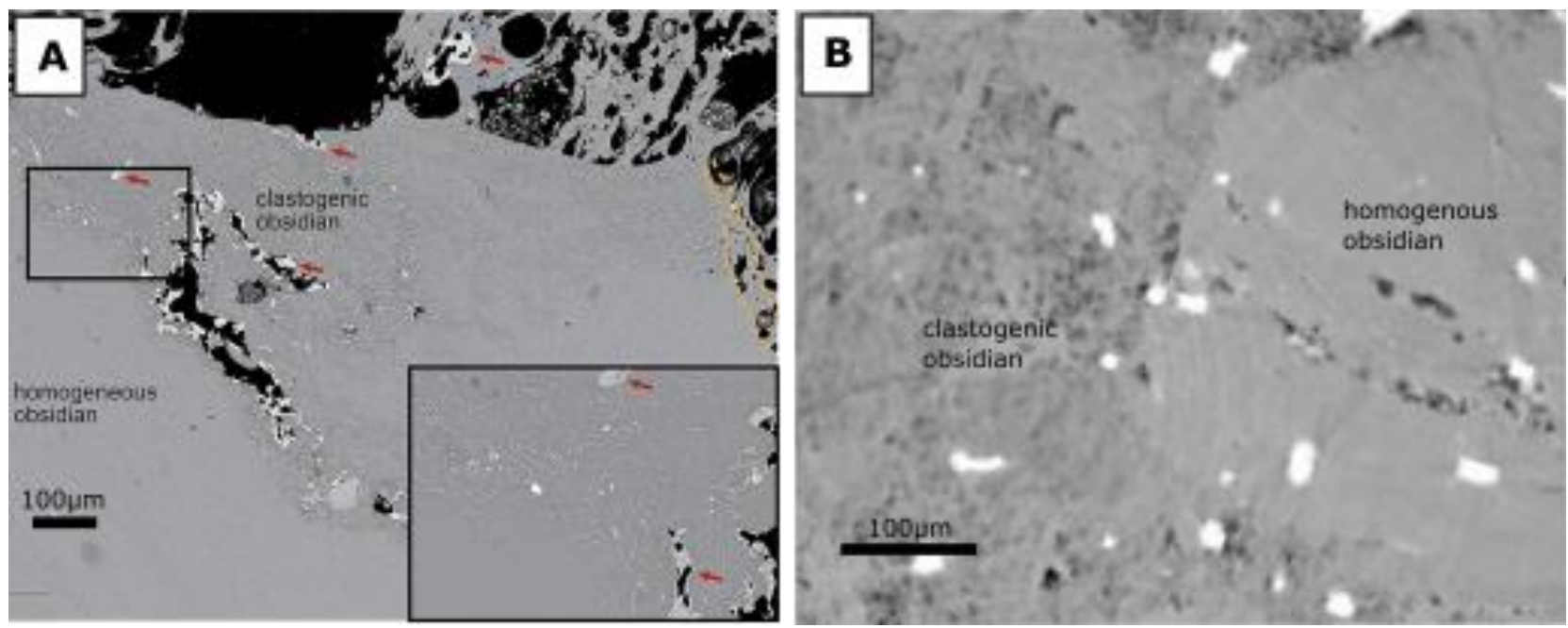

Figure 2.3 Internal textural variations within individual obsidian pyroclasts within composite bomb samples. A BSE (back scattered electron) image of an obsidian within a composite bomb showing a clastogenic obsidian, even containing remnants of ash particles of different composition (red arrows), and the clear boundary between that and the homogenous obsidian in the bottom left of the image with the square in the bottom right showing this boundary more clearly, adapted from Schipper et al. (2021). B XCT image of a composite bomb obsidian showing the clear border between a clastogenic obsidian on the left and a homogenous obsidian on the right of the image.

Some of the Cordón Caulle composite bombs also produced a textural phenomenon, where certain obsidians foamed in situ (Fig. 2.4 E), others remained dense (Fig. 2.4 B, D), and still others having variable degrees of foaming with certain regions remaining dense whilst other regions have foamed (Fig. 2.4 A, C). Heating and cooling gradients of the obsidians can be ruled out due to the proximity of dense obsidians (Fig. 2.4 B, D) to variably foamed obsidians (Fig. 2.4 A) at approximately the same location in the interior of the bomb. This variable foaming of obsidian clasts was also observed within erupted bombs from the 2008 Chaitén eruption showing that this is not an isolated phenomenon (Castro and Dingwell 2009; Major and Lara 2013; Castro et al. 2014). Chaitén obsidians' variable foaming, however, has been explained by the obsidian clasts having had widely varying volatile contents, with these being measured between 0.13-1.58 wt. $\% \mathrm{H}_{2} \mathrm{O}$ (Castro et al. 2014; Forte and Castro 2019). These variations between Chaitén bombs may have allowed for the obsidians to vesiculate and generate these in situ foamed obsidians. Previous work on the Cordón Caulle obsidians, however, do not report this variability in volatile content, with water contents consistently measured between only 0.04-0.31 wt. \% (Castro et al. 2014; Forte and Castro 2019). During evolution in the shallow conduit - where the Cordón Caulle 
composite bombs are thought to have originated from water is the only significant volatile present, as $\mathrm{CO}_{2}$ would have been lost at significantly greater depths (Toramaru 1995; Proussevitch and Sahagian 1998; Castro et al. 2013; Castro et al. 2014; Forte and Castro 2019; Schipper et al. 2019). Therefore, in the rest of the thesis, any reference to volatile content of Cordón Caulle samples is synonymous with water content.

Cordón Caulle's obsidians have among the lowest and most consistent volatile contents of any previously measured (Fig. 2.5); only eruptions with a statistically insignificant number of measurements have shown similarly low and consistent concentrations (Eichelberger and Westrich 1981; Newman et al. 1986; Castro et al. 2014). Heating experiments at atmospheric pressure by Forte and Castro (2019) also showed that obsidians from Chaitén with volatile concentrations similar to those of Cordón Caulle did not foam much, if at all, unlike the comparatively volatile-rich Chaitén obsidians $\left(>0.70\right.$ wt.\% $\left.\mathrm{H}_{2} \mathrm{O}\right)$. This means that volatile variations between the obsidians are unlikely to have caused the different secondary vesiculation behaviours of the obsidian within Cordón Caulle composite bombs. This is especially true for obsidians containing both foamed and dense domains (Fig. 2.4).

With the variability in foaming observed within the composite bombs, these composite bombs representing the pre-eruptive melt texturally, and erupted obsidians having low and consistent volatile contents, Cordón Caulle is the ideal eruption to study the effect of pre-existing textures - not volatile contents - on subsequent secondary foaming. 


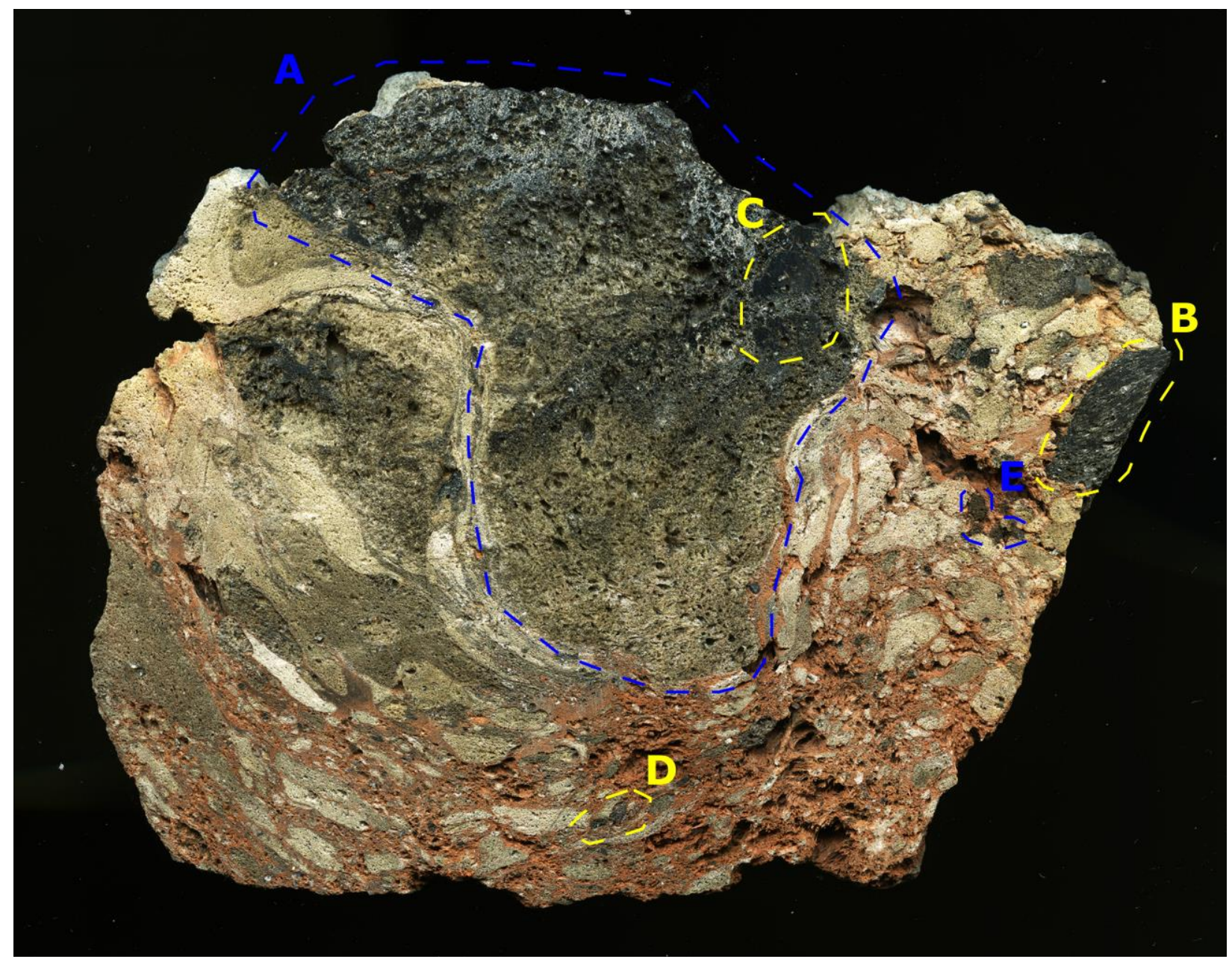

Figure 2.4 Vesiculation variability of obsidians within a composite bomb sample. The bomb has been sawn in half equatorially, but the outer perimeter of the bomb is as collected in the field. A partially foamed obsidian within the composite bomb highlighted by a blue dashed circle. B dense obsidian on the exterior of the composite bomb highlighted by a yellow dashed circle. $\boldsymbol{C}$ yellow dashed circle of a dense obsidian region within the vesiculated obsidian, showing the variability of the vesiculation within a single obsidian clast in the composite bomb. $\boldsymbol{D}$ dense obsidian within the internal region of the composite bomb highlighted by a yellow dashed circle. $E$ fully vesiculated obsidian within the internal region of the composite bombs highlighted by a blue dashed circle. 


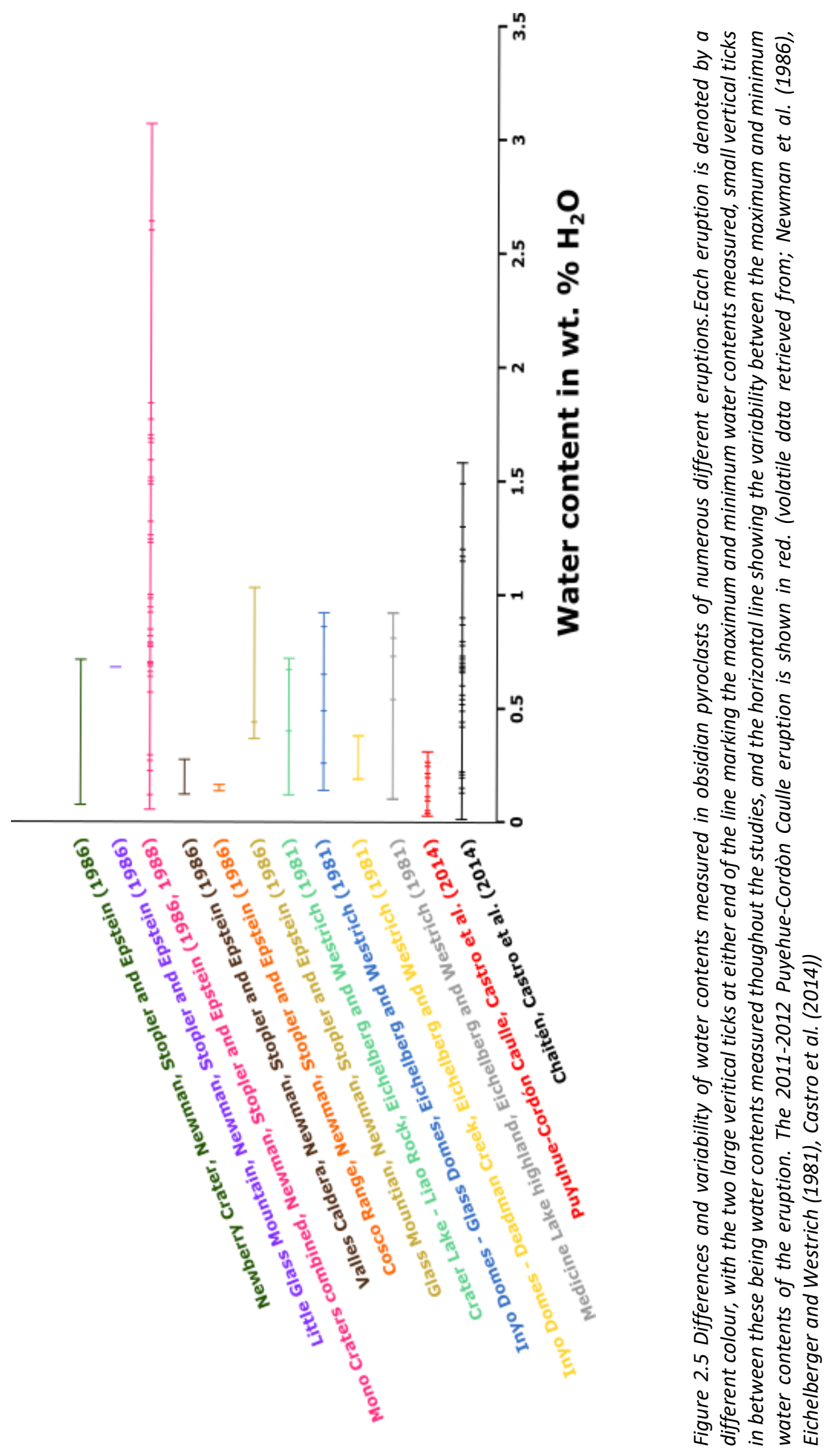




\section{Chapter 3. Methodology}

\section{1. $\quad$ X-Ray Computed Tomography $(X C T)$}

\subsubsection{XCT of natural Cordón Caulle bombs}

Preliminary scans of the composite bomb samples were conducted at the Australian Synchrotron (Clayton, Victoria, Australia) using the Imaging and Medical BeamLine (IMBL) (Hutch 3B) X-ray tomography unit (XCT). These initial scans were acquired by Whattam (2019), and a subset of this data presented in his thesis. Within this suite of rocks two subsets were used during the scanning process, large $2-3 \mathrm{~cm} \times 2-3 \mathrm{~cm} \times 5-8 \mathrm{~cm}$ cuboids cut from Cordón Caulle composite bombs in addition to small 'tube' samples (so named because multiple small samples were mounted together in the XCT beamline in a plastic tube) 0 f $0.5-1 \mathrm{~cm} \times 0.5-1 \mathrm{~cm}$ x 1.5-2 cm cuboids removed from larger composite bombs (Schipper et al. 2021). These initial cuttings by Whattam (2019) aimed at capturing as many textures within the bombs as possible, allowing for these samples to encompass numerous textural domains, including the obsidian domains that are the focus of this work. These scans allowed isolation of obsidian clasts for investigation into describing the internal textures present within the obsidians themselves, and how these textures can impact the secondary vesiculation process.

The X-Ray tomography imaging used the Australian synchrotron's "Ruby" detector with X-Ray energy of $45 \mathrm{KeV}$. Scans were made using a $180^{\circ}$ sample rotation and $0.3 / \mathrm{sec}$ exposure per radiograph, collecting 1,800 radiographs per sample. Due to the large size of the samples, and limited height of the Ruby detector, large samples had to be imaged in multiple overlapping sections and then stitched together to acquire a full tomographic dataset for each sample. The number of sections used depended on the size of the sample. Whattam (2019) aligned the scans for the samples whilst at the Australian Synchrotron using the Australian Synchrotron's X-Tract Imaging toolbox to make the 2D image slices into a representation of the 3D volume of the sample and then stitched the different scanned sections together to produce a full tomographic dataset of the large samples. The voxel edge lengths varied per size of the sample with large samples having $16.6 \mu \mathrm{m} / \mathrm{px}$ or $14 \mu \mathrm{m} / \mathrm{px}$ and the smaller 'tube' samples having $5.85 \mu \mathrm{m} / \mathrm{px}$. Reconstructed image stacks were then analysed and 
manipulated using the Thermo Scientific Avizo software package as both 3D volumes and 2D image slices.

\subsubsection{Post-heating XCT scans}

Unfortunately border closures resulting from the global COVID-19 pandemic meant that postheating scans could not be conducted using the same setup as the pre-experiment scans at the Australian Synchrotron. Instead, post-experiment scans of the same composite bomb samples were conducted at Otago University using a Bruker-MicroCT Skyscan 1172 high resolution X-Ray Computed Microtomography. Although this technique is slightly different to the IMBL XCT scans conducted, both will be referred to as XCT as both use density variations obtained through passing $\mathrm{x}$-rays through the sample. The post-experiment samples were all approximately the same size, being between 1-2 cm x 1-2 cm x 2-3 cm. However, due to the additional costs involved with XCT use at Otago, only a subset of ten of the most representative post-experiment samples were scanned. These samples encompassed a wide range of different textures, volatile contents, and post-experiment vesiculation profiles which allowed for the largest range of data possible.

The Otago XCT was conducted using the skyscan's 'Hamamatsu' camera setup to image the internal structures with an X-Ray energy of $80 \mathrm{KeV}$. Scans were made using $180^{\circ}$ sample rotation and 1.18/sec exposure per radiograph collecting 1,050 radiographs per sample. The rotation step before each image is captured is $0.4^{\circ}$ on average. To remove low energy X-Rays a $0.5 \mathrm{~mm}$ thick sheet of aluminium is used, which also aids in cleaning up the resulting images. The scans had a resolution of either $12.00 \mu \mathrm{m} / \mathrm{px}$ or $17.39 \mu \mathrm{m} / \mathrm{px}$, similar to that of the large samples scanned at the Australian Synchrotron. The samples were split in size with samples whose width is larger than $10 \mathrm{~mm}$ having scans at $17.39 \mu \mathrm{m} / \mathrm{px}$ and conversely samples of $10 \mathrm{~mm}$ or less have scans of $12.00 \mu \mathrm{m} / \mathrm{px}$. As with the natural samples, these image stacks were then transferred into the Avizo software package for $3 \mathrm{D}$ and $2 \mathrm{D}$ analysis and data manipulation. 


\subsection{Fourier Transform Infrared Spectroscopy (FTIR)}

To verify that the volatile contents of obsidian clasts within Cordón Caulle composite bombs were as uniformly low as reported by Castro et al. (2014) and to determine volatile variability per composite bomb type, Fourier Transform Infrared Spectroscopy (FTIR) was used. FTIR spectroscopy measures infrared radiation absorption of a sample by comparing it to a standard signature. Each molecule has a specific signature depending on the wavelength they are subjected to, with these molecules stretching or deforming in a specific way (Eichelberger and Westrich 1981; von Aulock et al. 2014). Therefore, when FTIR is used on a transparent piece of material, like obsidian, the water molecules within that material can be measured. This allows for the volatile content of the obsidian to be determined and the possible effects of variable volatile content on vesiculation through isobaric heating to be eliminated. This also allows for volatile variability within a single obsidian clast to be determined.

\subsection{1. $\quad$ FTIR wafer preparation}

FTIR requires light to be transmitted through a sample, which required the obsidians be prepared as doubly-polished, free-standing wafers. To save as much of the obsidians for later analysis as possible, small chips were taken from certain obsidians to be analysed. A minimum of one obsidian per composite bomb sample was selected so at least one water content could be measured per sample, although, where possible multiple measurements were taken. The small chips were removed using a sanding drill or a small screwdriver to obtain chips of 1$7 \mathrm{~mm} \times 0.5-5 \mathrm{~mm} \times 0.3-2 \mathrm{~mm}$. The location each chip was excavated from was recorded and labelled as well as a description of the site made to allow for correlation back to the hand sample and XCT scans.

Once obsidians chips were extracted, they were thinned and polished to allow FTIR light to be transmitted through the sample. Obsidian chips were temporarily mounted onto a glass slide using a Crystalbond 509 thermal cement. Crystalbond 509 has a very low melting point but is very hard, making it ideal to use as a glue for the obsidian chips. Small chunks of Crystalbond 509 are placed on the slide, followed by placing the slide on a hot plate at $70{ }^{\circ} \mathrm{C}$ to allow the Crystalbond to melt. Once melted the obsidian is pressed into the melted Crystalbond and taken off the heat to cool and allow the Crystalbond to solidify. Orientation 
for the first surface is unimportant as the focus for the initial side is to develop a flat, and polished surface. To develop such a surface, progressive sanding of the obsidian chip is required using, in order, P380-P600-P1200-P2000 silicon carbide papers whilst wet. At each stage, a reflective microscope is used to determine whether a flat surface is being maintained. The obsidian chips are finally polished using a $3 \mu \mathrm{m}$ suspended diamond paste. Once the initial side is polished and the next side can be sanded and polished in the same way (von Aulock et al. 2014).

Due to the requirement that parallel sides be polished for FTIR, the obsidian requires flipping. For this the Crystalbond 509 requires remelting, so the slide is placed back on the hot plate. When melted, care must now be taken with the obsidian chip to ensure that the polished side is on the bottom so that the new surface will be parallel to the existing surface. Once flipped, the obsidian will be cooled, sanded, and polished using the same method as the initial side, but thickness will have to be considered during this process. To determine thickness two approaches were used. A desired thickness range was first established using existing FTIR data from Castro et al. (2014) and an FTIR range table constructed by von Aulock et al. (2014), giving a target thickness of 90-200 $\mu \mathrm{m}$. During the sanding process thickness was continuously checked using a digital micrometre to ensure the thickness was within this range and once these obsidians neared these thicknesses they were checked to see whether light could pass through the sample using cross polarised light in a microscope, which is the second method for checking transparency of the sample (von Aulock et al. 2014). Care was also taken to ensure that the thickness was even across the wafer surface to avoid errors that might arise from thickness difference issues during wafer production. Once this had been completed the obsidian chip's thickness was checked again using the micrometre, and the wafer was removed from the slide by melting the Crystalbond and placed within a labelled container.

One final step had to occur to make the wafer ready for FTIR analysis, which was to ensure all residue Crystalbond 509 was dissolved to not interfere with FTIR results. Crystalbond 509 can completely dissolve in acetone, meaning that to remove this the obsidians just needed to be place within an acetone bath for $\sim 12$ hours. These baths consisted of $\sim 10 \mathrm{ml}$ of acetone placed in a beaker. The obsidians were then placed in the bath using tweezers, to avoid contamination. The baths were then covered using parafilm to avoid acetone evaporation due to the volatile nature of this substance at room temperature. Once the soaking was 
complete the obsidian wafers were then removed and allowed to sit for 5 minutes to evaporate all excess acetone, and to ensure the plastic containers would not dissolve under acetone contact. The obsidians were then measured for a final time under a micrometer before they were placed back in their labelled containers awaiting FTIR analysis.

\subsubsection{FTIR analysis}

The obsidian wafers were analysed at the University of Canterbury, using a Bruker Hyperion 2000 IR-microscope attached to a Bruker Vertex 70 spectrometer. A globar source was used to produce the Infrared source, with a potassium-bromide $(\mathrm{KBr})$ beamsplitter and a liquid nitrogen cooled MCT (mercury, cadmium, telluride) detector. These require certain prerequisites before any data acquisition can occur. The first step is to ensure that the MCT detector is cool enough to produce accurate results, which requires liquid nitrogen be placed at the back of the back of the Bruker Vertex 70 spectrometer to provide cooling of the detector. This cooling only lasts approximately 8 hours and if experiments run for longer than this the liquid nitrogen needs to be topped up. Once the nitrogen has been added the system needs to equilibrate before analysis can begin, which takes approximately 30 minutes. This then allows for the Bruker software of Opus to be opened, with this software controlling the microscope stage and focus. Opus also is the software used to quantify and display the spectra produced from the FTIR analysis.

\section{FTIR measurements}

Once Opus has been loaded and MCT detector cooled, analysis of obsidian wafers can commence. Before any experimentation, the sample stage sitting within the main stage of the Bruker Hyperion 2000 IR-microscope requires removal. This was accomplished by fully extending and moving the stage away from the instruments, with special care take to ensure the condenser and aperture are unaffected by this movement. The sample stage is then pushed into two springs and lifted out of the main stage with extra care taken to ensure the $\mathrm{KBr}$ window remains in place. The obsidian wafer is then removed from its labelled container and placed, centrally, in $\mathrm{KBr}$ window. The sample stage is then placed back into the slot of the main stage, again, with care taken to ensure that the obsidian wafer or $\mathrm{KBr}$ window is not affected when placing it back in. The sample must be centred, accomplished by using the 
same method as extracting the sample stage. The top of the sample is then placed in focus with visible light for later analysis. The sample is then photographed to allow identification and avoidance of bubbles and cracks. Photographs require the maximum extent of the obsidians in the $X$ and $Y$ location to be known and entered into the software so the set up can capture these images. Where possible these samples were photographed in both reflected visible light and transmitted infrared light.

Once the obsidian wafers are imaged, analysis of the sample can begin. To produce results a background signal must be recorded. This signal will then be used to gain baseline absorbance of molecules, which is used to normalize the obsidian wafer's molecular abundances. To accomplish this the stage must be moved so only the $\mathrm{KBr}$ window is visible. Before each analysis, the condenser needs to be raised and checked that it is aligned correctly. This requires that the condenser be adjusted so an approximate white circle can be seen. The condenser will then need to be aligned to produce a normal circle, which is done by using small knobs to ensure the circle is as spherical as possible. Once this is completed then knife edge apertures are used to define a $50 \mu \mathrm{m}$ square sample area to reduce noise and make the results more accurate by missing large bubble clusters within the samples. The set-up is then checked to confirm that the beam is in infrared before progression, and then the background noise is measured. This consists of 128 scans being conducted at this one background location, these scans being averaged, which determines one background noise spectrum. Following this, scanning of the obsidian wafers can be conducted. Using the images of the wafers in visible and infrared light, locations are selected to perform these scans. The selection method was random to allow for the best locations to be selected, and to ensure a good profile across the entire obsidian. Per sample, 10-15 locations were selected for analysis with care taken to verify these locations did not cover any bubble clusters or cracks. 128 scans were taken per location with the spectra being MIR (Mid-infrared), between 350 and 7000 $\mathrm{cm}^{-1}$ with an absorbance resolution of $4 \mathrm{~cm}^{-1}$. Initial results are displayed within the Opus software, however, to gain water contents the data needed to be integrated with a k-type $\mathrm{H}_{2} \mathrm{O}$ analysis the software provided. This resulted in a comparison of the peaks at 2460 and $3790 \mathrm{~cm}^{-1}$ which provided the $\mathrm{H}_{2} \mathrm{O}$ absorbance of the specified location.

Although thicknesses were measured using the digital micrometre, wafer thicknesses at each analytical spot were also verified using IR interference fringes, following the method of 
Nichols and Wysoczanski (2007) and von Aulock et al. (2014). These fringes are formed by the out-of-phase nature of two light beams sent toward the obsidian wafers. To get an ideal noise measurement for the fringes however a highly reflective surface needs to be used, which was a gold plate for this analysis. This gold plate was at a different height than the obsidian wafer, so the $\mathrm{Z}$ axis measurements were noted prior to focusing on the gold plate. The gold plate also had a few cracks present so when gaining a background reflectance, care was taken to avoid these so only the reflective gold plate was sampled. Once in focus the gold plate was measured with a $50 \mu \mathrm{m}$ square for 128 scans to gain this background reflectance, the same procedure as for water absorbance. After this, height was then returned to that of the obsidian wafer and saved points were then loaded so the same points within the sample were measured again. These points were then measured again for 128 scans to gain interference fringes. The wavenumbers between 2400 and $3500 \mathrm{~cm}^{-1}$ were analysed for this due to the low impact that elements had during these wave lengths and their production of these interference fringes.

\section{Analytical analysis of FTIR results}

With the FTIR data for both the thickness (through the interference fringes) and water absorbance, water contents for the obsidians can now be determined. To verify our thicknesses measured from the micrometre, we started by using the interference patterns. This used Equation 1 to accomplish this:

$d=\frac{m}{2 n(v 1-v 2)}$

Equation 1 determines the thickness of a sample using interference fringes with $d$ as the thickness of the measured points, $m$ related to the number of waves (small undulating waves in the overall trend) in a selected wavenumber (dimensionless), $n$ was the refractive index of the obsidian wafers (dimensionless), $v 1$ and $v 2$ were the wavenumber of the peak and trough of the constrained region $\left(\mathrm{cm}^{-1}\right)$. We assumed a constant refractive index $(n)$ across the sample of 1.5 using the work from Ulke et al. (2016) and the bulk rock composition determined by Castro et al. (2013). Lastly, identification of a large wave were wavelengths of the peak ( $v 1)$ and then the trough $(v 2)$ where these smaller waves were superimposed onto the overall trend within the FTIR signal. For most of the analysed FTIR waves produced this 
was unclear and, although a large wave trend could be determined the smaller interference fringes were often not observed, although a select few samples did manage to yield this trend. Following this identification, the small waves between a peak and trough were then counted to yield an $m$ value. This was compared to the micrometre data collected prior to scans, and a thickness was determined with errors noted (von Aulock et al. 2014; Ulke et al. 2016). Once the thicknesses had been established these were then used for the water content calculations. These calculations were then plugged into the Beer-Lambert law, displayed below in equation 2:

$\omega=\frac{A \times M}{\epsilon \times l \times p}$

The Beer-Lambert law is used to determine the water content of the obsidians once FTIR spectra are obtained. Water content is denoted by $\omega\left(w t . \% \mathrm{H}_{2} \mathrm{O}\right), A$ is the absorbance of the sample, which was measured using the FTIR data (dimensionless), $M$ is the molar mass of the obsidian $\left(\mathrm{gmol}^{-1}\right), \epsilon$ is the molar absorptivity of the sample $\left(\mathrm{Lmol}^{-1} \mathrm{I}^{-1}\right), \mathrm{I}$ is the thickness of the sample $(\mathrm{cm}), p$ is the density of the obsidians $\left(\mathrm{kgm}^{-3}\right)$. The thickness and absorbance were calculated using FTIR results or microprobe for each independent sample. The thickness of the sample was kept standard across all measurements due to the variations across the sample being within error for each point and not all points obtaining thicknesses through interference fringes, shown in equation 1. The absorbance for each location used the measured quantity for each independent location measurement. This helped to identify outliers and results that may have been interfered with by bubbles or cracks. The molar mass of the obsidians was gathered using the chemical formula and mass of the elements that compose of this. The molar absorptivity of the sample was determined using the model of Dobson et al. (1989), which is a model for determining water content from low absorptivity samples. Bulk obsidian values of erupted Cordón Caulle obsidians from Castro et al. (2013) were also used to verify the molar absorptivity value for the obsidians used. A density value was also calculated and estimated for the samples (Ericson et al. 1975; Castro et al. 2014). These bulk obsidian values show little variation between the erupted Cordón Caulle products meaning this is a valid method. Once all these variations are calculated, then the water contents can be calculated. Post calculation, water content of each sampled locality is averaged out for each sample so a bulk water content of the obsidian wafer sample can be 
known. These are then compared to the other samples so volatile variation of the obsidians sample-to-sample can be known and considered within the textural analysis.

\subsection{Heating experiments}

\subsubsection{Rock cutting}

The larger samples (large $2-3 \mathrm{~cm} \times 2-3 \mathrm{~cm} \times 5-8 \mathrm{~cm}$ ) already scanned by XCT needed to be reduced in size prior to heating experiment commencement. This is due to thermal gradients in the experimental furnace having the potential to unevenly heat the samples' exteriors and interiors. If the sample were left at the original size, then obsidians in the interior of the bombs would heat much differently to the obsidians on the exterior leading to differential vesiculation. To limit this effect and promote equal heating of the obsidians, the larger composite bomb samples were cut into samples $1 \mathrm{~cm} \times 1-2 \mathrm{~cm} \times 3 \mathrm{~cm}$ blocks. Prior to cutting, internal structures were checked on XCT scans, obsidians identified, and rocks marked to cut ensuring regions of interest were extracted. The locations were also photographed to allow for correlation of these cut samples to the tomographic images.

Cutting of the obsidians was also performed at the University of Canterbury using a Struers Labotom-5 rock saw with a $1.5 \mathrm{~mm}$ diamond blade which was run wet. This rock saw and thickness of the blade allowed for minimal amounts of waste when samples were cut although care was required during the cutting process. This care was required to avoid sample loss as composite bomb samples have natural weaknesses formed by internal cracks, which could fracture. The best way to avoid unnecessary breakages was to move the saw in a slow and consistent motion while cutting. Once the cutting of the samples had been completed the rock was reconstructed and individual pieces labelled to allow for correlation with the initial XCT scans taken of the image. The samples were then dried to allow water to evaporate and not affect the heating process. 


\subsubsection{Heating experiments}

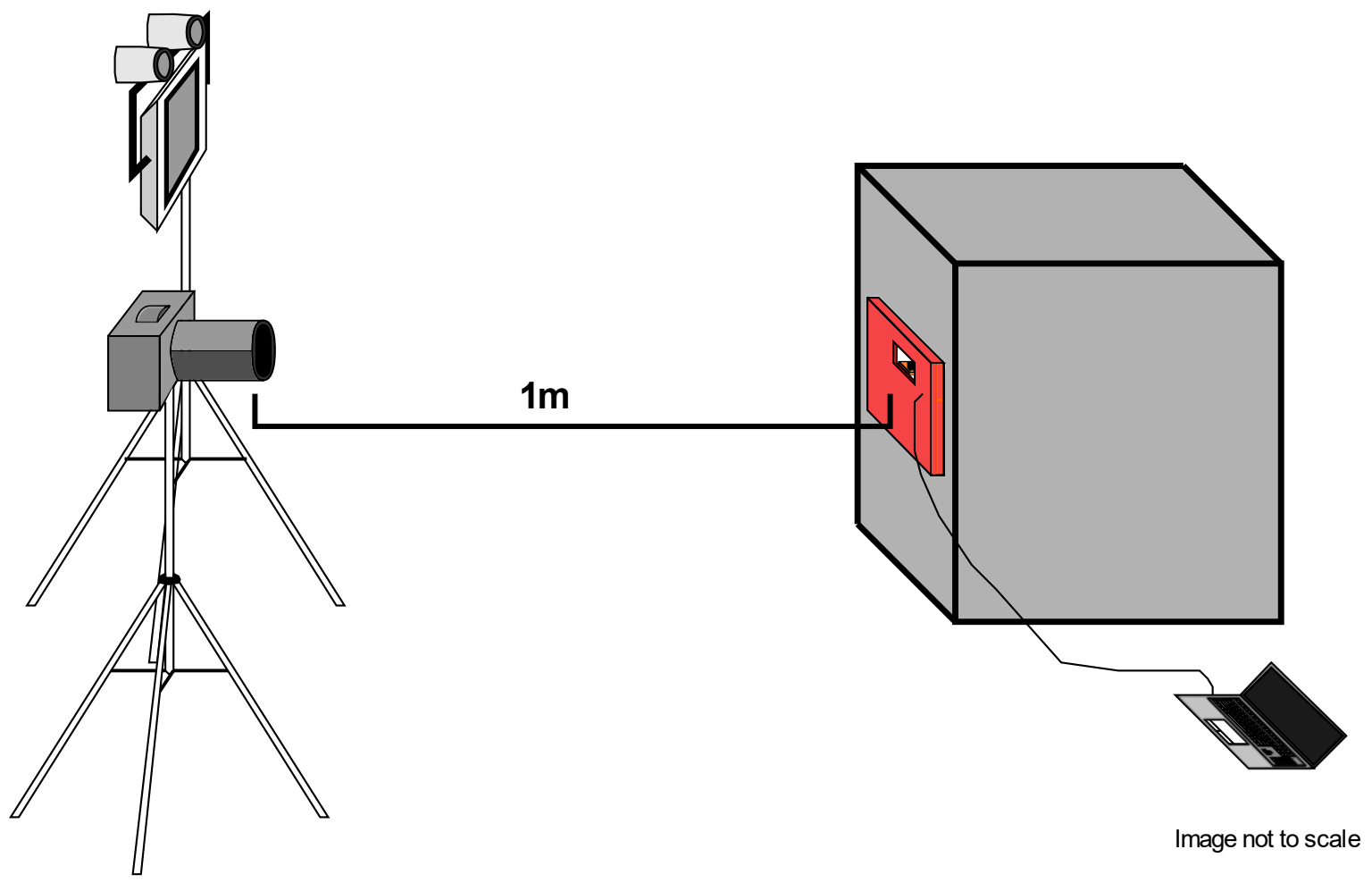

Figure 3.1 Schematic diagram of the set up used during the heating experiments. On the top right of the diagram is the M110 furnace where the heating experiments were conducted. While samples are being heated a thermocouple is placed within the furnace, this is connected to a PC where the data is continuously recorded during the experiments. A Nikon Z7 with an AF-S NIKKOR 28-300mm or a Sony RX-10 both with polarizing lens' take 1-3 second interval time-lapse pictures during the heating experiments. The camera was placed $1 \mathrm{~m}$ away from the furnace to avoid heat damage to the camera and allow for the whole sample to be visible. When the furnace was heated to $\sim 900^{\circ} \mathrm{C}$, the samples and walls surrounding glow red obscuring the sample with the added effect of hiding important features. To overcome this, light was supplied by LED floodlights and two bike lights shown in the top left. These had the advantage of displaying all features within the bomb and highlighting the samples in their entireties throughout the heating experiments. 
Heating experiments were conducted at University of Canterbury using a M110 Furnace. The furnace was preheated to $900^{\circ} \mathrm{C}$ for almost all samples although some were trialed at $850^{\circ} \mathrm{C}$ due to rapid vesiculation of some samples, but this temperature was insufficient to cause vesiculation of most samples and was then changed back to $900^{\circ} \mathrm{C}$. Once the oven had preheated, the samples were placed on a ceramic plate approximately $10 \mathrm{~cm}$ into the furnace to allow for uniform heating of all the samples and obsidians within. To verify temperature within the furnace near the obsidian's location, an N-Type thermocouple was positioned within the furnace at the same depth as the sample but $\sim 3 \mathrm{~cm}$ horizontally away from it (Fig. 3.1). temperatures were recorded using the program LABview and exported to excel with the mean temperature of the thermocouple and the temperature on the furnace being recorded. Due to the proximity of the thermocouple to the sample and more accurate reading of the thermocouple, these temperatures were favoured. To keep consistency, samples were heated for a maximum of 15 minutes for $900^{\circ} \mathrm{C}$. Some samples were heated in the furnace at $850^{\circ} \mathrm{C}$ samples for up to 20 minutes to see how these rocks vesiculated under this lower temperature, although these samples exhibited minimal change. Timing started as the furnace door shut after the sample was inserted and ended when the furnace door was again opened after either the designated time had passed or the amount of vesiculation was too great. This was judged visually and was thus a qualitative measure of the vesiculation but generally allowed for vesiculation of certain surfaces to be limited to workable quantities within post-experiment XCT scans. For these samples that were removed early, the time was stopped and recorded once the experiment ended to allow for some measure of this vesiculation to occur. Once the rocks were heated for the allotted time or desirable vesiculation had occurred, they were removed from the furnace and immediately quenched in a 1.5L metal bucket of water. This meant that vesiculation only occurred during the heating experiments and no further vesiculation occurred during the gradual cooling of the samples at atmospheric temperature. The samples were then allowed to dry before height, width, and depth measurements of the vesiculated samples were taken. This allowed for a quick comparison of the samples and helped with determining scale differences in heating photographs. 


\subsubsection{Photography of heating experiments}

Throughout the heating experiments photographs were taken to view textural changes, allowing for correlation to the textural scans of regions that have vesiculated (Fig. 3.1). The photos were captured using a Nikon Z7 with an AF-S NIKKOR 28-300mm lens and a Sony RX10 both with polarizing lenses. The photos were taken at either 1 second or 3 second intervals depending on the degree of vesiculation. Samples B21_AS23 and B16_AS18, which vesiculated rapidly, having 1 second interval photos but the remainder having 3 second intervals. However, during the heating process as the furnace reached $900^{\circ} \mathrm{C}$ the entirety of the furnace began to glow red due to the heat and the samples were obscured. This required external lighting for samples to be able to be observed in these conditions. This was accomplished using a $50 \mathrm{~Hz}, 20 \mathrm{~W}$ LED floodlight in combination with at least one LED bike light to illuminate the samples (Fig. 3.1). Throughout the heating experiments, images were transferred to a computer and placed in a labelled folder. These images were then analysed through comparison of two images at separate time intervals to determine the rates of vesiculation throughout the experiments. These were compared to the specimens in hand sample to verify regions we may have missed in just the photo analysis.

\section{4. $\quad$ Textural analysis}

Qualitative and quantitative analysis of samples were made from both pre-experiment natural samples and post-heating samples. The qualitative analysis consisted of looking at the hand samples and XCT scans of natural and heated samples to find separate textures within a specific obsidian. The quantitative analysis focused on the independent properties of these obsidians such as porosity, water content, and volume change of the whole obsidian and of the specific textures present within the independent samples.

\subsubsection{Natural sample analysis}

\section{Qualitative analysis}

The qualitative analysis of these specific natural samples consisted of two major areas, the external textures of the sample which are visible in hand sample and heating experiment photography, and the internal textures which were identified from the natural and heated 
XCT scans. The first look at the textures were in hand sample. This analysis aided in identifying areas of interest and helped align the internal scans. Photos taken during the heating experiments were aligned with the initial images of the experiments representing the natural samples. However, the initial textures of the images can be shown from the XCT too if the images are rendered as a 3D volume.

The main portion of the qualitative analysis centred around the XCT images. These scans were processed in the imaging software of Avizo. Due to the large number of scans present in each natural sample XCT scan, these had to be changed into a .tiff LDA (large data file) before they were in a workable state. This rendered the scans as grey-scale density images with highdensity objects (e.g. iron-oxides) having high greyscale values and low-density objects (e.g. air or void space) having low values. These density differences then allowed for regions within the obsidian to be highlighted and different textures had slightly varying density values which were able to be isolated and observed in detail. For initial observations high density objects such as crystals and indentations within the obsidians were the focus as these could be easily matched to specific regions on the hand sample. High-density objects also provided the added benefit of not changing shape when the samples underwent the heating experiments, and although not needed for textural analysis, were noted for alignment of the natural and postheating XCT scans. The matching of textures was easy for the already-small tube samples, but the large samples required cutting for heating experiments as mentioned earlier. This required specific textures and high-density objects to define areas of interest and make sure what was being looked at was the correct region of the sample.

After regions of interest had been identified, these images needed to be cropped and subsampled to allow the data to be in a workable state with relation to scan size and fitting within the furnace. These different textures and obsidians within composite bomb samples to be highlighted. This uses the 'extract subvolume' tool in Avizo to isolate the region of interest or remove as much background as possible to make the scans workable. This also allows the scans to be 'subsampled' which, for example, if you subsample by two will take every second scan of a specific region. This makes the data more workable but doesn't reducing the accuracy of the scans (i.e going from a resolution of $5 \mu \mathrm{m}$ to $10 \mu \mathrm{m}$ ) and due to this was limited as much as possible. 
The resulting data were then manipulated with 'edit new label field' to highlight these specific textures. This allowed for multiple different tools in selecting different textures within the obsidians and composite bombs. These tools include "lasso" which selects a specific region defined by the user, "interpolate" which extends selected fields between two or more images through non selected images, "magic wand" to select one specific feature of a defined density, and "thresholding" which selected everything between two defined greyscale values. These tools were used in unison although care had to be taken when using any tool as the density values of the greyscale images were so close together that the automated software could not determine the differences, so manual methods were generally required. This selected the different textural regions and allowed for an easier view of these regions of interest.

\section{Quantitative analysis}

Quantification of textures on XCT scans was done in Avizo and guided by qualitative analysis. This requires the use of the already defined textures from the 'edit new label field' function to then gain porosity and volume data per texture.

The volume of each obsidian is determined through expanding the selection of the separate textures within a specific obsidian. If all textures are selected within a specific obsidian or composite bomb sample, then that means that collectively the volume of the whole obsidian or composite bomb has been selected. Avizo also allows for the volume of the obsidians or specific textures be determined through the process of 'material statistics'. This process allows for the number of pixels in each slice to be known and adds these together before determining the number of pixels per volume. After adding in the resolution of the scans, Avizo calculates a volume of each material. This result is a volume for each specific textural element, which is helpful in itself to see how the specific textures' volumes changed once heated. To gain the whole sample or obsidian volume, each individual specific texture is summed.

$\varnothing=\frac{V_{V}}{V_{T}} \times 100$

[Eq. 3] 
Porosity can then be determined for these specific regions using equation $3 . \emptyset$ is the porosity of the melt (percentage), $V_{v}$ is the volume of the void space $\left(\mathrm{mm}^{3}\right)$ and $V_{T}$ is the total volume of the material $\left(\mathrm{mm}^{3}\right)$. The void space calculations required re-entrance into the 'edit new label field'. The next step requires that the voids within the specific texture be selected and labelled in a different field. Once these voids are labelled, porosity measurements are obtained in the same way as overall volumes, except their will now be an extra part accounting for this porosity within the textures. Volumes of the voids as $V_{v}$ and the volume of the total texture (void space and obsidian texture portion) are entered into the $V_{t}$ of equation 3. The porosity of the whole rock is done in a similar way with all the bubble concentrations being divided by the total volume of the rock. The alternate method for this is to use Avizo's 'porosity analysis wizard'. This automates the void selection process once the material and voids are defined by thresholding for the independent textures and then produces the porosities as a percentage. Either method can be used although the prior method was preferred due to the more controllable nature for selecting specific regions at greater ease.

\subsubsection{Heated sample analysis}

\section{Qualitative analysis}

Scans of the heated samples were conducted at a lower resolution than the natural sample scans as mentioned above (section 3.1). Due to having a lower number of scans, they did not require transition into a LDA format. These samples and obsidians within them still underwent the process of 'extract subvolume' to remove background from the samples but did not require subsampling to form useable data. However, these samples did require a greyscale equilibration, so the densities displayed between 0-255 which was accomplished using 'greyscale transform' in Avizo. Once this was completed, individual textures were investigated and highlighted in an identical method as the natural samples.

Once an independent analysis of both natural and heated textures was complete, then comparisons between the samples could occur. This required alignment of the primary orthogonal planes (XYZ) so that both sets of data can be analysed within the same frame, accomplished using 'Image registration' within the Avizo suite. This used the relation of the high-density inert objects as reference and created a new image of the natural sample and 
natural obsidians that has the same orthogonal planes as the post-heated sample and obsidian. The natural samples were chosen to be aligned with the heated samples due to their higher resolution and would therefore be more accurate once rendered, and fewer areas inferred. Once these planes were aligned, the textures (where possible) and high-density inert segments were matched for specific regions to compare changes that had occurred during the heating process. These results highlight the structural changes observed during heating and aid in determining why certain textures vesiculated more than others.

\section{Quantitative analysis}

Methods for gaining porosity of this section are identical to the natural samples. These were conducted for both volume and porosity measurements for the heated textures and obsidians within composite bomb samples. Porosity change for the obsidians was compared after this, using equation 4 below, which represents the porosity increase through heating of specific textures or obsidians $\left(\Phi_{\text {change }}\right)$. $\Phi_{\text {post }}$ is the porosity of the post heated obsidian (dimensionless) and $\Phi_{\text {natural }}$ is the porosity of the natural obsidian (dimensionless). This measurement also aids in the reconstructions of the obsidians during the qualitative analysis.

$\emptyset_{\text {change }}=\emptyset_{\text {heated }}-\emptyset_{\text {natural }}$

As both porosities are known this comparison and analysis can take place. This porosity change is effective in determining how much a texture has changed through heating and if there is a change to rate of vesiculation across samples. Additionally, it can show which textures experienced higher amounts of vesiculation within the samples and isolate these, verifying which textures within the obsidians have the largest increase in porosity.

Lastly, volume measurements of the heated and natural textures were taken for each sample. Volume change for these textures were then compared, shown in equation 5, which represents the percentage volume change of the specific texture through the heating process $\left(V_{\text {change }}\right) . V_{\text {post }}$ is the volume of the post heated texture $\left(\mathrm{m}^{3}\right)$ and $V_{\text {natural }}$ is the volume of the natural texture $\left(\mathrm{m}^{3}\right)$. This measurement also aids in the reconstructions of the textures during the qualitative analysis.

$V_{\text {change }}=\frac{V_{\text {post }}}{V_{\text {natural }}} \times 100$ 


\section{Chapter 4. Results}

\subsection{Samples}

Composite bomb samples and sub samples are displayed below in Table 4.1. A generalised description of the bomb's appearance in hand sample and dominant internal textures are provided, which align with the study of Schipper et al. (2021). The composite bombs have also been defined by a dominant texture or pyroclastic material within the bombs themselves referred to as the 'composite bomb type' which consists of: 1) matrix dominated, 2) pumice dominated, 3) obsidian dominated, 4) obsidian and fine matrix dominated composite bombs. Each of these different types of composite bombs are welded assemblages of heterogenous material but are dominated by either a fine-grained matrix separating larger clastic material (1), pumice clasts (2), or obsidian clasts (3). The one exception to this rule is that of obsidian and fine ash matrix (4), which is a subset of the obsidian composite bombs containing a visible fine matrix between obsidian clasts. This distinction is because these samples share properties of both the matrix and obsidian dominated composite bombs, so this middle member is justified and allows for a minor distinction and separation to occur between the types. These composite bomb type distinctions allow for the macroscopic textural relationship to secondary vesiculation to be analysed.

These dominant textures are also visible within the XCT samples if images are present (Table 4.1). The XCT samples are small sections of the greater composite bombs, extracted through cutting, and then scanned at the Australian synchrotron. Initially these XCT scans were used to determine regions of obsidian clasts within the composite bomb samples and textures of interest prior to creating subsamples of the XCT samples for future analysis. To verify location of the XCT subsampling, obsidian and pyroclastic material was matched within the scanned data and the XCT subsamples, with amendments and cropping of the data made accordingly. Once these regions were selected, the sample was cut into the XCT subsamples, displayed below. Naming conventions following this section will drop the P16- section of the naming convention, and instead be the XCT sample name followed by the XCT subsample name (e.g. B07_AS19_1A). 


\begin{tabular}{|c|c|c|c|c|c|}
\hline Sample & $\begin{array}{l}\text { Composite } \\
\text { bomb type }\end{array}$ & $\begin{array}{l}\text { Description of } \\
\text { sample }\end{array}$ & $\begin{array}{l}\text { XCT sample with photo of samples below } \\
\text { where captured }\end{array}$ & $\begin{array}{l}\text { Thin section } \\
\text { created for } \\
\text { XCT sample } \\
(X) \\
\end{array}$ & $\begin{array}{l}\mathrm{XCT} \\
\text { subsamples }\end{array}$ \\
\hline Unknown & $\begin{array}{l}\text { Matrix } \\
\text { dominated }\end{array}$ & $\begin{array}{l}\text { Fine matrix within } \\
\text { the sample with } \\
\text { obsidian veins } \\
\text { running through it. }\end{array}$ & Extra ASO3 & & $\begin{array}{l}1 \mathrm{~A} \\
2 \mathrm{~B} \\
2 \mathrm{C} \\
\mathrm{ML2} \\
\mathrm{ML3} \\
\text { MU1 } \\
\text { Broken }\end{array}$ \\
\hline P16_B07 & $\begin{array}{l}\text { Pumice } \\
\text { dominated }\end{array}$ & $\begin{array}{l}\text { Low-density } \\
\text { pumice clasts of } \\
\text { variable size } \\
\text { wielded together } \\
\text { with a fine pink } \\
\text { matrix with } \\
\text { sporadic obsidian } \\
\text { clasts to } \sim 5 \mathrm{~cm} \text {. }\end{array}$ & B07 & $x$ & $\begin{array}{l}1 A \\
1 B \\
2 A \\
2 B \\
3 A \\
3 B \\
4 A \\
4 B\end{array}$ \\
\hline \multirow[t]{3}{*}{ P16_B09 } & \multirow[t]{3}{*}{$\begin{array}{l}\text { Obsidian and } \\
\text { fine matrix } \\
\text { dominated }\end{array}$} & \multirow[t]{3}{*}{$\begin{array}{l}\text { High-density } \\
\text { obsidian bomb, } \\
\text { with an occasional } \\
\text { low-density orange } \\
\text { matrix separating } \\
\text { obsidians. }\end{array}$} & B09_AS06 & $x$ & $\begin{array}{l}\text { A1 } \\
\text { B1 } \\
\text { A2 } \\
\text { B2 } \\
\text { B3 } \\
\text { C1 } \\
\text { C2 }\end{array}$ \\
\hline & & & B09_AS07 & $x$ & $\mathrm{M} 2 \mathrm{~A}$ \\
\hline & & & B09_T5 & & $\begin{array}{l}1 \\
3\end{array}$ \\
\hline \multirow[t]{2}{*}{ P16_B10 } & \multirow[t]{2}{*}{$\begin{array}{l}\text { Obsidian } \\
\text { dominated }\end{array}$} & \multirow{2}{*}{$\begin{array}{l}\text { High-density } \\
\text { obsidian } \\
\text { dominated bomb } \\
\text { with lithics present } \\
\text { throughout but no } \\
\text { clear matrix. }\end{array}$} & B10_AS01 & $x$ & $\begin{array}{l}\mathrm{A} 1 \\
\mathrm{~B} 1 \\
\mathrm{~B} 2\end{array}$ \\
\hline & & & B10_T5 & & $\begin{array}{l}1 / 2-1 \\
1 / 2 \\
-2\end{array}$ \\
\hline P16_B11 & $\begin{array}{l}\text { Obsidian } \\
\text { dominated }\end{array}$ & $\begin{array}{l}\text { High-density } \\
\text { obsidian composite } \\
\text { bomb with banded, } \\
\text { vesiculated internal } \\
\text { textures present. }\end{array}$ & B11_T1_1 & & 1 \\
\hline \multirow[t]{2}{*}{ P16_B13 } & \multirow[t]{2}{*}{$\begin{array}{l}\text { Obsidian } \\
\text { dominated }\end{array}$} & \multirow{2}{*}{$\begin{array}{l}\text { High-density } \\
\text { obsidian composite } \\
\text { bomb with lava like } \\
\text { lithics. }\end{array}$} & B13_ASO2 & $x$ & $\begin{array}{l}1 \\
2 \\
\end{array}$ \\
\hline & & & B13_T5 & & $1 / 2$ \\
\hline P16_B14 & $\begin{array}{l}\text { Obsidian } \\
\text { dominated }\end{array}$ & $\begin{array}{l}\text { High-density } \\
\text { obsidian composite } \\
\text { bomb }\end{array}$ & B14_AS17 & $x$ & 1 \\
\hline P16_B16 & $\begin{array}{l}\text { Matrix } \\
\text { dominated }\end{array}$ & $\begin{array}{l}\text { Matrix dominated } \\
\text { with numerous in } \\
\text { situ foaming as well } \\
\text { as obsidian, lithic } \\
\text { and pumice clasts } \\
\text { within }\end{array}$ & B16_AS18 & $x$ & $\begin{array}{l}\text { A1 } \\
\text { B1 } \\
\text { A2 } \\
\text { B2 } \\
\text { B3 } \\
\text { B4 } \\
\end{array}$ \\
\hline
\end{tabular}




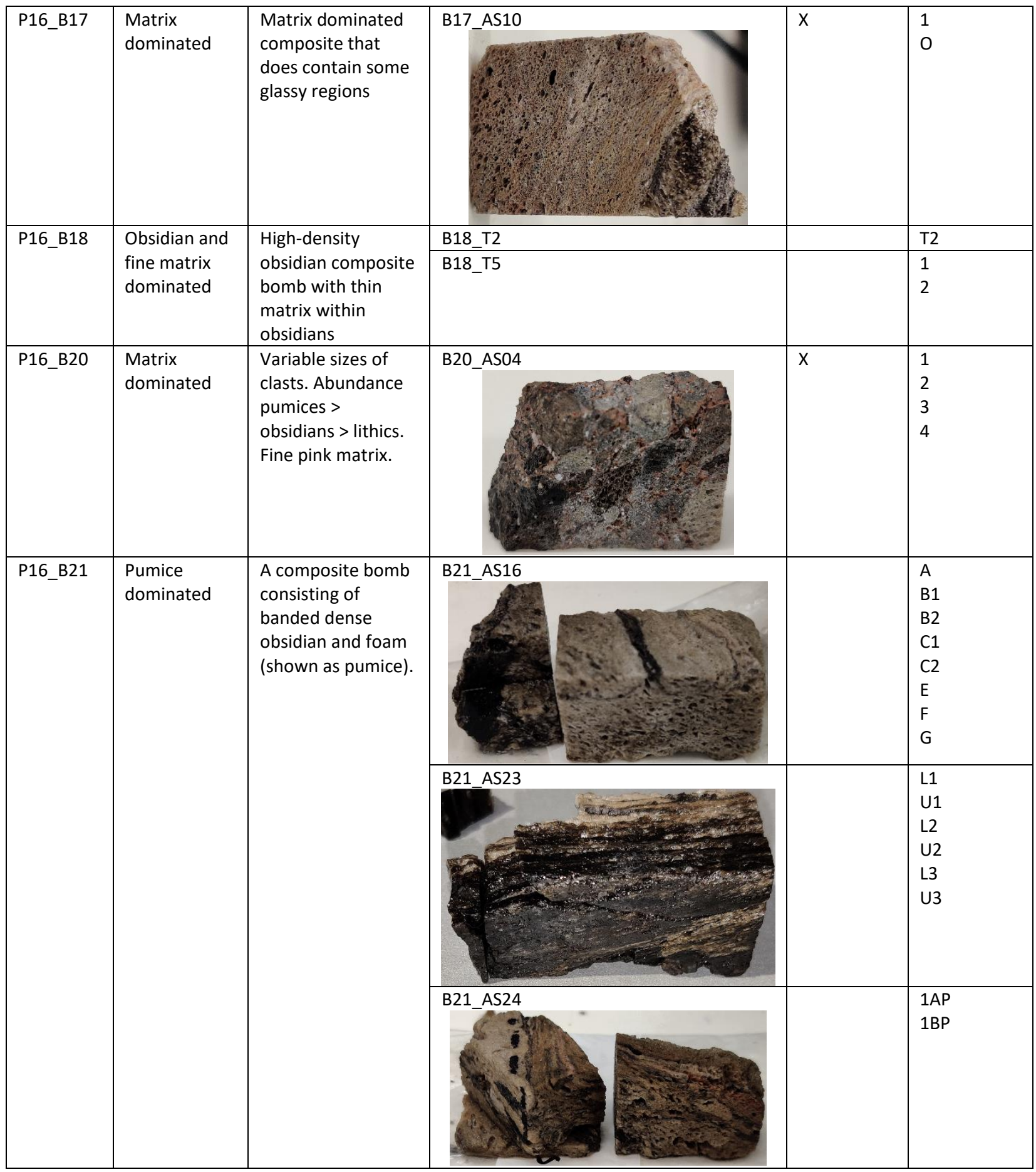

Table 4.1 Composite bomb classes and alterations made for our experiments. The first column lists the composite bomb sample name of the rock, followed by the composite bomb type (described above) with a generalised description of this bomb from Schipper et al. (2021) and its composition/textures. The XCT samples were made by Whattam (2019) for XCT scanning and textural observations with images obtained prior to subsampling, thin sections were made close to the XCT samples to be able to show minerals within the samples and aid in determining what certain clasts are in XCT, lastly the XCT subsamples are cuts made to XCT samples to reduce the size of the samples for the later analysis. 


\subsection{Volatile content measurements}

During the subsampling process, water contents of the obsidians extracted from composite bombs were obtained, which are representative of the volatile content of Cordón Caulle (Section 2). Table 4.2 displays the water contents as determined by FTIR. Measured $\mathrm{H}_{2} \mathrm{O}$ within the composite bomb sample suite varies little, between $0.07-0.32 \pm 0.05$ wt. $\% \mathrm{H}_{2} \mathrm{O}$. This means that the entire composite bomb suite has comparable water contents to those previously analysed by Castro et al. (2014), which found a variability of $0.03-0.31$ wt. \% $\mathrm{H}_{2} \mathrm{O}$. Castro et al. (2014) had determined that water contents for Cordón Caulle pyroclastic obsidians were low compared to those from other silicic volcanoes (e.g., Chaitén Forte and Castro (2019); Mono craters Newman et al. (1986); etc), but they did not note the internal texture or variation within the individual obsidian clasts themselves. Therefore, these new water content data (Table 4.2), coupled to textural observations, allow for a link between obsidian $\mathrm{H}_{2} \mathrm{O}$ contents and textures.

When the compositions are compared obsidian-to-obsidian within a singular XCT scanned sample (e.g B21_AS23, B09_AS06, etc.) the variance is within error of each independent obsidian further indicating the low variability in volatile concentrations within a single sample (Table 4.2). When obsidian-obsidian variation is compared within the entire composite bomb sample (e.g., P16_B21) more variability is observed, typically outside errors, of up to $0.14 \pm$ 0.05 wt. \% $\mathrm{H}_{2} \mathrm{O}$, disregarding the thick and opaque sample (B21_T5_1) which likely did not transmit enough infrared light to get an accurate measurement (Table 4.2). However, this variability is not consistent across all bombs, with P16_B09 and P16_B10 samples remaining within error of volatile contents measured (Table. 4.2). Even at its most extreme, the measured variability in volatile contents of obsidian erupted from Cordón Caulle are still low and relatively uniform compared to obsidian from other silicic volcanoes.

Lastly, when water contents are compared across composite bomb type, further trends become apparenty. Samples that are pumice dominated, but still contain some minor obsidian clasts, have the highest water content of between $0.18-0.32 \pm 0.05$ wt. $\% \mathrm{H}_{2} \mathrm{O}$ (Fig. 4.1). Within hand samples these tend to appear more vesicular than other obsidian layers (Table. 4.1). This already-vesiculated texture and higher water content may promote 
vesiculation within these textures and suggests overall higher water contents existed within these pumice dominated composite bombs.

Obsidians and fine matrix dominated composite bomb samples had moderate water contents. They ranged from $0.08-0.22 \pm 0.03$ wt.\% $\mathrm{H}_{2} \mathrm{O}$, although most of these samples were within $0.10-0.20$ wt.\% $\mathrm{H}_{2} \mathrm{O}$. This overlaps with obsidian from the obsidian dominated composite bomb samples, which had between $0.07-0.20 \pm 0.05$ wt. $\% \mathrm{H}_{2} \mathrm{O}$. Although these samples overlap, over half of obsidian dominated samples (5/9 samples) were $\leq 0.10 \mathrm{wt} \% \mathrm{H}_{2} \mathrm{O}$ showing the overall low volatile contents present within these samples. This also further highlights the textural response of volatiles within these samples with each composite bomb type displaying varied volatile contents to these other composite bomb types.

Although overall the erupted products of Cordón Caulle do have variable volatile contents, they are considerably low and consistent compared to obsidians globally (Fig. 2.5). Still, obsidians from pumice dominated bombs have the highest water content, while those from matrix dominated samples have moderate water contents, and those from obsidian dominated samples have the lowest volatile contents. Although the degrees of saturation during experimental heating will be relatively the same due to the low overall water concentrations - which is what makes Cordón Caulle ideal for this study - trends in volatile contents of composite bomb types should be considered when assessing how pre-existing internal textures affect the vesiculation process.

Number of obsidians at specific water content

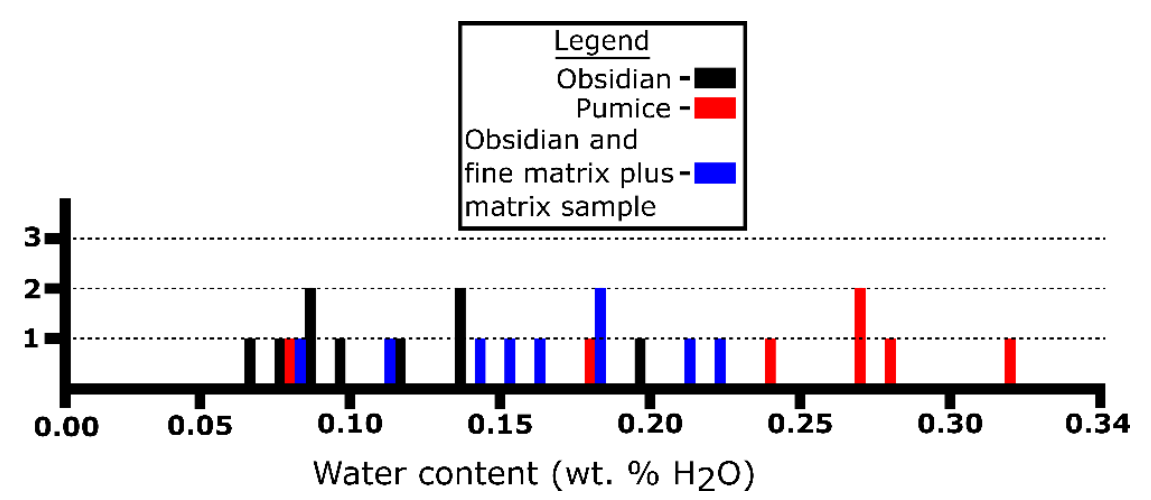

Figure 4.1 Histogram of obsidian water contents grouped by texture of composite bomb samples from which each was extracted. 


\begin{tabular}{|c|c|c|c|}
\hline Type of composite bomb & $\begin{array}{l}\text { Sample number of obsidian } \\
\text { wafer }\end{array}$ & $\begin{array}{l}\text { Water content } \\
\left(\text { wt. } \% \mathrm{H}_{2} \mathrm{O}\right)\end{array}$ & $\begin{array}{l}\text { Wafer thickness } \\
(\mu \mathrm{m})\end{array}$ \\
\hline \multirow[t]{9}{*}{ Obsidian dominated } & B11_T1_1_C & $0.07 \pm 0.02$ & $134 \pm 5$ \\
\hline & B13_AS02_FIB_B & $0.08 \pm 0.02$ & $168 \pm 5$ \\
\hline & B13_AS02_FIB-A & $0.09 \pm 0.02$ & $151 \pm 5$ \\
\hline & B10_AS01_A4 & $0.09 \pm 0.01$ & $208 \pm 5$ \\
\hline & B10_AS01_B2 & $0.10 \pm 0.03$ & $177 \pm 5$ \\
\hline & B10_T5_1/2_2 & $0.12 \pm 0.03$ & $189 \pm 5$ \\
\hline & B10_T5_1/2_1 & $0.14 \pm 0.03$ & $116 \pm 5$ \\
\hline & B10_AS01_a3a & $0.14 \pm 0.04$ & $205 \pm 5$ \\
\hline & B11_T1_1_a & $0.20 \pm 0.05$ & $166 \pm 5$ \\
\hline \multirow[t]{7}{*}{ Pumice dominated } & B21_T5_1 & $0.08 \pm 0.02$ & $225 \pm 5$ \\
\hline & B21_AS23_1 & $0.18 \pm 0.04$ & $132 \pm 5$ \\
\hline & B21_AS23_2 & $0.24 \pm 0.02$ & $229 \pm 5$ \\
\hline & B21_AS16_2 & $0.27 \pm 0.02$ & $222 \pm 5$ \\
\hline & B21_AS24_1 & $0.27 \pm 0.02$ & $207 \pm 5$ \\
\hline & B21_AS23_3 & $0.28 \pm 0.03$ & $205 \pm 5$ \\
\hline & B21_AS16_2A & $0.32 \pm 0.05$ & $167 \pm 5$ \\
\hline Matrix dominated & B20_AS05_1 & $0.11 \pm 0.01$ & $148 \pm 5$ \\
\hline \multirow{8}{*}{$\begin{array}{l}\text { Obsidian and fine matrix } \\
\text { dominated }\end{array}$} & B18_T5_a & $0.08 \pm 0.01$ & $202 \pm 5$ \\
\hline & B09_AS06_1 & $0.14 \pm 0.03$ & $94 \pm 5$ \\
\hline & B09_AS06_2 & $0.15 \pm 0.02$ & $106 \pm 5$ \\
\hline & B09_AS06_4_1 & $0.16 \pm 0.01$ & $122 \pm 5$ \\
\hline & B09_T5_3a & $0.18 \pm 0.03$ & $139 \pm 5$ \\
\hline & B09_T5_1a & $0.18 \pm 0.03$ & $203 \pm 5$ \\
\hline & B18_T2_B1 & $0.21 \pm 0.03$ & $149 \pm 5$ \\
\hline & B18_T2_a & $0.22 \pm 0.03$ & $122 \pm 5$ \\
\hline
\end{tabular}

Table 4.2 Water contents of obsidian samples, grouped into composite bomb types from which they were extracted (Schipper et al. 2015; Cassidy et al. 2018; Whattam 2019). This separation also allows for further macroscopic textural analysis of water contents and less variation across the samples within each category. Also given are FTIR wafer thicknesses as measured by micrometer or interference fringes per sample. These are used for conversion of measured absorbances to $\mathrm{H}_{2} \mathrm{O}$ concentrations using the Beer-Lambert law (Equation 2). 


\subsection{Heating experiments}

Descriptions of the heating experiments to which each composite bomb XCT subsample was subjected are listed in Table 4.3. Table 4.3 also describes the qualitative style of foaming observed in each experiment, separated into four main vesiculation styles: (1) isolated spherical foaming, (2) isolated planar foaming, (3) isotropic expansion, and (4) shrivelling, which are described below in Section 4.5. Variations in time and slight temperature fluctuations during the heating experiments are also listed in Table 4.3. Different experimental times were chosen based on dynamic observation of how each sample reacted to heating. The goal was to limit vesiculation and changes within the composite bomb structure so both natural and heated samples could be correlated in natural and heated XCT scans. Temperature fluctuations occurred just through transitions between experiments, where the door to the furnace was opened when placing and removing the samples. 


\begin{tabular}{|c|c|c|c|c|c|c|c|c|}
\hline $\begin{array}{l}\text { Experiment } \\
\text { number }\end{array}$ & $\begin{array}{l}\text { Date } \\
(\mathrm{dd} / \mathrm{mm} / \mathrm{yy})\end{array}$ & Sample & $\begin{array}{l}\text { Temperature } \\
\left({ }^{\circ} \mathrm{C}\right)\end{array}$ & Time & $\begin{array}{l}\text { Qualitative foam } \\
\text { seen }\end{array}$ & $\begin{array}{l}\text { Photographs } \\
(\mathrm{X})\end{array}$ & \begin{tabular}{|l} 
CT scans \\
Natural $(X)$
\end{tabular} & $\begin{array}{l}\text { CT scans } \\
\text { Heated }(X)\end{array}$ \\
\hline 001 & $09 / 07 / 20$ & B14_AS17_1 & $840 \pm 3^{\circ} \mathrm{C}$ & 20 mins & $\begin{array}{l}\text { Expansion } \\
\text { Planar foaming }\end{array}$ & $x$ & & \\
\hline 002 & $09 / 07 / 20$ & B17_AS10_1 & $900 \pm 10^{\circ} \mathrm{C}$ & 15 mins & Expansion & $x$ & $x$ & \\
\hline 003 & $09 / 07 / 20$ & Extra AS03_1A & $860 \pm 5^{\circ} \mathrm{C}$ & 10 mins & $\begin{array}{l}\text { Spherical foaming } \\
\text { Expansion }\end{array}$ & $x$ & & \\
\hline 004 & $09 / 07 / 20$ & Extra AS03_2B & $920 \pm 10^{\circ} \mathrm{C}$ & 10 mins & \begin{tabular}{|l|} 
Spherical foaming \\
Expansion
\end{tabular} & $\mathrm{x}$ & & \\
\hline 005 & $09 / 07 / 20$ & B21_AS23_B & $900 \pm 4^{\circ} \mathrm{C}$ & 7 mins & $\begin{array}{l}\text { Planar foaming } \\
\text { Expansion }\end{array}$ & $x$ & $\mathrm{x}$ & \\
\hline 006 & $09 / 07 / 20$ & B21_AS23_C & $900 \pm 4^{\circ} \mathrm{C}$ & 2 mins 35 secs & $\begin{array}{l}\text { Planar foaming } \\
\text { Expansion }\end{array}$ & $\mathrm{x}$ & $\mathrm{x}$ & \\
\hline 007 & $09 / 07 / 20$ & B09_AS06_1 & Unrecorded & 10 mins & $\begin{array}{l}\text { Spherical foaming } \\
\text { Expansion }\end{array}$ & & $x$ & \\
\hline 008 & $09 / 07 / 20$ & Extra ASO3_ML3 & $920 \pm 10^{\circ} \mathrm{C}$ & 2 mins 35 secs & Expansion & $X$ & & \\
\hline 009 & $09 / 07 / 20$ & Extra AS03_ML2 & $920 \pm 10^{\circ} \mathrm{C}$ & 10 mins & Expansion & $x$ & & \\
\hline 010 & $09 / 07 / 20$ & Extra AS03_2B & $894 \pm 2^{\circ} \mathrm{C}$ & 10 mins & $\begin{array}{l}\text { Spherical foaming } \\
\text { Expansion }\end{array}$ & $x$ & & \\
\hline 011 & $09 / 07 / 20$ & B21_AS23_E & $845 \pm 2^{\circ} \mathrm{C}$ & 15 mins & $\begin{array}{l}\text { Planar foaming } \\
\text { Expansion }\end{array}$ & $x$ & $x$ & \\
\hline 012 & $09 / 07 / 20$ & Extra AS03_MU1 & $830 \pm 10^{\circ} \mathrm{C}$ & 15 mins & Expansion & $x$ & & \\
\hline 013 & $09 / 07 / 20$ & Extra AS03_Broken & $822 \pm 2^{\circ} \mathrm{C}$ & 15 mins & $\begin{array}{l}\text { Spherical foaming } \\
\text { Expansion }\end{array}$ & $x$ & & \\
\hline 014 & $13 / 07 / 20$ & B09_AS07_M2A & $900 \pm 10^{\circ} \mathrm{C}$ & 10 mins & Expansion & $X$ & $X$ & \\
\hline 015 & $13 / 07 / 20$ & B20_ASO4_2 & $870 \pm 5^{\circ} \mathrm{C}$ & 10 mins & Expansion & $X$ & & \\
\hline 016 & $13 / 07 / 20$ & B21_AS23_L2 & $880 \pm 5{ }^{\circ} \mathrm{C}$ & 2 mins 58 secs & $\begin{array}{l}\text { Planar foaming } \\
\text { Expansion }\end{array}$ & $x$ & $x$ & $x$ \\
\hline 017 & $13 / 07 / 20$ & B20_AS05_2 & $880 \pm 5^{\circ} \mathrm{C}$ & 10 mins & $\begin{array}{l}\text { Planar foaming } \\
\text { Expansion } \\
\text { Shrivelling }\end{array}$ & $x$ & $x$ & \\
\hline
\end{tabular}




\begin{tabular}{|c|c|c|c|c|c|c|c|c|}
\hline 018 & $13 / 07 / 20$ & B09_AS06_C & $873 \pm 3^{\circ} \mathrm{C}$ & $\begin{array}{l}15 \text { mins } 20 \\
\text { secs }\end{array}$ & Expansion & $x$ & $x$ & \\
\hline 019 & $13 / 07 / 20$ & B09_AS06_C & $874 \pm 3^{\circ} \mathrm{C}$ & 15 mins & Expansion & $x$ & $x$ & \\
\hline 020 & $13 / 07 / 20$ & B20_AS05_3 & $867 \pm 4^{\circ} \mathrm{C}$ & 15 mins & \begin{tabular}{|l} 
Expansion \\
Shrivelling \\
\end{tabular} & $x$ & $x$ & \\
\hline 021 & $14 / 07 / 20$ & B09_AS06_B3 & $888 \pm 3^{\circ} \mathrm{C}$ & 15 mins & Expansion & $\mathrm{X}$ & $\mathrm{X}$ & \\
\hline 022 & $14 / 07 / 20$ & B10_AS01_B1 & $886 \pm 4^{\circ} \mathrm{C}$ & 15 mins & $\begin{array}{l}\text { Spherical foaming } \\
\text { Expansion }\end{array}$ & $x$ & $x$ & $x$ \\
\hline 023 & $15 / 07 / 20$ & B21_AS23_L1 & $890 \pm 4^{\circ} \mathrm{C}$ & $1 \mathrm{~min} 56 \mathrm{secs}$ & Expansion & $x$ & $x$ & \\
\hline 024 & $15 / 07 / 20$ & B21_AS23_U3 & $871 \pm 5^{\circ} \mathrm{C}$ & $1 \mathrm{~min} 45 \mathrm{secs}$ & $\begin{array}{l}\text { Planar expansion } \\
\text { Expansion }\end{array}$ & $x$ & $x$ & \\
\hline 025 & $15 / 07 / 20$ & B20_AS05_4 & $890 \pm 3^{\circ} \mathrm{C}$ & 15 mins & $\begin{array}{l}\text { Planar foaming } \\
\text { Shrivelling }\end{array}$ & $x$ & $x$ & \\
\hline 026 & $15 / 07 / 20$ & B10_AS01_A1 & $876 \pm 3^{\circ} \mathrm{C}$ & 15 mins & Expansion & $x$ & $x$ & \\
\hline 027 & $16 / 07 / 20$ & B10_AS01_B2 & $885 \pm 3^{\circ} \mathrm{C}$ & 15 mins & Expansion & $x$ & $x$ & \\
\hline 028 & $16 / 07 / 20$ & B21_AS23_G & $900 \pm 10^{\circ} \mathrm{C}$ & 2 mins & $\begin{array}{l}\text { Planar foaming } \\
\text { Expansion }\end{array}$ & $x$ & $x$ & \\
\hline 029 & $16 / 07 / 20$ & B21_AS23_F & $883 \pm 5^{\circ} \mathrm{C}$ & 2 mins & \begin{tabular}{|l|} 
Spherical foaming \\
Planar foaming \\
Expansion \\
\end{tabular} & $x$ & $x$ & \\
\hline 030 & $16 / 07 / 20$ & B21_AS23_L3 & $883 \pm 5^{\circ} \mathrm{C}$ & 2 mins & $\begin{array}{l}\text { Spherical foaming } \\
\text { Planar foaming } \\
\text { Expansion }\end{array}$ & $x$ & $x$ & $x$ \\
\hline 031 & $16 / 07 / 20$ & B21_AS23_U2 & $890 \pm 10^{\circ} \mathrm{C}$ & $1 \mathrm{~min} 30 \mathrm{secs}$ & $\begin{array}{l}\text { Planar foaming } \\
\text { Expansion }\end{array}$ & $x$ & $x$ & \\
\hline 032 & $16 / 07 / 20$ & B09_AS06_B2 & $900 \pm 10^{\circ} \mathrm{C}$ & 15 mins & $\begin{array}{l}\text { Spherical foaming } \\
\text { Expansion }\end{array}$ & $x$ & $x$ & \\
\hline 033 & $16 / 07 / 20$ & B09_AS06_B1 & $886 \pm 3^{\circ} \mathrm{C}$ & 15 mins & $\begin{array}{l}\text { Spherical foaming } \\
\text { Expansion }\end{array}$ & & $x$ & \\
\hline 034 & $16 / 07 / 20$ & B09_AS06_A1 & $891 \pm 3^{\circ} \mathrm{C}$ & 15 mins & $\begin{array}{l}\text { Spherical foaming } \\
\text { Expansion }\end{array}$ & $x$ & $x$ & \\
\hline 035 & $16 / 07 / 20$ & B17_AS10_0 & $886 \pm 3^{\circ} \mathrm{C}$ & 3 mins & Shrivelling & & $x$ & \\
\hline
\end{tabular}




\begin{tabular}{|c|c|c|c|c|c|c|c|c|}
\hline 036 & $16 / 07 / 20$ & B20_AS05_1 & $890 \pm 3^{\circ} \mathrm{C}$ & 15 mins & $\begin{array}{l}\text { Expansion } \\
\text { Shrivelling }\end{array}$ & $x$ & $\mathrm{X}$ & $x$ \\
\hline 037 & $16 / 07 / 20$ & B07_AS19_4A & $878 \pm 5^{\circ} \mathrm{C}$ & 15 mins & Shrivelling & $\mathrm{x}$ & $\mathrm{X}$ & \\
\hline 038 & $16 / 07 / 20$ & B07_AS19_3A & $889 \pm 5^{\circ} \mathrm{C}$ & 15 mins & $\begin{array}{l}\text { Spherical foaming } \\
\text { Expansion } \\
\text { Shrivelling }\end{array}$ & $x$ & $x$ & \\
\hline 039 & $16 / 07 / 20$ & B07_AS19_2A & $880 \pm 5^{\circ} \mathrm{C}$ & 15 mins & $\begin{array}{l}\text { Expansion } \\
\text { Shrivelling }\end{array}$ & $x$ & $x$ & \\
\hline 040 & $16 / 07 / 20$ & B07_AS19_1A & $891 \pm 3^{\circ} \mathrm{C}$ & 15 mins & $\begin{array}{l}\text { Planar foaming } \\
\text { Shrivelling }\end{array}$ & $x$ & $x$ & \\
\hline 041 & $16 / 07 / 20$ & B07_AS19_1B & $889 \pm 4^{\circ} \mathrm{C}$ & 15 mins & $\begin{array}{l}\text { Planar foaming } \\
\text { Shrivelling }\end{array}$ & $x$ & $x$ & $x$ \\
\hline 042 & $16 / 07 / 20$ & B07_AS19_2B & $900 \pm 10^{\circ} \mathrm{C}$ & 15 mins & $\begin{array}{l}\text { Spherical foaming } \\
\text { Shrivelling }\end{array}$ & $x$ & $\mathrm{X}$ & \\
\hline 043 & $16 / 07 / 20$ & B07_AS19_3B & $880 \pm 3^{\circ} \mathrm{C}$ & 15 mins & \begin{tabular}{|l|} 
Spherical foaming \\
Expansion \\
Shrivelling \\
\end{tabular} & $x$ & $x$ & \\
\hline 044 & $17 / 07 / 20$ & B07_AS19_4B & $875 \pm 8^{\circ} \mathrm{C}$ & 15 mins & $\begin{array}{l}\text { Expansion } \\
\text { Shrivelling }\end{array}$ & $x$ & $x$ & \\
\hline 045 & $17 / 07 / 20$ & B21_AS24_1AP & $894 \pm 5^{\circ} \mathrm{C}$ & 5 mins & $\begin{array}{l}\text { Planar foaming } \\
\text { Shrivelling }\end{array}$ & $\mathrm{x}$ & $x$ & \\
\hline 047 & $17 / 07 / 20$ & B21_AS24_1BP & $890 \pm 5^{\circ} \mathrm{C}$ & 10 mins & $\begin{array}{l}\text { Planar foaming } \\
\text { Shrivelling }\end{array}$ & $x$ & $x$ & \\
\hline 048 & $17 / 07 / 20$ & B21_AS16_A & $900 \pm 10^{\circ} \mathrm{C}$ & $1 \mathrm{~min} 30$ secs & \begin{tabular}{|l|} 
Spherical foaming \\
Expansion
\end{tabular} & $\mathrm{x}$ & $x$ & \\
\hline 049 & $17 / 07 / 20$ & B21_AS16_B & $880 \pm 8^{\circ} \mathrm{C}$ & $1 \mathrm{~min} 55 \mathrm{secs}$ & $\begin{array}{l}\text { Planar foaming } \\
\text { Expansion }\end{array}$ & $\mathrm{x}$ & $\mathrm{X}$ & \\
\hline 050 & $17 / 07 / 20$ & B21_AS23_C & $888 \pm 8^{\circ} \mathrm{C}$ & 5 mins & $\begin{array}{l}\text { Planar foaming } \\
\text { Shrivelling }\end{array}$ & $x$ & $x$ & \\
\hline 051 & $17 / 07 / 20$ & B16_AS18_A1 & $879 \pm 4^{\circ} \mathrm{C}$ & 10 mins & $\begin{array}{l}\text { Spherical foaming } \\
\text { Expansion }\end{array}$ & $x$ & $x$ & $x$ \\
\hline
\end{tabular}




\section{8}

\begin{tabular}{|c|c|c|c|c|c|c|c|c|}
\hline 052 & $17 / 07 / 20$ & B16_AS18_B2 & $890 \pm 10^{\circ} \mathrm{C}$ & 3 mins & $\begin{array}{l}\text { Spherical foaming } \\
\text { Shrivelling }\end{array}$ & $x$ & $x$ & \\
\hline 053 & $17 / 07 / 20$ & B16_AS18_A2 & $888 \pm 4^{\circ} \mathrm{C}$ & 3 mins & $\begin{array}{l}\text { Spherical foaming } \\
\text { Expansion } \\
\text { Shrivelling }\end{array}$ & $x$ & $x$ & \\
\hline 054 & $17 / 07 / 20$ & B16 AS18 B1 & $876 \pm 7^{\circ} \mathrm{C}$ & 2 mins & Expansion & $\mathrm{x}$ & $\mathrm{x}$ & \\
\hline 055 & $17 / 07 / 20$ & B16_AS18_B3 & $900 \pm 10^{\circ} \mathrm{C}$ & 10 mins & $\begin{array}{l}\text { Spherical foaming } \\
\text { Expansion }\end{array}$ & $x$ & $x$ & \\
\hline 056 & $17 / 07 / 20$ & B16_AS18_B4 & $860 \pm 8^{\circ} \mathrm{C}$ & 2 mins & $\begin{array}{l}\text { Spherical foaming } \\
\text { Expansion }\end{array}$ & $x$ & $x$ & \\
\hline 057 & $17 / 07 / 20$ & B11_T1_1 & $885 \pm 6^{\circ} \mathrm{C}$ & 15 mins & $\begin{array}{l}\text { Spherical foaming } \\
\text { Expansion }\end{array}$ & $\mathrm{X}$ & $\mathrm{x}$ & $\mathrm{x}$ \\
\hline 058 & $17 / 07 / 20$ & B09_T5_1 & $886 \pm 5^{\circ} \mathrm{C}$ & 15 mins & $\begin{array}{l}\text { Spherical foaming } \\
\text { Expansion }\end{array}$ & $x$ & $x$ & \\
\hline 059 & $17 / 07 / 20$ & B09_T5_3 & $880 \pm 5^{\circ} \mathrm{C}$ & 15 mins & $\begin{array}{l}\text { Spherical foaming } \\
\text { Expansion }\end{array}$ & & $x$ & \\
\hline 060 & $17 / 07 / 20$ & B18_T5_1 & $879 \pm 4^{\circ} \mathrm{C}$ & 15 mins & $\begin{array}{l}\text { Spherical foaming } \\
\text { Expansion }\end{array}$ & $x$ & $x$ & $x$ \\
\hline 061 & $17 / 07 / 20$ & B18_T5_2 & $880 \pm 5^{\circ} \mathrm{C}$ & 15 mins & $\begin{array}{l}\text { Spherical foaming } \\
\text { Expansion }\end{array}$ & $x$ & $x$ & $x$ \\
\hline 062 & $17 / 07 / 20$ & B18_T2 & $878 \pm 3^{\circ} \mathrm{C}$ & 10 mins & $\begin{array}{l}\text { Spherical foaming } \\
\text { Expansion }\end{array}$ & $x$ & $x$ & $x$ \\
\hline 063 & $17 / 07 / 20$ & B10_T5_1/2_2 & $863 \pm 10^{\circ} \mathrm{C}$ & 10 mins & Expansion & $x$ & $x$ & \\
\hline 064 & $17 / 07 / 20$ & B10_T5_1/2_1 & $880 \pm 5^{\circ} \mathrm{C}$ & 10 mins & Expansion & $x$ & $\mathrm{x}$ & \\
\hline 065 & $17 / 07 / 20$ & B13_T5_1/2 & $880 \pm 4^{\circ} \mathrm{C}$ & 10 mins & Shrivelling & $x$ & $x$ & \\
\hline 066 & $17 / 07 / 20$ & B13_AS02_1 & $876 \pm 4^{\circ} \mathrm{C}$ & 15 mins & Expansion & $x$ & $\mathrm{x}$ & \\
\hline 067 & $17 / 07 / 20$ & B13_AS02_2 & $880 \pm 4^{\circ} \mathrm{C}$ & 15 mins & Shrivelling & $x$ & $x$ & \\
\hline
\end{tabular}

Table 4.3 Heating experiments conducted on samples. The table displays (from right to left): the heating experiment's number, date this experiment took place, sample that was heated, temperature the sample was heated to, time the sample was heating, apparent foaming observed during and after heating with four types seen (spherical foaming (isolated spherical foaming), planar foaming (isolated planar foaming), expansion (isotropic expansion), and shrivelling), whether photographs were taken during the heating experiments ( $X$ if present), whether the natural sample was scanned using XCT (X if present), whether the heated sample was scanned using XCT (X if present). 


\subsection{Qualitative results}

Photographs were taken throughout the heating experiments providing a time lapse of foaming throughout experimentation, and XCT scans obtained for both the natural and heated samples, pre- and post- heating experiments for a subset of samples. Both the photographs and XCT scans are presented below as 'qualitative data'. Photographs within the heating experiments were taken at a 3 second interval or 1 second interval, depending on amount of vesiculation seen from previous samples, allowing for changes in vesiculation to be monitored during heating experiments instead of just analysed before and after. Combined, the heating experiment photographs and XCT scans allow for specific foaming trends to be observed during the heating experiments and a determination of the representative nature of the internal textures produced by the XCT scans.

The heating experiments highlighted four main vesiculation styles (Table. 4.3). The first three involved volume expansion, as: (1) localised spherical foaming in a spherical/hemispherical shape, (2) localised planar foaming, and (3) isotropic expansion of the main obsidian body. The last vesiculation style involved a volume reduction, as (4) shrivelling and shrinking in size, which typically occurred within pumice regions of composite bombs but also in some obsidian pyroclasts. Although all of these can occur simultaneously at different regions within the same sample, they seem to be unique features independent of one another.

Although all XCT subsamples were scanned prior to heating (as mentioned in section 4.1), only 10 samples could be rescanned after being heated (Table. 4.3). These 10 samples were selected to be representative of the different styles of vesiculation observed during the heating experiments. These also highlighted specific textures, which will be defined below, where this foaming appears to occur: (a) isolated homogenous obsidian, (b) large homogenous obsidian, (c) clastogenic obsidian, (d) obsidian proximal to pumice, (e) vesiculated band within homogenous obsidian. This section aims to show the similarities present within each vesiculation style visually and texturally using the heating experiment photographs and the natural and heated XCT scan comparison. 


\subsection{1. $\quad$ Localised spherical foaming}

Localised spherical foaming occurs when a small region or regions of the sample vesiculates at a much higher amount than the surrounding material. This localised foaming is typified by the development of a spherical-hemispherical lobe protruding from the composite bomb sample (Fig. 4.2 A and B). These lobes can form as a singular spherical lobe protruding from the sample (Fig. 4.2 A) or as a cluster of multiple smaller spherical lobes superimposed on one larger lobe (Fig. 4.2 B). As there is one area of enhanced spherical lobing, this allows for classification as the same phenomena. Localised spherical foaming can appear throughout the sample, irrespective of composite bomb sample orientation (Fig. 4.2).

Almost all heating experiments which exhibit this foaming were heated for 15 minutes (Table. 4.3), with the most dramatic foaming occurring within the middle 5-10 minutes period of the experiment, after the initial foam has formed at $\sim 5$ minutes (Fig. 4.2). Prior to heating, obsidians which experienced localised spherical foaming had no visible disconformity to explain why these localised regions preferentially foamed (Fig. 4.2 A, B). However, this phenomenon is experienced across numerous samples, all with varying dominant composite bomb textures (Table 4.3), showing how abundant localised spherical foaming is. Although the regions displayed in Figure. 4.2 show this heating occurring at the top of these samples, there is evidence in other samples of this forming at the front and sides of images although it is obscured when samples were viewed through the window of the furnace. 


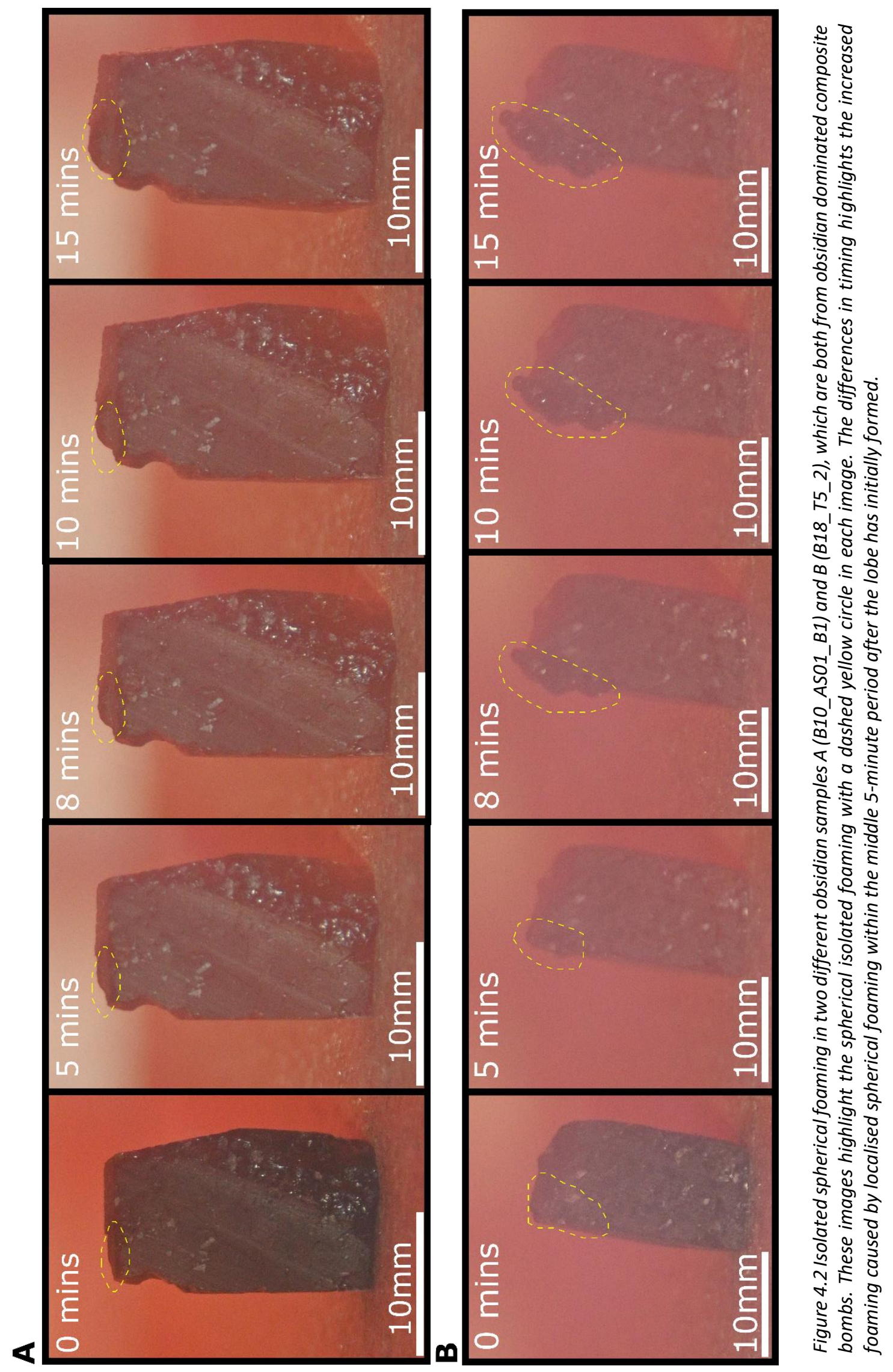


Texturally, localised spherical foaming is relatively similar across scanned heated samples, being located within isolated "homogenous obsidian" regions (Fig 4.3 A, B). This region is referred to as "homogeneous", following Schipper et al. (2021), due to the obsidian being almost uniform in texture with little to no evidence of it having been of a clastogenic origin (composed of sintered ash). The obsidians are also crystal poor and contained visibly low initial porosities, typical of a homogenous obsidian. These isolated homogenous obsidians are surrounded by other materials, typically matrix (Fig. 4.3 B), although occasionally are adjacent to other regions of homogenous or clastogenic obsidian (Fig. 4.2 A). These isolated homogenous obsidians are relatively small $(<\sim 8 \mathrm{~mm}$ in diameter) and have a spheroid shape. Due to the extensive foaming exhibited during localised spherical foaming, it is hard to determine which structures within the texture promoted the secondary vesiculation of these regions and not that of the adjacent large homogenous obsidian (which has no clear shape and occupies a larger area) but the spherical size and smaller surface area relative to bubble structures may have allowed these isolated homogenous obsidian regions to vesiculate to a greater extent and form this localised spherical foaming (Fig. 4.3). The increase in size also appears to generate stress within the immediately adjacent regions, generating cracks proximal to the spherical isolated foaming, with this being especially evident within the matrix dominated composite bombs (Fig. 4.3 B). 


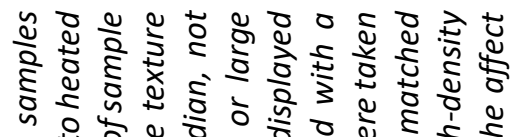

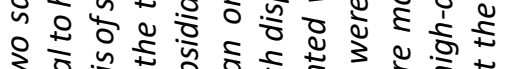

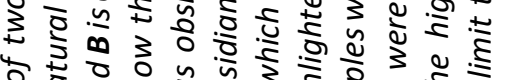

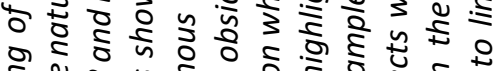

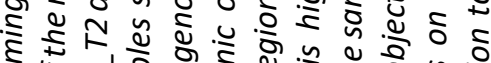

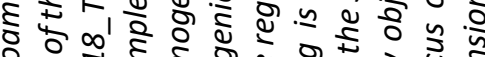

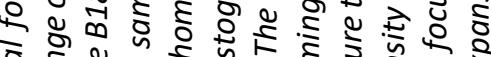
वे टे ㅎำ

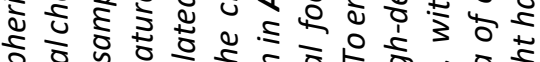

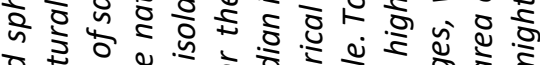

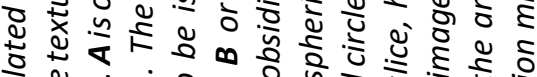

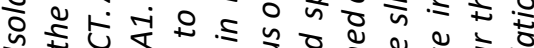

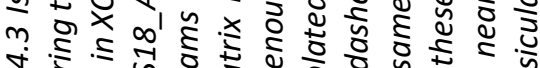

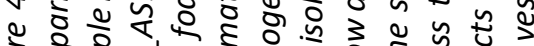
今े है है
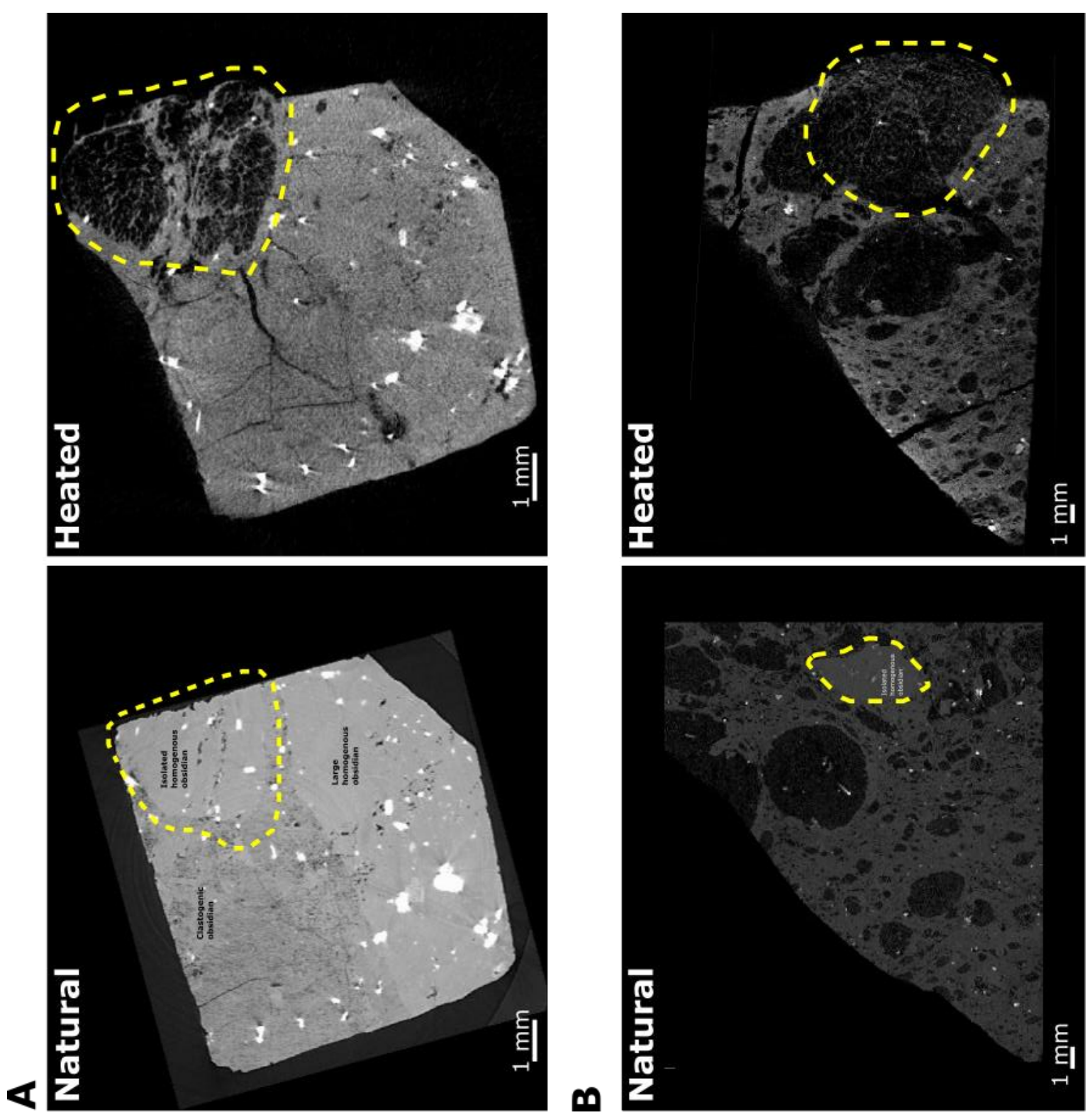


\subsubsection{Isolated planar foaming}

Isolated planar foaming is comparable to localised spherical foaming, in that it is enhanced vesiculation at a specific region compared to the rest of the sample. However, isolated planar foaming yields protruding shapes that are extremely planar, with some of these having undulations superimposed on the overall linear foaming (Fig. 4.4). Although these undulations can obscure the overall planar foaming due to the slightly larger bulbous regions (Fig. $4.4 \mathrm{~A}$ 2:58), when compared to prior images of this foaming, the overall uniformly linear expansion of the vesiculation can be seen, especially just prior to lobe development (Fig. 4.4 A at 2 mins). In other samples, planar foaming is uniform, lacking any additional spherical-like nodule growth (Fig. 4.4 B).

Isolated planar foaming was solely seen within pumice dominated composite bombs, coincident with pre-existing bubble structures along planar features prior to heating (Fig. 4.4

A, B). Due to extremely rapid vesiculation rates of natural samples when heated, heating time intervals varied between 1 minute 30 seconds to 3 minutes between samples to limit vesiculation (Table. 4.3, Fig. 4.4). Longer heating times would have resulted in numerous errors associated with the correlation of natural and heated samples due to immense volume change (Fig. 4.4). For each of these experiments, images were taken every 1 second so changes could be seen at a higher resolution then the 3 second interval of previous samples. Lastly, during the heating of these samples one side of the sample was preferentially vesiculated during the development of isolated planar foams (Fig. 4.4 right side of sample $\mathbf{A}$, front of sample B). 


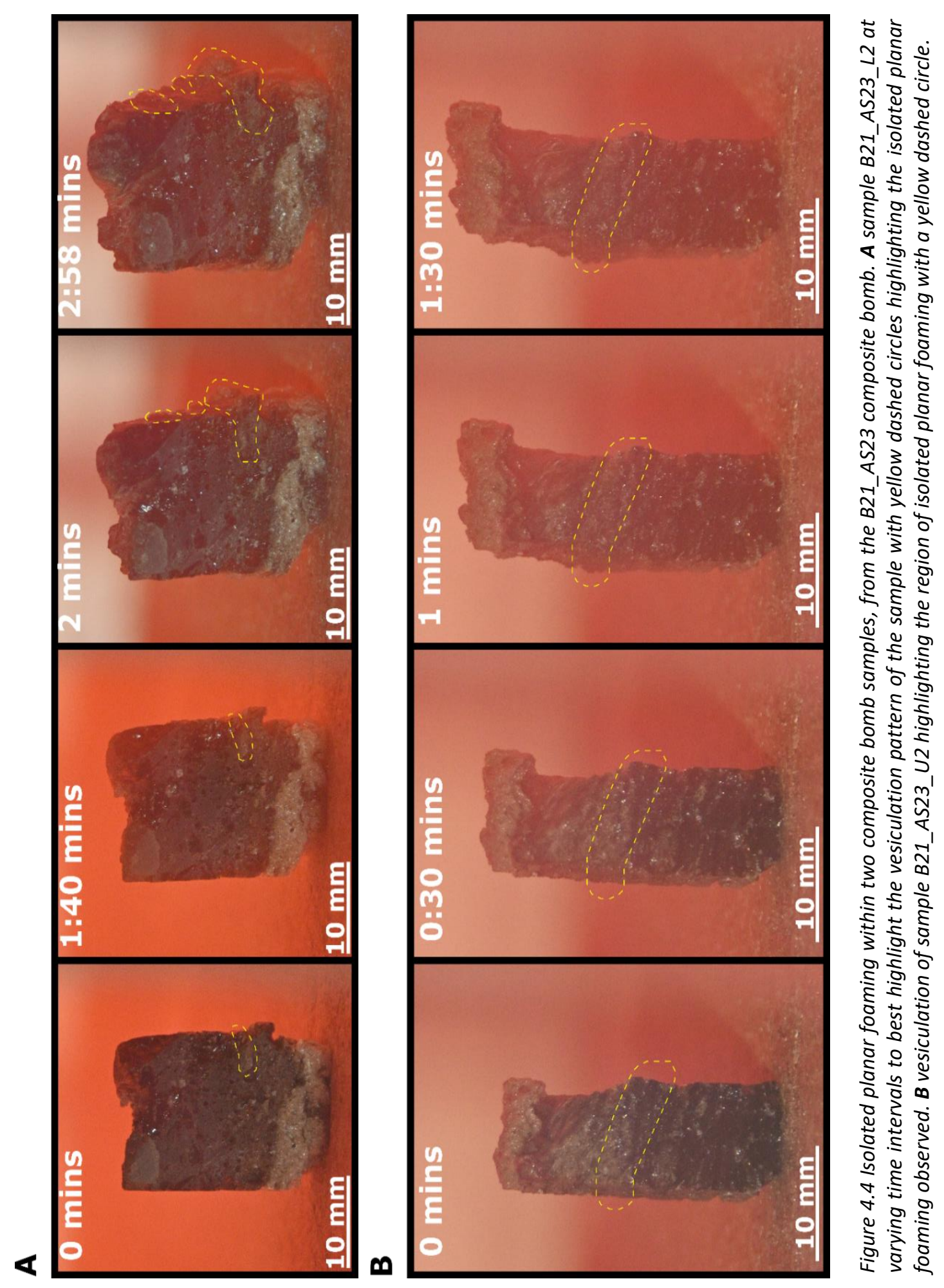


Although many samples showed isolated spherical foaming (26), comparatively few samples showed isolated planar foaming (15). The samples that had planar foaming appeared more vesicular prior to heating than other samples and typically consist of a combination of pumice and dense obsidian pyroclastic material (Fig. 4.4 and Fig. 4.5). The areas that did exhibit planar foaming had an initially high porosity, and the vesicles comprising these regions were sheared and elongate (Fig. 4.5). These vesicles are also relatively closely packed (Fig. 4.5 B), distinct from other regions within the samples. Typically, regions which vesiculate in this manner have varied vesicles sizes with up to $\sim 3 \mathrm{~mm} x \sim 2 \mathrm{~mm} x \sim 1 \mathrm{~mm}$ vesicles present prior to heating (Fig. 4.5) with some samples even having multiple regions within the single sample exhibiting isolated planar foaming (Fig. 4.5 A). These regions then vesiculate parallel with the sheared direction of the vesicles (Fig. 4.5). 

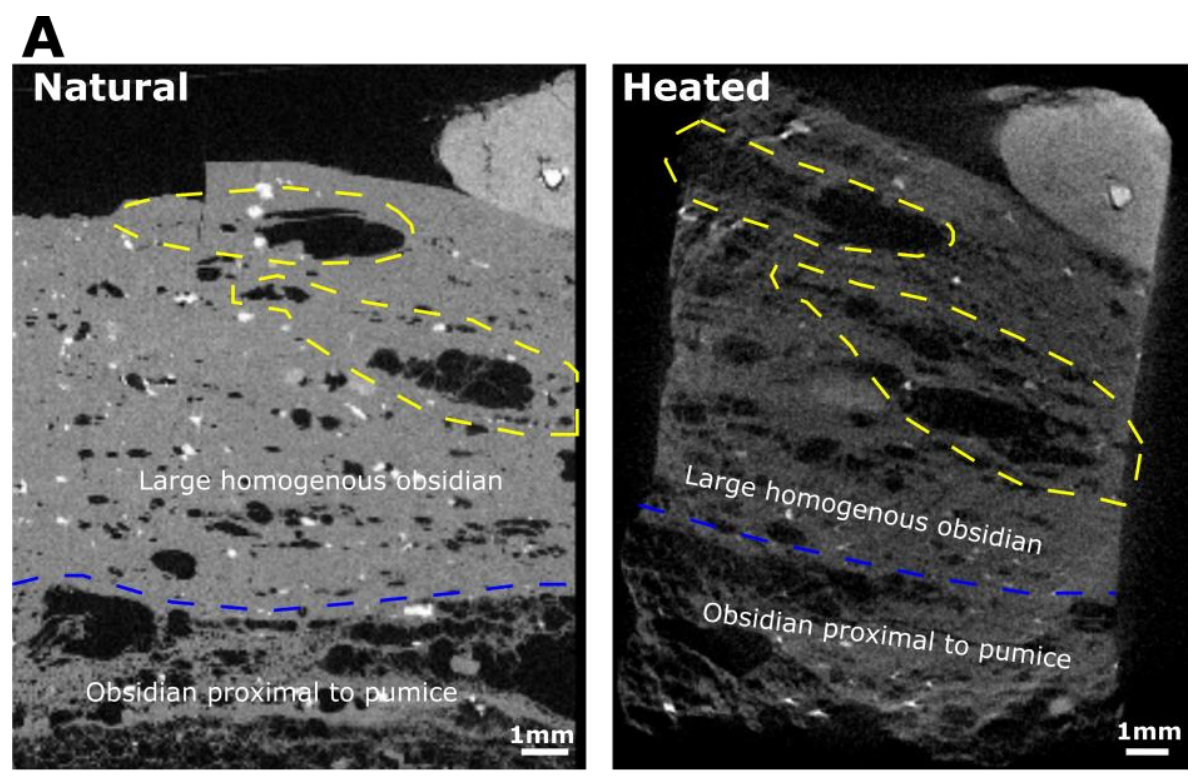

B
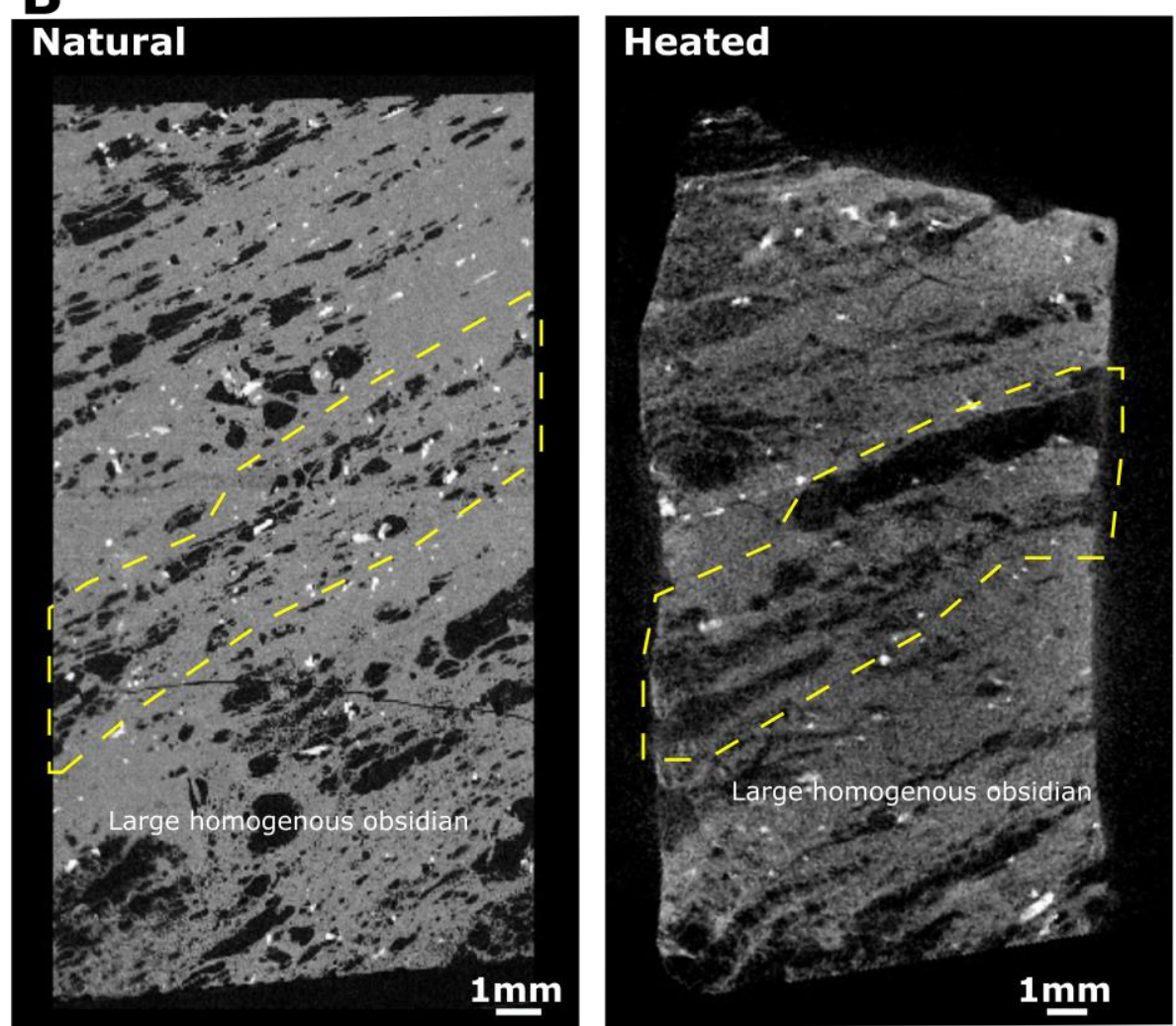

Figure 4.5 Isolated planar foaming displayed in XCT within two B21_AS23 samplesA (B21_AS23_L2) and B (B21_AS23_L3). The dashed circles show the areas where banded foaming has occurred typically through a combination of bubble growth, and coalescence. $\boldsymbol{A}$ is comprised of large homogenous obsidian, obsidian proximal to pumice and vesiculated bands within the homogenous obsidian (highlighted in yellow). B lacks the obsidian proximal to pumice and is just comprised of large homogenous obsidian and vesiculated bands within the homogenous obsidian (highlighted in yellow). 


\subsubsection{Isotropic foaming}

When the expansion of the composite bomb sample occurs in a way that the shape of the natural sample is preserved during heated, then the foaming is described as isotropic expansion. This is the most common vesiculation style to have occurred during heating of the composite bomb samples. Figure 4.6 demonstrates the isotropic foaming of the obsidians by superimposing a yellow dashed outline of the natural sample, on both the heated and natural samples to highlight the growth. No images are shown from during the heating experiments as this process appears to occur at a steady rate throughout the heating experiments. Although this outline can make certain regions within the sample appear to vesiculate at a greater amount than others, this phenomenon is likely an artifact of the image alignment between the natural sample outline and the heated samples, with opposing corners and sides showing apparent heightened change due to it being farthest from the centre of the image alignment (Fig. 4.6). However, this could also be a real feature of the vesiculation process itself, as the textures present may be causing certain regions within the obsidians to vesiculate more dramatically than others. There is also greater expansion near the top of these obsidians, either because the vertical growth of the sample is unconstrained (Fig. 4.6), or because this is the hottest region of the furnace although thermocouple data showed variations of $\leq 5^{\circ} \mathrm{C}$ from bottom to top of each sample.

The 2D nature of photographs used to examine experimental vesiculation places limitations on 3D interpretations. Obsidians which expand in an isotropic manner, but towards the camera can translate to regions being translated closer to the stage, which would appear as a possible volume contraction within the obsidian (Fig. 4.6 B). In actuality the sample has vesiculated so much that the sample began to fold and this region only appears to have shrunk because the area behind it has expanded (Fig 4.6 B). This also highlights the need for XCT and volume descriptions otherwise this may be misinterpreted from just the photographs, although they are a useful tool in identifying these initial processes. 

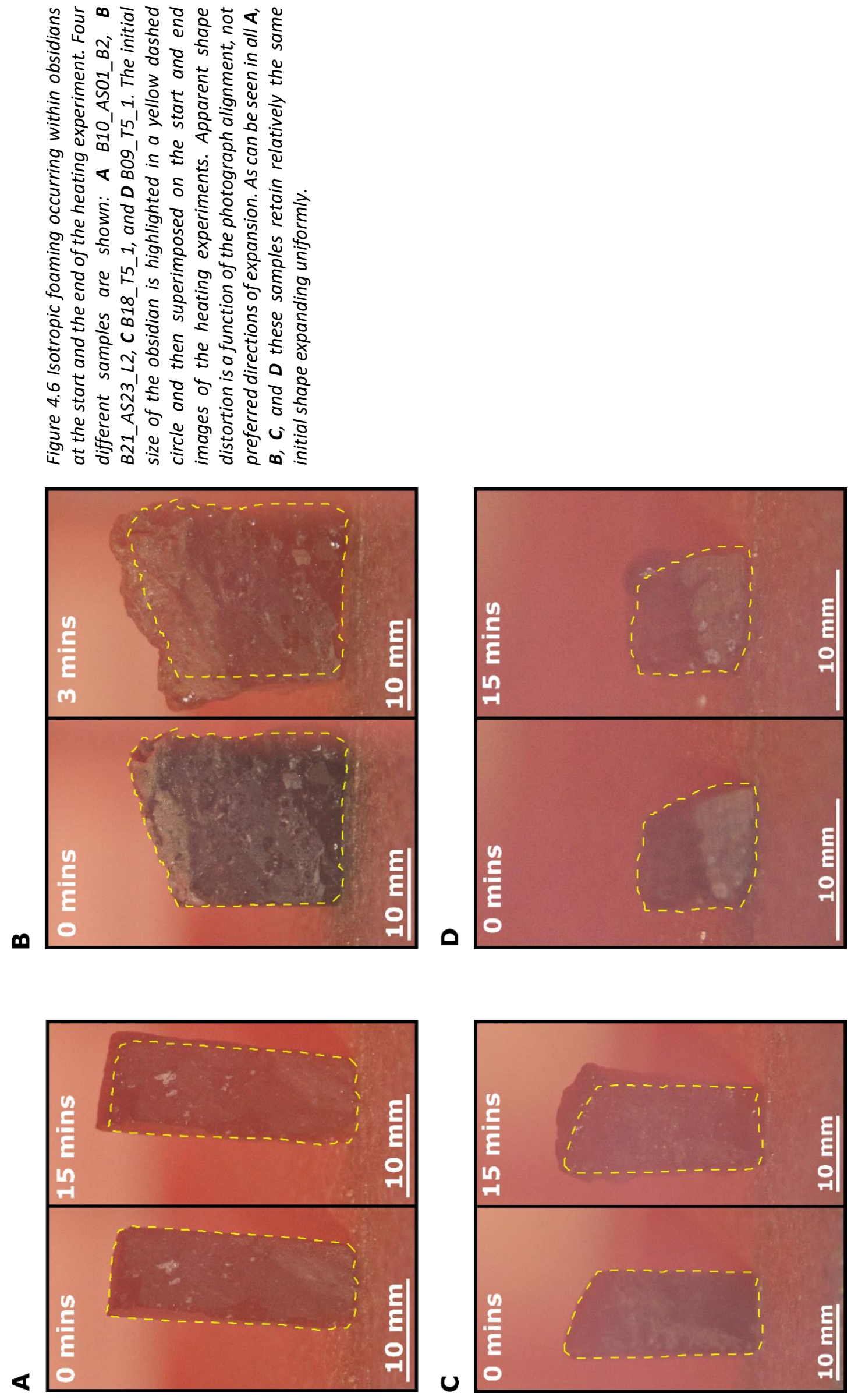
The most predominant expansion observed during the heating experiments was isotropic foaming. Samples appeared to foam isotropically regardless of the internal textural heterogenity, and retained their overall shape from start to finish of the experiments (Fig. 4.6 and 4.7). These all tend to occur within large homogenous obsidian textures within the composite bombs themselves. Certain regions within the samples appear to nucleate, however, due to this being a quantative analysis and scans potentially missing small relict bubble structures, nucleation can not be definitively seen. However, large degrees of heterogenous growth (Fig. 4.7 A) and homogenous growth (Fig. 4.7 B, C) were observed within the samples, with the latter being the dominant process. Certain bubbles appear to vesiculate to a greater extent with other bubble structures nearby remaining of relatively the same size. This shows the overall heterogenous growth of bubbles and may signify a trend where growth is favoured in regions already experiencing growth (Fig. 4.7). However, within these samples growth of these pre-existing bubble structures is the most common process occurring within isotropic expansion, although the amount of growth varies vastly between bubble structures during heating (Fig. 4.7). 


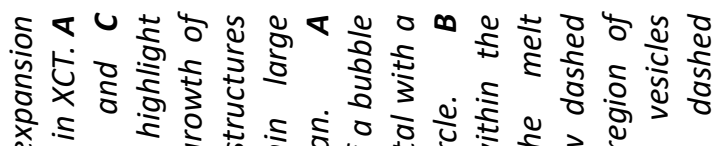

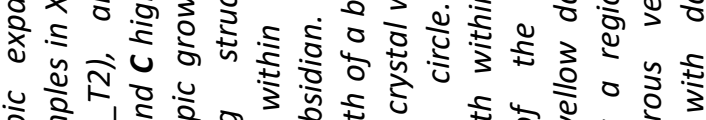

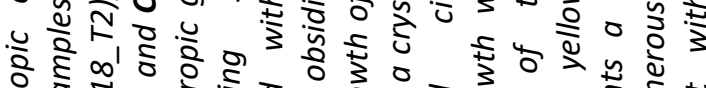

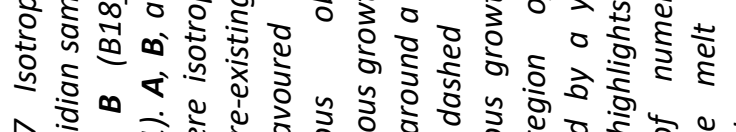

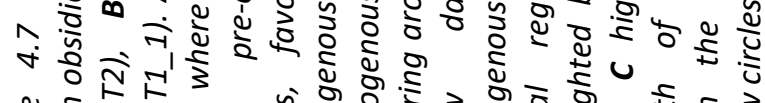

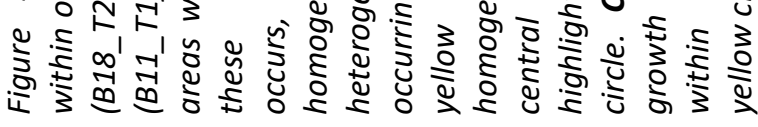
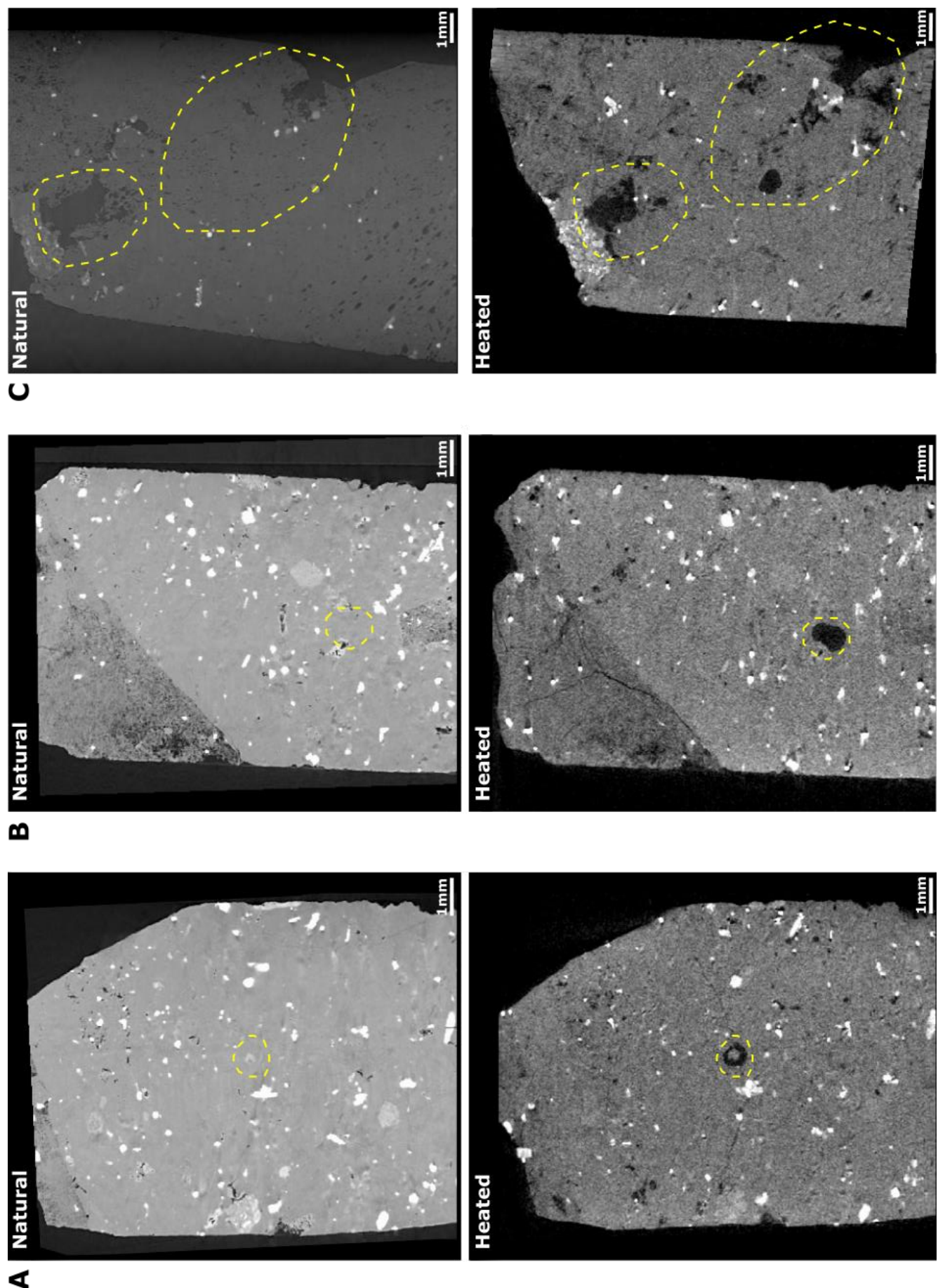


\subsubsection{Shrivelling}

Most obsidians and composite bomb samples expanded during heating experiments. However, some samples showed shrivelling of different regions, leading to a reduction in the size of the sample. This phenomenon was rare within the composite bomb samples, it was observed predominantly within pumice regions of composite bomb samples, with some dense obsidian regions exhibited this vesiculation style also (Fig. 4.8). Shrivelling can be obscured within 2D photographs due to the red tinge produced during the heating experiments, a reduction in size can be observed when the natural sample outline is superimposed on the heated sample, as was done for the isotropic foaming (Fig. 4.6 and 4.8). Both the pumice and obsidian regions within the samples appear to shrivel isotropically, retaining the same relative shape from natural to heated samples, although a darkening in colour from off-white to a black-orange colour is observed within the pumice regions (Fig. 4.8 B, C, D). Each sample that demonstrates this shrivelling also collapses towards the interior of the sample (Fig. 4.8), showing that despite the materials being different, the process occurs similarly across obsidian and pumice regions, meaning trends seen within the pumice regions can inform us about the obsidian regions.

Finally, these shrivelling samples demonstrate that even if a composite bomb sample displays one dominant secondary vesiculation style, local regions can behave differently (Fig. 4.8 B, C). However, presence of an expanded region within one sample does not mean that another sample with similar hand sample appearance and a similar composite bomb type will vesiculate in the same way (Fig. 4.8 B, D). These different processes happening simultaneously within different bombs over the heating experiments further highlight the variability within samples and independence of different local vesiculation styles. 


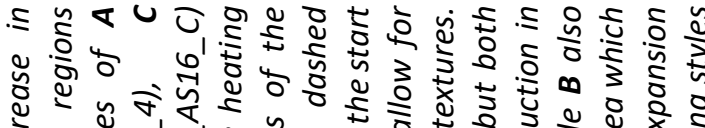

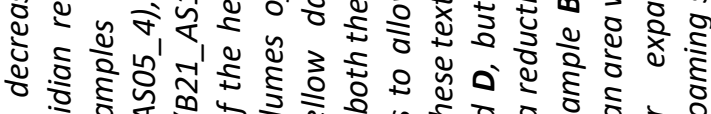

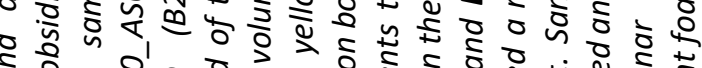

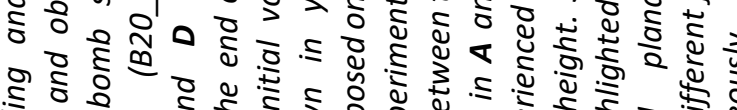
สัข

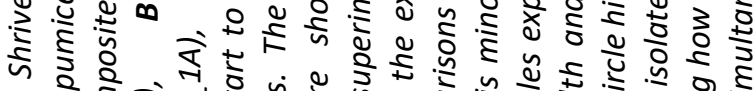

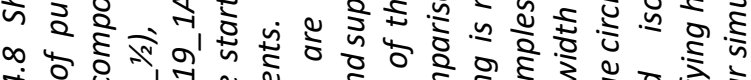
ข

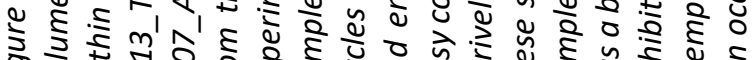

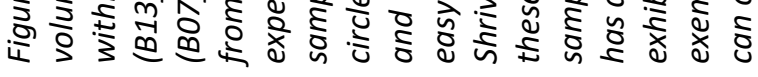
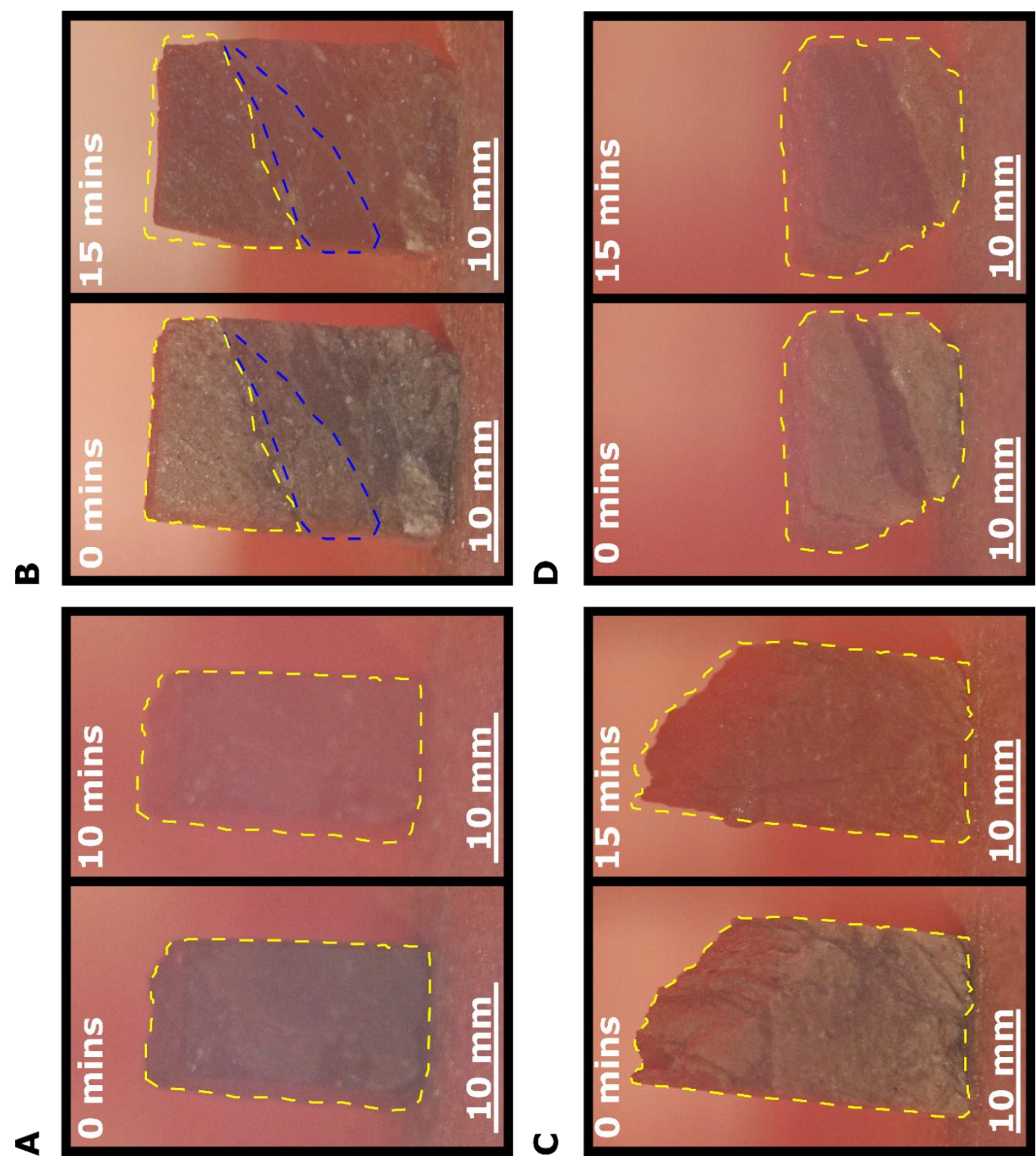
Shrivelling occurs predominantly within the pumice regions of the composite bomb samples, although did occasionally occur within obsidian regions (Fig. 4.9). Shared between both the pumice and obsidian shrivelling regions is the appearance of coalescence and growth of the bubbles structures to form linear and connected bubble structures while, simultaneously decreasing the overall number of vesicles within the samples (Fig. 4.9). This connection of the vesicles will allow, if carried to the exterior, an outgassing pathway which can effectively allow for a reduction in size. All natural samples display elogated bubble structures which continue into the heated samples further confirming outgassing associated with coalescence as the dominant process, as if growth was dominant the bubbles would be more symmetrical once heated (Fig. 4.9). Shrivelled samples also show cracks forming once heated, which provide additional pathways through which outgas can occur, further restricting their growth (Fig. 4.9 A, C). Coalescence and crack development appear to cooperatively provide permeable pathways as the regions vesiculate and then shrivel. 


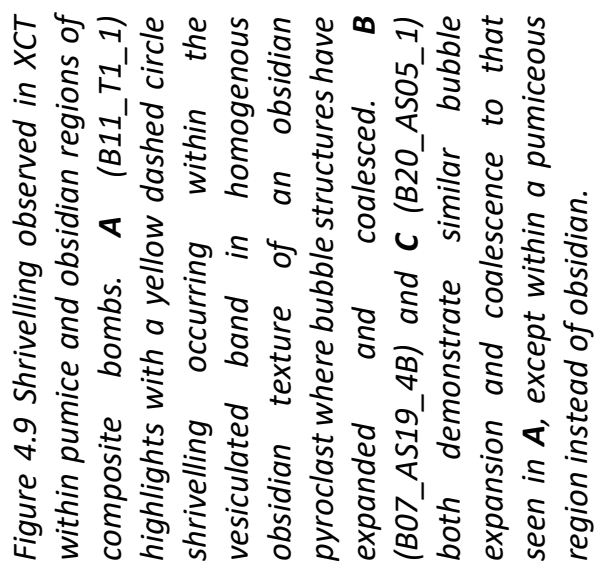
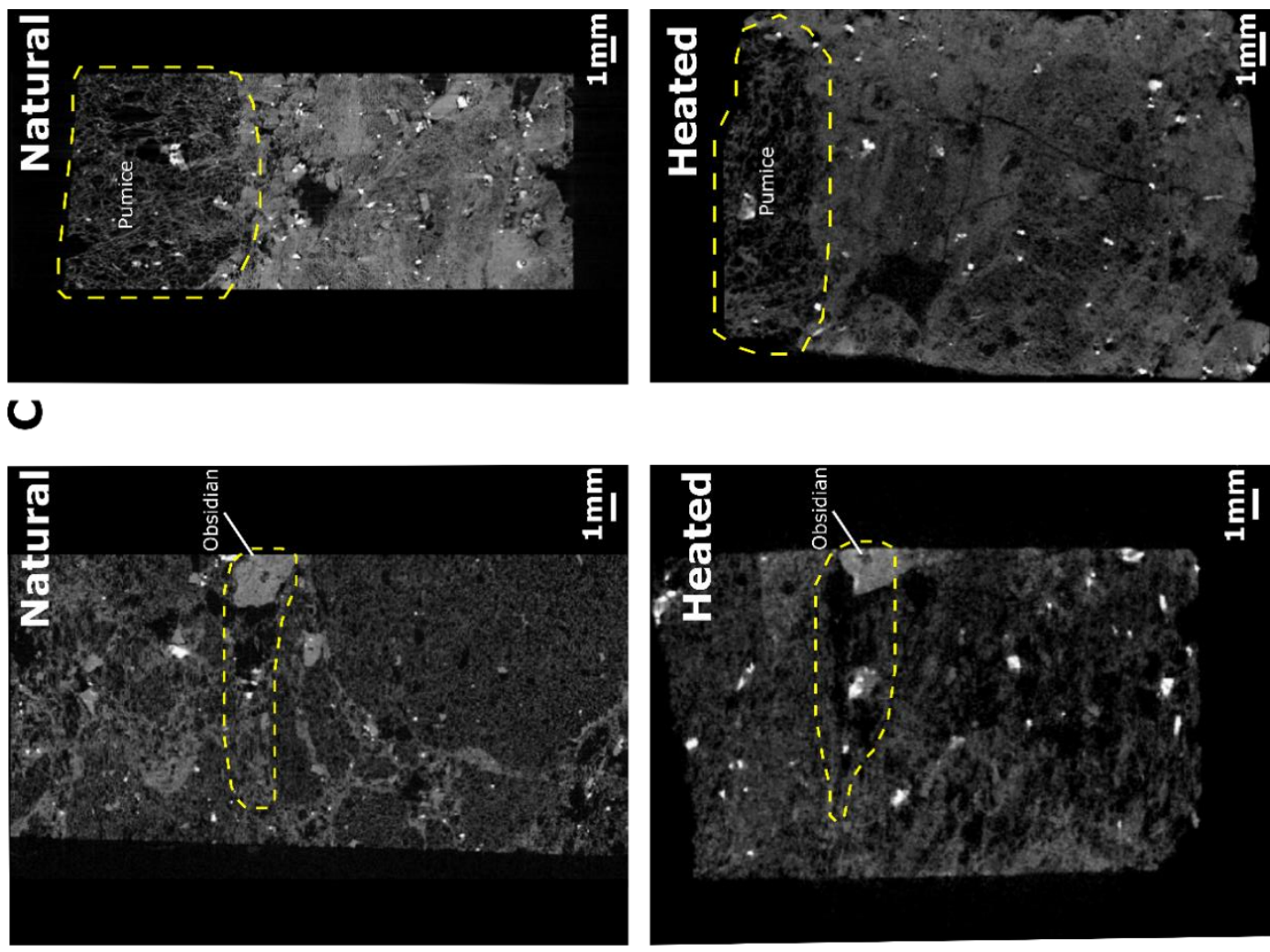

$\boldsymbol{\infty}$
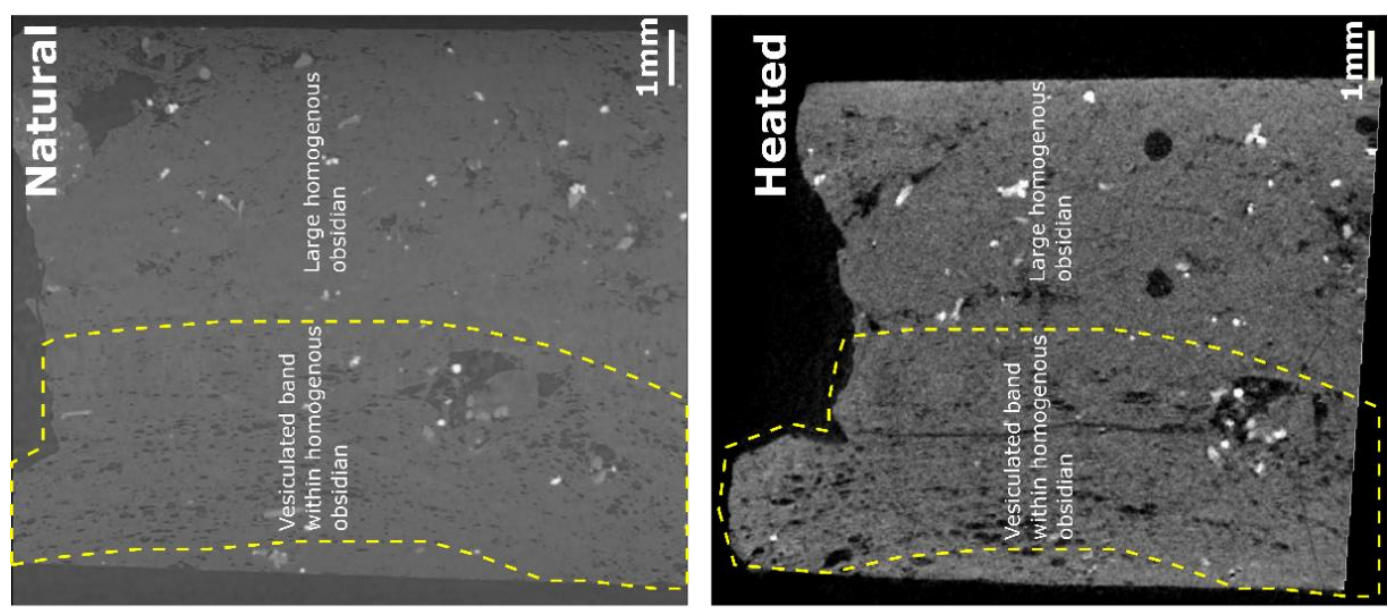

\section{$\varangle$}




\section{5. $\quad$ Foaming style versus composite bomb type}

Additional to the internal textural response to secondary vesiculation, the overall macroscopic foaming observed can be quantified by the overall composite bomb type to verify whether there is a textural trend within the qualitative foaming observed during the heating experiments. In the following we will identify the generic trend of each specific composite bomb type and whether these impact the overall vesiculation style of samples.

Pumice dominated composite bombs primarily display planar foaming (15/24 samples) and isotropic expansion (17/24 samples) (Fig. 4.10). Although it is hidden within the data, the composite bombs which displayed planar foaming and expansion all have obsidian clasts adjacent to the foaming domains (e.g., Fig 4.9). When adjacent obsidian clasts are not present, then shrivelling (11/24 samples) of the pumice locality becomes prevalent instead of expansion (Fig. 4.10, Fig. 4.9).

Obsidian and fine matrix dominated composite bombs frequently displayed isolated spherical foaming regions (9/18 samples) and overall isotropic expansion (17/18 samples) (Fig. 4.10). These obsidians may vesiculate more easily due to expansion being accommodated by space present within the matrix. This also can isolate specific homogenous obsidians promoting the isolated spherical foaming observed within multiple samples (Fig. 4.3). One sample did experience shrivelling however, that was within a large pumice region within the sample, similar to those which experienced this shrivelling in the pumice dominated composite bombs.

Obsidian dominated composite bombs displayed diverse foaming trends, including all types of expansion and shrivelling. The shrivelling of obsidians samples was rare however (2/13 samples), although is an overall important process which will be discussed later. The majority of obsidian dominated composite bomb samples experienced either isolated spherical foaming (5/13 samples) or isotropic expansion (11/13 samples). These bombs are dominated by textural regions of large homogenous obsidians, clastogenic obsidian, or regions of isolated homogenous obsidian. Their response to heating is similar to the obsidian and fine matrix dominated composite bombs except with fewer samples displaying isolated spherical foaming. 
The last dominant composite bomb type described is that of matrix dominated composite bombs. These samples comprise of multiple different components and as such, display numerous different vesiculation styles, including isolated spherical foaming (5/11 samples), planar foaming (2/11 samples), isotropic expansion (9/11 samples), and shrivelling (6/11 samples). This varied response within these heterogenous sample shows that it is not strictly the overall dominant texture of the composite bomb samples, but instead the internal textures, as shown previously, that dictate the vesiculation style.

Although these composite bomb types display varied responses dependent on the texture (Fig 4.10), they are not exclusively shared across that composite bomb type. This shows that secondary vesiculation style is not solely a function of the dominant macroscopic texture with the exception of isolated planar foaming, which is the only secondary vesiculation style that links closely to composite bomb type, which mainly occurred within pumice dominated composite bombs.

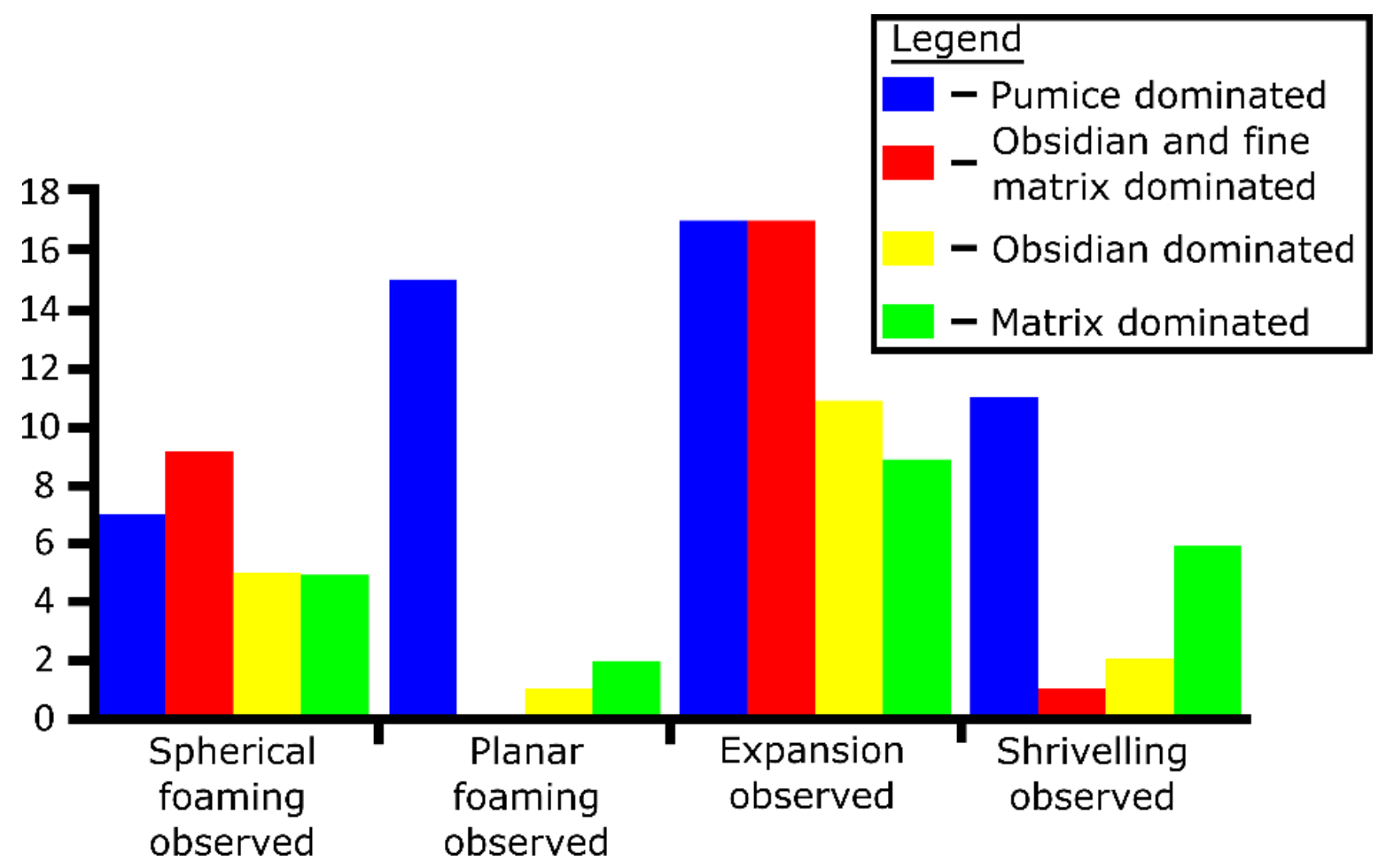

Figure 4.10 Histogram of foaming observed throughout the heating experiments per composite bomb type. The blue bar denote pumice dominated composite bombs, with 24 samples heated. The red bar denotes obsidian with fine matrix samples, with 18 samples heated. The yellow bar represents dense obsidian samples, with 13 samples heated. Matrix dominated composite bombs are shown as the green bar with 11 samples heated. The number of samples heated is important to note when comparing the data as this shows overall how many samples experienced this foaming. XCT Comparison limitations 
Although XCT scans of the samples do provide great advantages when analysing the internal textures present within the composite bomb samples, there are some limitations with this analysis. Due to the different scanners used, the resolution can differ between scans of the natural and heated samples, although similar features are still highlighted (Fig. 4.11). This is most notable when regions of textural difference within the scans are shown, even within a singular obsidian clast (e.g., Fig. 4.11). Although these features are still apparent, they are less defined within the heated samples compared to the natural samples (Fig. 4.11). However, high-density crystals are retained and imaged in both natural and heated sample scans. This allows for correlation and alignment of natural and heated scans, ensuring that the same localities are compared between the two samples. Even given the different scanning techniques the main features of the samples are seen within the scans, although some finer details are slightly obscured within the post-heating scans (e.g., Fig. 4.11).

The natural and heated XCT scans permit internal textures of samples to be compared, there are three major limitations to the technique used. The first limitation is that scans are only made before and after the heating experiments. This means that changes which occurred during the vesiculation of the sample whilst heating occurred are overlooked. Although this is supplemented by the heating experiment photographs the internal texture development is missed and interpretations are required to determine how the sample evolved using before and after snapshots. The second limitation is that XCT only produces density-difference images of the samples, meaning that all crystals, such as Fe-Ti oxides, zircons, and biotite appear as high-density objects within the scanned images. Again, this was slightly rectified with thin sections for some of the scanned samples, but not all scanned samples have thinsections, and these minerals are thus unknown (Table 4.1). Lastly, are the errors associated with the micron resolution. This causes smaller, sub-micron scale bubble structures to be overlooked during the natural and heated sample scans resulting in an error observed between the scans. This can also cause fine, bubble films at higher porosities and volume measurements to be skewed. This limitation is shared across the natural and heated scans but does mean potentially significant small bubbles structures that could aid in secondary vesiculation are overlooked (section 1.3). 

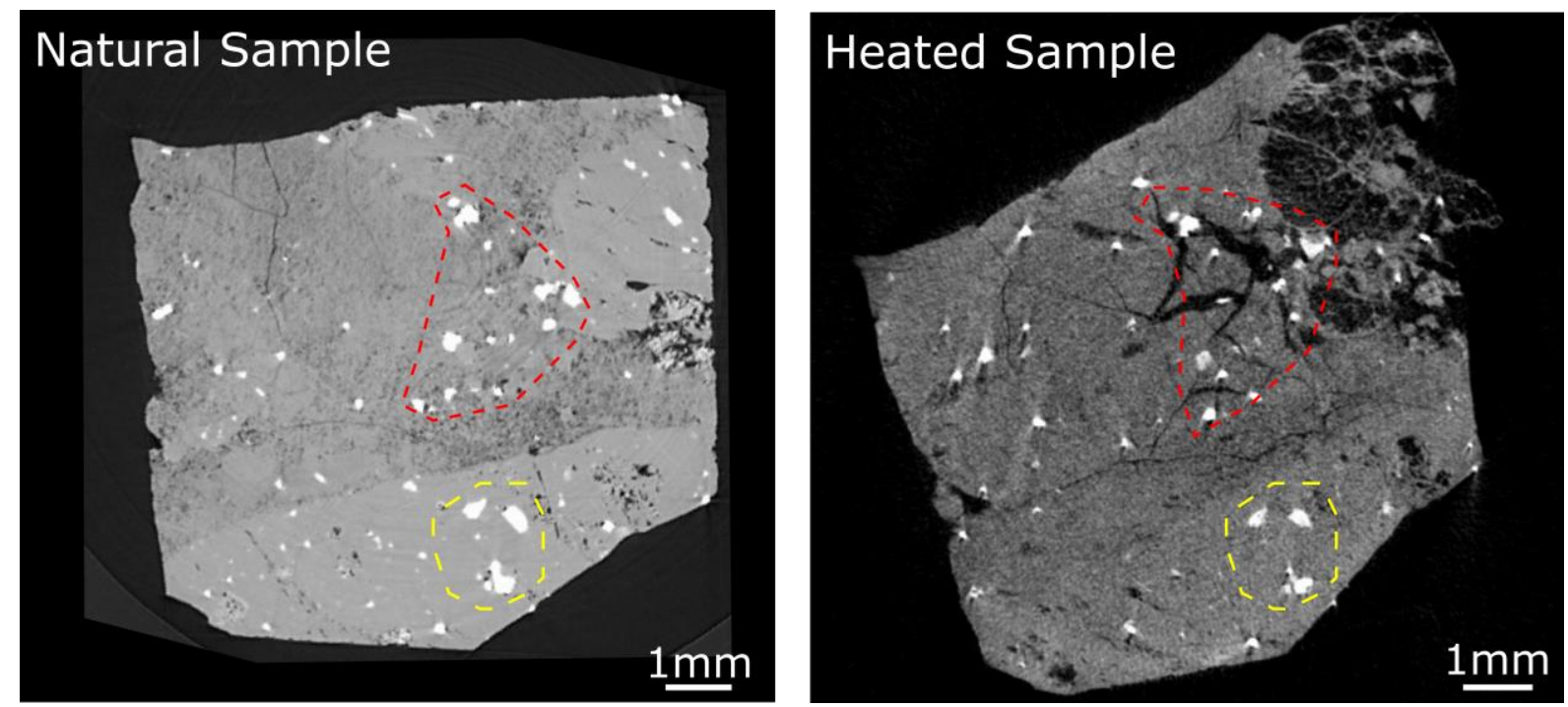

Figure 4.11 Comparison of XCT scans of a natural and heated sample. High density, inert crystals (red and yellow dashed circles) used to correlate the images are highlighted to show how scans were aligned. The sample shown, B18_T2, was selected to demonstrate limitations in the comparison of the XCT scans.

\subsection{Porosity measurements}

Porosities were calculated from the XCT scans of the specific textures present within the obsidian pyroclasts of the samples. The relatively low resolution of the scans (minimum of $5 \mu \mathrm{m} / \mathrm{px}$ ) is insufficient to guarantee that all porosity is captured in the scans. However, this imaging error is shared across the natural and heated samples so that porosity measurements are comparable between all scans. With this considered, the minimum porosity measurements are displayed in Table 4.4, for each of the samples that were scanned by XCT after heating. These sample textures are separated into categories to align with the work of Schipper et al. (2021) and that of the qualitative textural analysis. Table 4.4 displays the sample's water contents, texture, natural porosity, heated porosity, and porosity increase. The textures listed on this table are isolated homogenous obsidian, large homogenous obsidian, clastogenic obsidian, obsidian proximal to pumice, vesiculated bands in homogenous obsidian, and lithic material. The volumes of the natural and heated texture are indicated as measured using XCT and the Avizo software, although these can have large inherit errors discussed below. The changes in porosity with heating are shown by the porosity increase column or direct comparison of the natural and post-heating porosity. 
Additionally, this table shows the water contents measured from the obsidian, irrespective of the texture these were extracted from (Table 4.3).

The volume change of the samples during heating must be examined. This change is quantified through the method discussed earlier. Within each sample there is a general trend that the heated samples have a larger volume, as would be expected. However, these observations in volume are not always translated into the actual size change observed during the heating experiments (Table. 4.4, Appendix 1). A noteworthy example is B18_T5_1 within the large homogenous obsidian texture (Table 4.4). These show larger volumes within the natural samples but higher porosity measurements within the heated samples. If the dimensions of the samples are examined and compared to the porosity values, these irregularities are more apparent (Appendix 1). This is likely due to an artifact of the either the scanning process, or an error associated with the human manipulation of data resulting in these differing, and overall low volumes with the scanned data. Although these values may differ from that of hand samples, the porosity measurement is a measure of the volume of the dense material to the void space. Irrespective of whether the whole sample is measured the porosity measurement still represents the whole rocks porosity as porosity is a percentage of total void space of a region to the total volume of the region. Small errors may arise due to the whole sample area not being sampled but the porosity measurements are still representative of that specific sample.

When natural versus heated porosity of each obsidian are compared (Fig. 4.12, Table. 4.4), all samples increased in porosity during heating, apart from one isolated homogenous obsidian within sample B07_AS19_1B, which remained at the same porosity after heating. This one isolated homogenous obsidian that did not vesiculate may have been misidentified, or the poorer resolution during the XCT scans may have missed any small increase in porosity. The amount of vesiculation that occurs during heating appears to relate to the initial porosity, with higher initial porosities translating to a higher porosity in the heated sample (Fig. 4.12, Table. 4.4). This is accentuated when the natural textures are taken out when they appear to plateau (see below). This porosity increase implies that if there are pre-existing bubbles structures within a specific texture it is easier to increase the porosity of that texture. 


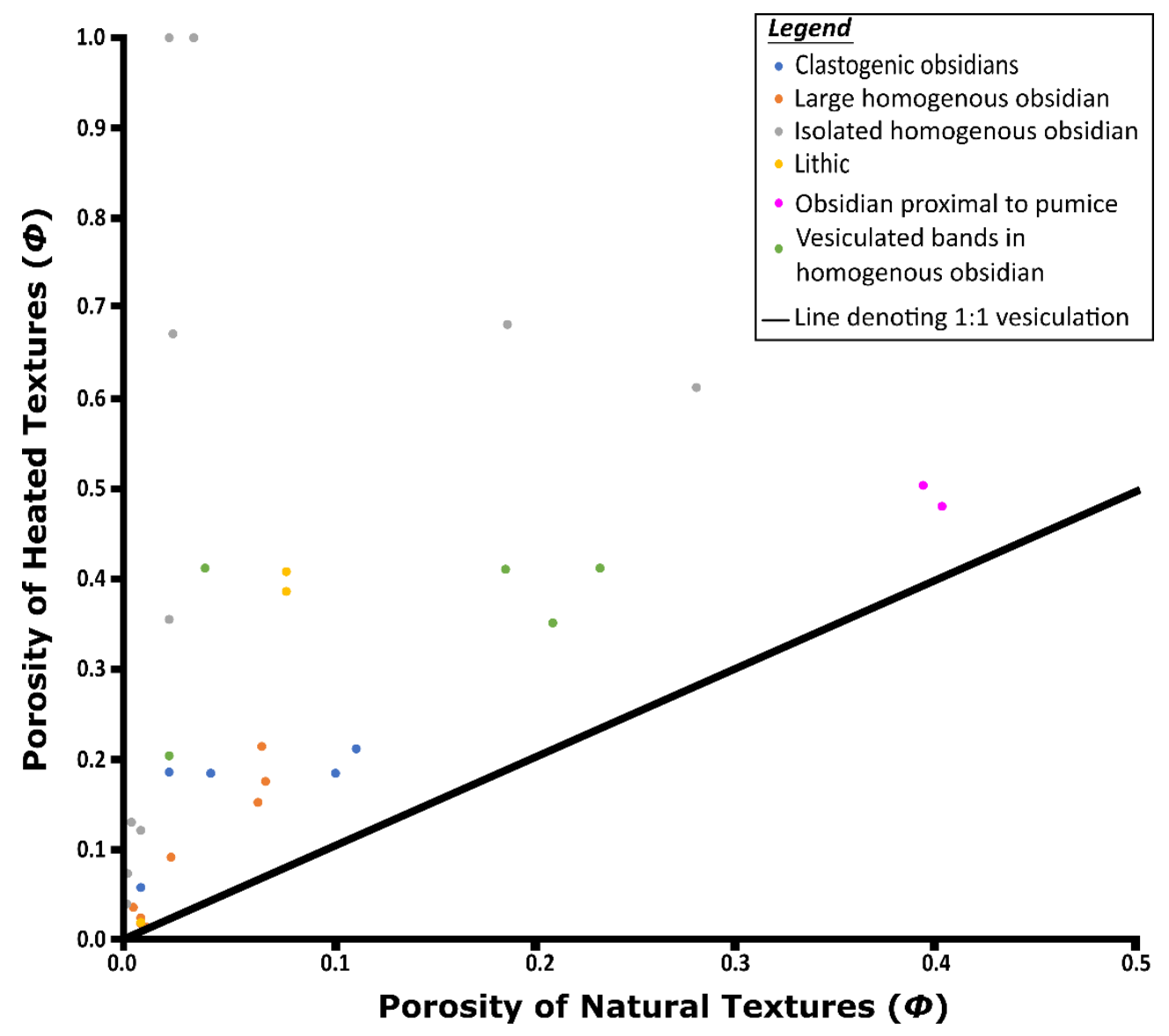

Figure 4.12 Porosity changes during the heating of natural obsidians. Textural groups are the same as shown in Table. 4.4, with the legend highlighting which each point represents. The inclined horizontal line denotes 1:1 would indicate no porosity change. 
Degrees of secondary vesiculation vary between different obsidian textures, followed by the development of a plateau region where the porosity of the samples appears to reach a certain level regardless of the initial porosity (Fig. 4.12). Isolated homogenous obsidian defines a near-vertical line with the relationship of initial porosity to heated porosity before this heated porosity plateaus at $\sim 0.67$. There are two samples which exceed this where the porosity approaches 1 (Fig. 4.12, Table. 4.4) and again highlights issues with scan resolution at high porosities where bubble walls are thin. This plateau also develops within the vesiculated bands in homogenous obsidian and clastogenic obsidian, the former showing a higher porosity increase with respect to initial porosity compared to the latter. The plateaus of these samples are also different, with vesiculated bands in homogenous obsidians plateauing at a porosity of $\sim 0.40$ whereas clastogenic obsidians plateau at $\sim 0.18$.

Three obsidian textures do not display these porosity plateaux: lithics, large homogenous obsidian and obsidian proximal to pumice. Lithics are a special case as they are largely crystalline (Fig. 4.7 C and Fig. 4.7 A), but despite this, they do modestly vesiculate upon being heated (Fig. 4.12). Large homogenous obsidians vesiculate to a lesser degree relative to the initial porosity and fails to achieve plateau values. This does not mean that a plateau does not exist for this texture but likely the large homogenous obsidians did not vesiculate enough to reach this point during the heating experiments. Lastly, obsidian proximal to pumice start with an initially high porosity of $\sim 0.40$ and once heated this porosity increases to $\sim 0.48$ and $\sim 0.50$. This could be their plateau region but due to only two obsidian proximal to pumice textures being scanned, there is too little data to be certain. 


\begin{tabular}{|c|c|c|c|c|c|c|c|}
\hline Sample & $\begin{array}{l}\text { Water Content } \\
\text { (whole rock, not } \\
\text { texturally defined, } \\
\text { wt.\% } \mathrm{H}_{2} \mathrm{O} \text { ) }\end{array}$ & Texture & $\begin{array}{l}\text { Volume } \\
\text { texture } \\
\text { natural }\left(\mathrm{mm}^{3}\right)\end{array}$ & $\begin{array}{l}\text { Volume } \\
\text { texture } \\
\text { heated }\left(\mathrm{mm}^{3}\right)\end{array}$ & $\begin{array}{l}\text { Porosity } \\
\text { content } \\
\text { Natural } \\
(\%) \\
\end{array}$ & $\begin{array}{l}\text { Porosity } \\
\text { content post } \\
\text { heated (\%) }\end{array}$ & $\begin{array}{l}\text { Porosity } \\
\text { increase } \\
\text { (\%) }\end{array}$ \\
\hline B18_T5_1 & 0.0758 & $\begin{array}{l}\text { Clastogenic obsidian } \\
\text { Large homogenous obsidian }\end{array}$ & $\begin{array}{l}50.7 \\
817\end{array}$ & $\begin{array}{l}262 \\
638 \\
\end{array}$ & $\begin{array}{l}11.700 \\
1.16 \\
\end{array}$ & $\begin{array}{l}21.1 \\
1.35 \\
\end{array}$ & $\begin{array}{l}9.35 \\
0.186 \\
\end{array}$ \\
\hline B18_T5_2 & 0.0758 & $\begin{array}{l}\text { Large homogenous obsidian } \\
\text { Isolated homogenous obsidian }\end{array}$ & $\begin{array}{l}735 \\
20.9\end{array}$ & $\begin{array}{l}657 \\
414\end{array}$ & $\begin{array}{l}2.44 \\
3.15\end{array}$ & $\begin{array}{l}3.08 \\
66.1\end{array}$ & $\begin{array}{l}6.6 \\
63.0\end{array}$ \\
\hline B18_T2 & $\begin{array}{l}0.2201 \\
0.2134\end{array}$ & $\begin{array}{l}\text { Isolated homogenous obsidian } \\
\text { Clastogenic obsidian } \\
\text { Large homogenous obsidian }\end{array}$ & $\begin{array}{l}25.9 \\
115 \\
433 \\
\end{array}$ & $\begin{array}{l}67.3 \\
144 \\
642\end{array}$ & $\begin{array}{l}2.48 \\
0.358 \\
0.568\end{array}$ & $\begin{array}{l}67.0 \\
5.70 \\
3.56\end{array}$ & $\begin{array}{l}64.5 \\
4.74 \\
2.99\end{array}$ \\
\hline B10_AS01_B1 & 0.0988 & $\begin{array}{l}\text { Vesiculated bands in } \\
\text { homogenous obsidians } \\
\text { Clastogenic obsidian } \\
\text { Lithic } \\
\text { Large homogenous obsidian }\end{array}$ & $\begin{array}{l}704 \\
\\
82.4 \\
76.2 \\
2640 \\
\end{array}$ & $\begin{array}{l}311 \\
47.7 \\
15.6 \\
1430 \\
\end{array}$ & $\begin{array}{l}2.31 \\
\\
10.7 \\
8.23 \\
0.327 \\
\end{array}$ & $\begin{array}{l}20.3 \\
\\
18.3 \\
38.6 \\
1.66 \\
\end{array}$ & $\begin{array}{l}18.0 \\
7.64 \\
30.3 \\
0.730 \\
\end{array}$ \\
\hline B11_T1_1 & 0.0726 & $\begin{array}{l}\text { Lithic } \\
\text { Vesiculated band in homogenous } \\
\text { obsidian } \\
\text { Large homogenous obsidian } \\
\text { Vesiculated band in homogenous } \\
\text { obsidian } \\
\text { Clastogenic obsidian }\end{array}$ & $\begin{array}{l}9.55 \\
3.31 \\
\\
305 \\
5.52 \\
\\
81.5\end{array}$ & $\begin{array}{l}9.81 \\
8.95 \\
\\
896 \\
18.7 \\
196 \\
\end{array}$ & $\begin{array}{l}8.23 \\
21.5 \\
0.327 \\
4.17 \\
\\
2.31 \\
\end{array}$ & $\begin{array}{l}40.7 \\
34.7 \\
\\
2.41 \\
41.1 \\
18.5 \\
\end{array}$ & $\begin{array}{l}32.4 \\
13.4 \\
1.48 \\
36.9 \\
16.1 \\
\end{array}$ \\
\hline B21_AS23_L2 & $\begin{array}{l}0.1755 \\
0.2376 \\
0.2793\end{array}$ & $\begin{array}{l}\text { Large homogenous obsidian } \\
\text { Lithic } \\
\text { Obsidian proximal to pumice } \\
\text { Vesiculated band in homogenous } \\
\text { obsidian } \\
\text { Isolated homogenous obsidian }\end{array}$ & $\begin{array}{l}4980 \\
47.1 \\
3820 \\
1440 \\
\\
159 \\
\end{array}$ & $\begin{array}{l}10100 \\
476 \\
6500 \\
5500 \\
\\
2440 \\
\end{array}$ & $\begin{array}{l}6.34 \\
0.885 \\
40.0 \\
13.2 \\
\\
19.3\end{array}$ & $\begin{array}{l}21.3 \\
1.88 \\
50.3 \\
40.3 \\
\\
68.1\end{array}$ & $\begin{array}{l}14.4 \\
0.991 \\
10.3 \\
21.7 \\
48.8 \\
\end{array}$ \\
\hline B21_AS23_L3 & 0.2793 & $\begin{array}{l}\text { Obsidian proximal to pumice } \\
\text { Vesiculated band in homogenous } \\
\text { obsidian }\end{array}$ & $\begin{array}{l}1220 \\
360\end{array}$ & $\begin{array}{l}1650 \\
578\end{array}$ & $\begin{array}{l}40.3 \\
23.9\end{array}$ & $\begin{array}{l}48.0 \\
41.1\end{array}$ & $\begin{array}{l}7.07 \\
17.3\end{array}$ \\
\hline
\end{tabular}




\begin{tabular}{|c|c|c|c|c|c|c|c|}
\hline & & $\begin{array}{l}\text { Large homogenous obsidian } \\
\text { Isolated homogenous obsidian }\end{array}$ & $\begin{array}{l}2010 \\
267\end{array}$ & $\begin{array}{l}1740 \\
399\end{array}$ & \begin{tabular}{|l|}
6.75 \\
28.7
\end{tabular} & $\begin{array}{l}15.2 \\
61.1 \\
\end{array}$ & \begin{tabular}{|l|}
8.41 \\
32.5 \\
\end{tabular} \\
\hline B07_AS19_1B & Unmeasured & $\begin{array}{l}\text { Large gomogenous obsidian } \\
\text { Clastogenic obsidian } \\
\text { Isolated homogenous obsidian } \\
\text { Isolated homogenous obsidian } \\
\text { Isolated homogenous obsidian } \\
\text { Isolated homogenous obsidian } \\
\text { Isolated homogenous obsidian }\end{array}$ & $\begin{array}{l}7.24 \\
0.314 \\
0.426 \\
1.91 \\
1.56 \\
3.63 \\
0.563 \\
\end{array}$ & $\begin{array}{l}4.44 \\
0.330 \\
0.223 \\
1.40 \\
1.54 \\
1.79 \\
0.436 \\
\end{array}$ & \begin{tabular}{|l|}
7.13 \\
4.41 \\
0.386 \\
0.366 \\
0.0165 \\
0.232 \\
0.429 \\
\end{tabular} & $\begin{array}{l}17.5 \\
18.4 \\
0.386 \\
12.1 \\
3.96 \\
7.27 \\
13.0 \\
\end{array}$ & \begin{tabular}{|l|}
10.3 \\
14.0 \\
0.000 \\
11.1 \\
3.94 \\
7.04 \\
12.6 \\
\end{tabular} \\
\hline B16_AS16_A1 & unmeasured & $\begin{array}{l}\text { Isolated homogenous obsidian } \\
\text { Isolated homogenous obsidian } \\
\text { Isolated homogenous obsidian }\end{array}$ & $\begin{array}{l}125 \\
2.42 \\
5.16\end{array}$ & $\begin{array}{l}549 \\
95.0 \\
95.0\end{array}$ & $\begin{array}{l}2.342 \\
3.56 \\
2.34\end{array}$ & $\begin{array}{l}35.4 \\
99.9 \\
99.9\end{array}$ & $\begin{array}{l}33.1 \\
96.3 \\
97.5\end{array}$ \\
\hline
\end{tabular}

Table 4.4 Porosity and volume change from natural to heated samples observed for specific textures, calculated from XCT.The table displays, from right to left: the sample scanned, water contents measured from the obsidians which are representative of the whole sample and unrelated to specific textures, the textures present within the sample, the volume of the specific texture of the sample measured using XCT, the porosity content of the natural and post heated sample texture in percentages, and the porosity increase of the textures due to heating. 


\section{Chapter 5. Discussion}

\subsection{Textural representation of scanned heated samples}

The subset of 10 samples scanned after the heating experiments encompassed numerous textures within them and showed different trends for secondary vesiculation when heated. However, for these to be representative of the remainder of the samples, similarities between the internal textures of samples examined only with natural XCT scans and those with both natural and heated XCT scans need to be established. Throughout this investigation, the naming conventions (Section 4.4) will be carried on with the internal textures being described as; 'isolated homogenous obsidian', 'large homogenous obsidian', 'clastogenic obsidian', 'vesiculated band within homogenous obsidian', 'lithic', and 'obsidian proximal to pumice', with the macroscopic vesiculation style observed described as: 'localised spherical foaming', 'localised planar foaming', 'isotropic expansion', and 'shrivelling'. Similarities between the vesiculation styles will be investigated to verify if the selected heated scanned samples are representative of all samples.

Localised spherical foaming and cracking of proximal matrix material is one of the most common vesiculation styles seen, with most samples having experienced this (Fig. 4.10, Table 4.3). The typical protruding lobes that this causes aid in determining the regions where this vesiculation occurred within the natural samples (Fig. 5.1 A, B, C, D). The trend observed within the natural and heated scanned samples appears to occur within the natural-only scanned samples once these are compared with the heating experiment photographs, where localised spherical foaming occurs within isolated homogenous obsidian textures during heating (Fig. 5.1 A, B, C, D). There is also no discrimination to this foaming based on position of the isolated homogenous obsidians within each sample: whether outcropping on the exterior (Fig. 5.1 A, D) or encapsulated in the interior of the sample (Fig. 5.1 B, C). This foaming also displays evidence that if on the interior of the sample this isolated spherical foaming causes stress on adjacent regions, and cracking of surrounding regions verifying the enhanced size these vesiculate to (Fig. 5.1 B and C, Fig. 4.3). These isolated, small, dense homogenous obsidian regions being of smaller size seem to promote greater vesiculation. The smaller size and volume of these specific 'homogenous obsidian melts' means diffusion has to occur over a shorter distance to reach a bubble melt interface than other textures within the samples. 
This smaller distance means that diffusion of volatiles to pre-existing bubble structures will occur more quickly and vesiculation will be heightened (Hurwitz and Navon 1994; Navon and Lyakhovsky 1998). These isolated homogenous obsidians could also be one explanation for the large amount of vesiculation seen within some obsidian regions within composite bombs erupted from Cordón Caulle (Fig. 2.4 in study site, Schipper et al. 2021, Pistolesi et al. 2015).

Localised planar foaming has observed similarities between the samples with natural-only scans and samples with both natural and heated scans textures (Fig. 4.10, Fig. 5.1 G, H). Each of the samples that experience this vesiculation were within composite bombs that were pumice dominated but with obsidian regions and pumice fiamme (Fig. 4.10, Fig. 5.1 G, H, Appendix 1), with this vesiculation style occurring within the minor obsidian regions (Schipper et al. 2021). All samples which exhibit this localised planar foaming within the vesiculated band within homogenous obsidian texture (Fig. 5.1 G, H). The regions that foamed appear to have no pumice within or proximal to them, although that may be obscured within the scans, and generally consisted of a mixture of isolated large $\sim 1 \mathrm{~mm}$ bubbles and small sub-millimetre bubbles (Fig. 5.1 G, H). The localised planar foaming is most dramatic within obsidian regions that had already undergone a large amount of vesiculation and shear deformation, (Fig. 5.1 G, H) more so than compared to other samples with vesiculated bands within obsidians that did not have any shear fabric (Fig. 5.1 E, F). However, there may be some other controls such as water content or overall porosity that may have influenced this secondary vesiculation, which are discussed below.

The last foaming observed in the rock suite is that of isotropic expansion. Preferred regions of foaming for this texture are hard to identify within the natural and heated scans, but appear to favour pre-existing bubble structures, as predicted by classical nucleation theory (Prousevitch et al. 1993; Hurwitz and Navon 1994; Navon and Lyakhovsky 1998). However, within the samples, there is a clear trend that this isotropic foaming occurs within the large homogenous obsidian domains (Fig. 5.1 A-D, G, H). The general trend for these isotropic expansion samples is that vesiculation appears to occur within the large homogenous obsidian textures. 

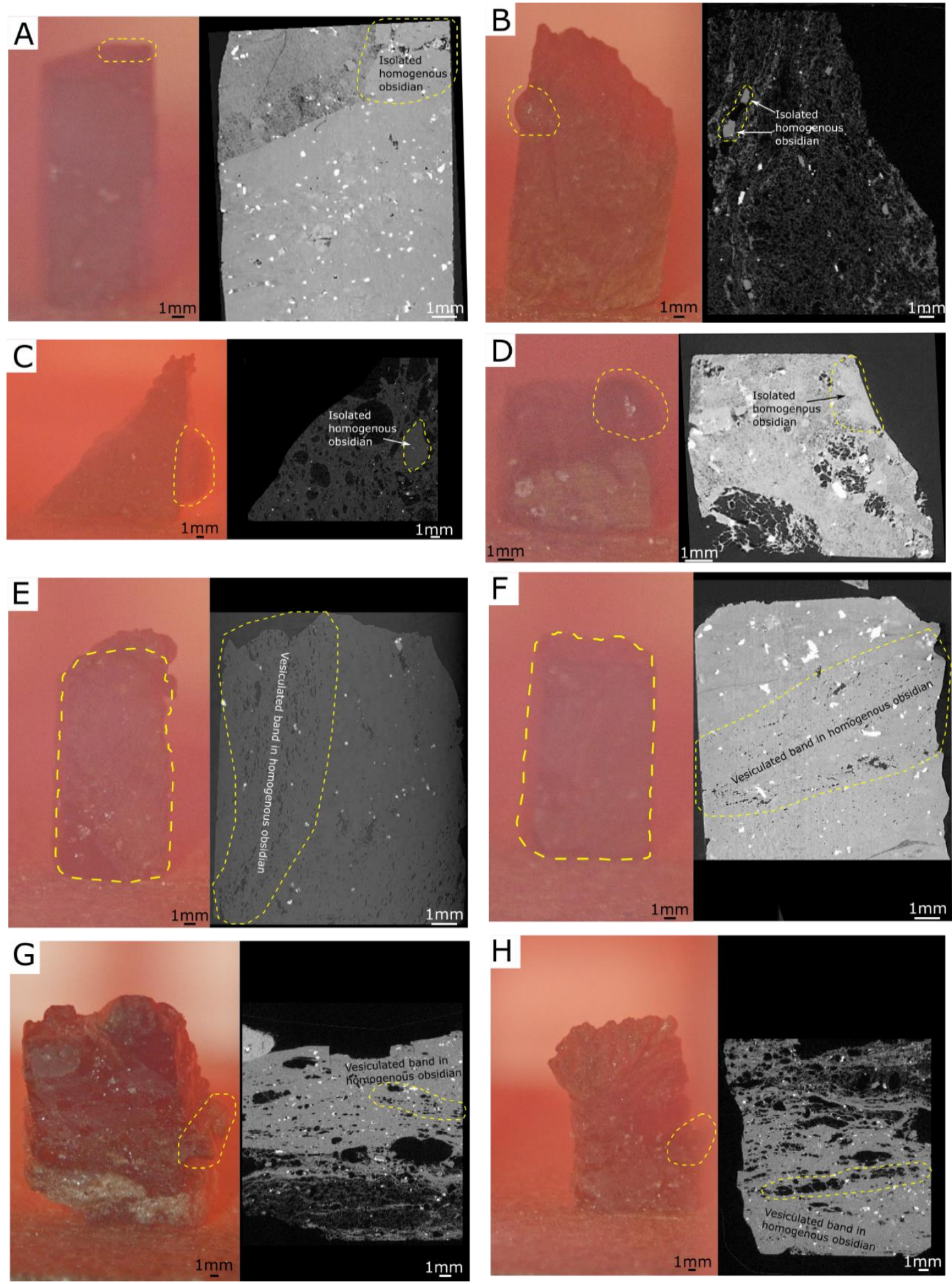

Figure 5.1 Areas of foaming within composite bomb samples' showing the heating sample within the furnace (left) and the XCT scan of natural sample (right), highlighting the structures where the foaming/shrivelling occurred or was inferred to have occurred (yellow dashed circles). A, C, E, G are different types of foaming that occurred where the structures were analyzed in both natural and heated sample XCT. B, D, F, $\boldsymbol{H}$ show similar regions where the same type of foaming occurred (yellow circle in the heating experiments) and where similar vesiculation was inferred to occur in samples for which post-heating XCT scans were not obtained (yellow circle within XCT scans). A-D highlight regions where localised spherical foaming occur in samples. $\boldsymbol{E}, \boldsymbol{F}$ highlights regions where shrivelling has occurred within the dense obsidian regions. $\boldsymbol{G}, \boldsymbol{H}$ samples where localised planar foaming occurs within samples. Shrivelling is mainly observed within pumicious regions of 
composite bombs but also occurs within obsidian regions (Fig. 4.8, Fig. 4.10). Although pumice regions can inform us as to trends that result in shrivelling, they are not representative but these can inform about how obsidian regions within samples react (Stevenson et al. 1997; Herbert and Andrew 2002). Shrivelling of obsidian pyroclasts is observed in vesiculated bands within homogenous obsidians, similar to those formed by localised planar foaming (Fig. 5.1 E, F). Only three obsidian regions in composite bombs experienced shrivelling (Table 4.3), showing the rarity with which this occurred. Only one of these samples were scanned both as a natural and heated sample. This limited number of observations precludes definitive conclusions about shrivelling, although previous work has highlighted the role of interconnected bubble networks and surface tension allowing outgassing and then the resultant shrivelling (Kennedy et al., 2016). Typically, however, shrivelled obsidians within samples appear to have large regions occupied by vesiculated bands within homogenous obsidians that have abundant, smaller bubbles (to a maximum of 1mm) (Fig. $5.1 \mathrm{E}, \mathbf{H}$ ). The shrivelling obsidian samples are dominated by large homogenous obsidian with vesiculated bands within them, meaning a low overall porosity within the sample (Fig. 5.1 E, H). This is in direct contrast to the vesicular and mixed composition of the localised planar foaming (Fig. $5.1 \mathbf{G}, \mathbf{H})$. This is likely a factor for the vesiculation difference between the samples, but there may also be a water content affect as mentioned with the localised planar expansion, which will be discussed later.

When the same type of vesiculation has occurred across different samples, the same internal textures are present across these samples, demonstrating that the natural and heated XCT scanned samples are representative of the composite bombs as a whole. There is also evidence that the independent textures described cause different vesiculation styles, irrespective of natural and post scans having been performed, highlighting the textural control to secondary vesiculation proposed. 


\subsection{The effect of volatile contents on porosity change}

The same vesiculation styles are observed across multiple bombs in regions that appear texturally similar, there still may be a volatile content affect influence the porosity change experienced upon these regions being heated (Prousevitch et al. 1993; Hurwitz and Navon 1994; Navon and Lyakhovsky 1998). To determine if the response of the sample is driven by volatile content the water concentrations of the obsidians are compared with the porosity change of the natural obsidian once heated specific to the texture for samples that were scanned in natural and heated states (Fig. 5.2). The selected textures investigated were isolated homogenous obsidians (Fig. 5.2 A), clastogenic obsidians (Fig. 5.2 B), large homogenous obsidians (Fig. 5.2 C), and vesiculated bands within homogenous obsidians (Fig. 5.2 D). These textures had a significant amount of data per sample ( $>3$ measurements) and were the main regions where the identified vesiculation styles occurred.

Broadly, there appears to be no clear link between volatile content and the porosity increase of obsidians due to heating-induced secondary vesiculation, regardless of their initial textures. Variability in foaming occurs irrespective of volatile content, with some obsidian textures displaying with a lower volatile content foaming more than obsidians with higher volatile contents at similar initial porosities (Fig. 5.2 A, B, C).

Large homogenous obsidians appear to have a tendency of higher volatile contents to produce more vesiculation (Fig. $5.2 \mathrm{C}$ ). There appears to be higher vesiculation associated with samples with $0.20-0.30$ wt. $\% \mathrm{H}_{2} \mathrm{O}$ compared to the other samples with $<0.20$ wt.\% $\mathrm{H}_{2} \mathrm{O}$ (Fig. 5.2 C). However, once the cluster of lower porosity samples with a natural porosity of < 0.05 are isolated, there is equivalent, if not more, porosity increase within the lowest volatile content samples of between $0.05-0.10$ wt.\% $\mathrm{H}_{2} \mathrm{O}$. This shows that there is essentially no volatile content affect within the vesiculation of these samples. Instead, the samples appear to be due to a higher initial porosity of the samples. Overall, the samples display a low increase in porosity, with all samples in this specific vesiculation style displaying an increase in porosity of $\sim 2.6 \mathrm{x}$ the initial porosity. However, when the samples of a low initial porosity are excluded $(<0.05)$ then a much higher and steady increase in porosity is observed of $\sim 6 x$ the initial porosity, much the same, although less steep, as other textures (heated porosity is: $\sim 21 \mathrm{x}$ for isolated spherical foaming, $\sim 2 x$ for clastogenic, $\sim 10 x$ for vesiculated band within homogenous 
obsidian, all measurements taken until the samples reach the apparent $P_{m}$ and $x$ is initial porosity, Table. 4.2). This highlights the increasing ease with which textures can expand/vesiculate when starting with a higher initial porosity, as opposed to when starting with a higher initial volatile content within the Cordón Caulle samples (Lavallée et al. 2015; Forte and Castro 2019).

A texture that highlights the relative effects of porosity versus volatile content on secondary vesiculation is in the clastogenic obsidians. The highest volatile content sample has the lowest secondary vesiculation compared to the lower volatile content obsidians (Fig. 5.2 B). This volatile content difference is $\sim 0.10$ wt.\% $\mathrm{H}_{2} \mathrm{O}$ which, within the Cordón Caulle samples, is considerable due to the universally low contents measured (Table 4.4). We can also see this increase in natural porosity causing increased porosity until the plateau value is reached, which will be discussed later.

Vesiculated bands within homogenous obsidians (Fig. 5.2 D) are interesting features within the samples. The sample shown in Fig. 5.2 D has the same appearance as other samples with low natural porosity, vesiculating less than samples with higher initial porosity, until a plateau value is reached (Fig. 5.2 D). However, one of the samples at a higher natural porosity vesiculates to a lesser extent compared to nearby obsidians. This specific obsidian that vesiculates to a lower porosity once heated is of a lower volatile content than the two samples that reached the plateau value (Fig. 5.2 D). The lower volatile sample (B11_T1_1) decreases also displays a decrease in volume, shrivelling as it was heated as opposed to the other samples which displayed localised planar foaming. Although this process may relate to the lower volatile content of the sample, it still displays an increase in porosity. This increase is below the plateau value of the sample, but does show the tendency to vesiculate appears unaffected. Although this may be an error associated in the input of the data as typically an increase in porosity relates to an increase in size, other porosity data from this sample display expected trends making it a likely result although perplexing. Another sample also displays this dip of the apparent maximum porosity plateaux, albeit in a different texture, that of isolated homogenous obsidian (Fig. 5.2 A) with a higher water content. However, this sample still displayed an increase in size as opposed to the shrivelling that occurred in the vesiculated band within homogenous obsidians (Fig. 5.2 D). Due to this being off the plateau value, in a separate texture and of a higher volatile content it is unlikely to be a volatile affect but instead 
another process, discussed later. Although the volatile content may have affected the vesiculation style, the data do not indicate any consistent link between volatile content and the observed dip of the apparent maximum porosity plateau.

Some higher water content samples within the P16_B21 suite had experiments cut short due to them having rapidly and dramatically foamed upon heating (Table. 4.3). These samples vesiculated to extreme amounts in less than 3 minutes, which may be due to heightened water content $\left(>0.3 \mathrm{wt} . \% \mathrm{H}_{2} \mathrm{O}\right)$, although their full effects on porosity would be masked due to experiments being cut short. However, this effect could also be due to their association within pumice dominated composite bombs and already having undergone a large amount of vesiculation in nature, before the experiments (Table. 4.2, 4.3, Fig. 5.2). Vesiculation is comparatively minor in matrix-, obsidian and fine matrix-, and obsidian- dominated composite bombs with high volatile contents (0.18-0.22 wt. \% $\left.\mathrm{H}_{2} \mathrm{O}\right)$, although the samples do not quite reach volatile contents as high as in the pumice dominated composite bomb samples (up to 0.32 wt. \% $\mathrm{H}_{2} \mathrm{O}$, Table. 4.2 and 4.3). Unfortunately, volatile contents were not obtained from the other composite bomb sample (P16_B18) for which experiments were cut short to compare whether this was a volatile content effect or a textural effect. Similarly, prior to heating P16_B18 samples had a lot of pumice and obsidian clasts situated near each other, but this sample was within a matrix dominated composite bomb. Due to this we cannot determine whether the degree of vesiculation observed within the P16_B21 and P16_B18 bomb samples were controlled by textural or volatile content effects, or a combination of both. 

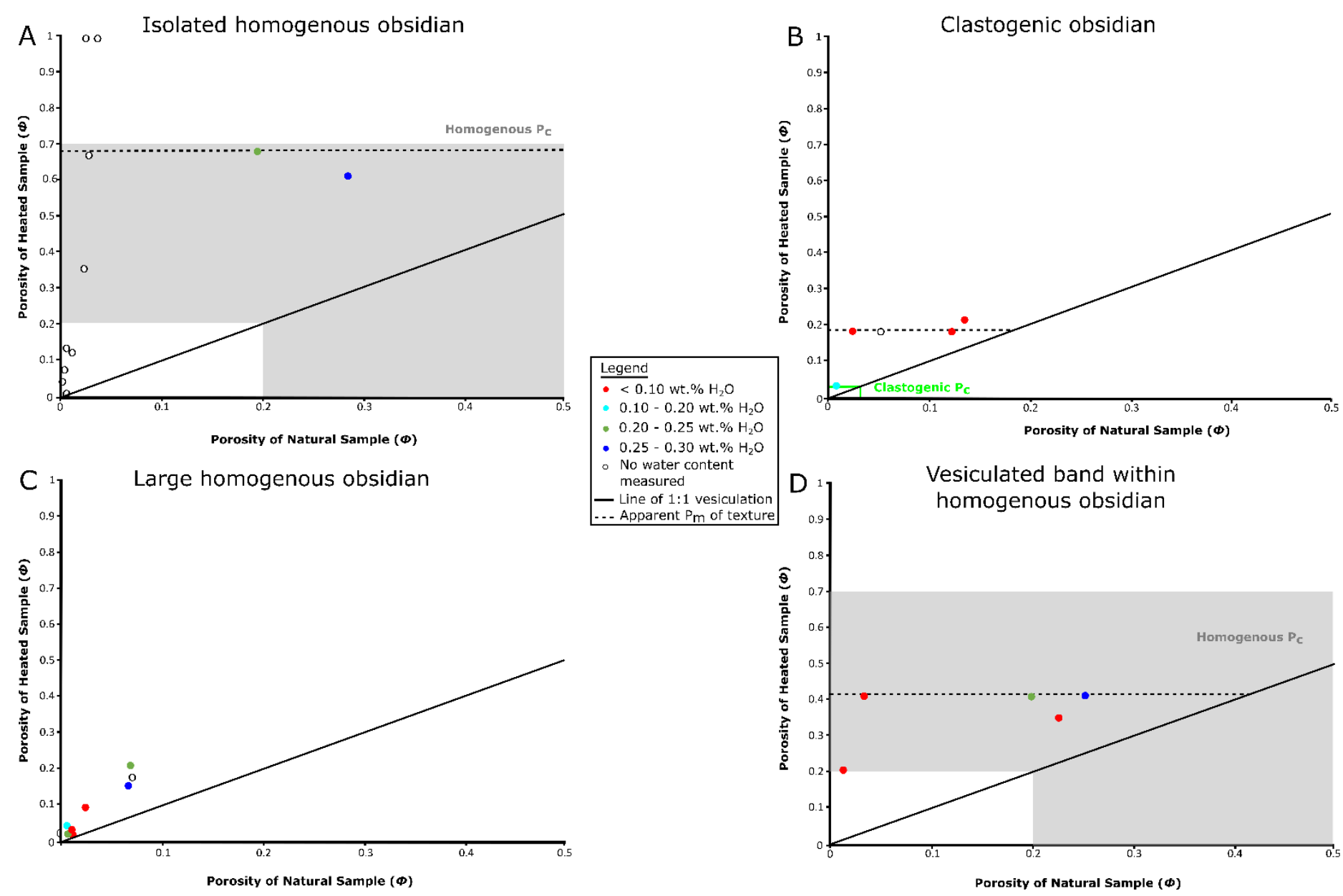

Figure 5.2 Effect of initial volatile contents on the porosity changes during heating experiments. Each image has a black line denoting 1:1 vesiculation and the dashed black line depicting the apparent permeability threshold $\left(P_{m}\right)$. The grey area in $\boldsymbol{A}$ and $\boldsymbol{D}$ shows the measured variation of the percolation threshold $\left(P_{c}\right)$ within typical homogenous obsidians (Rust and Cashman 2004; Wadsworth et al. 2014), B has a solid green line depicting measured clastogenic obsidians $P_{c}$ (Wadsworth et al. 2014). $\boldsymbol{A}$ vesiculation of isolated homogeneous obsidians. $\boldsymbol{B}$ vesiculation of clastogenic obsidians. $\boldsymbol{C}$ vesiculation of large homogenous obsidians. $\boldsymbol{D}$ vesiculation of vesiculated bands within homogenous obsidians. 
If all the measured obsidian textures are compared, there is no clear relationship between initial volatile contents and porosity change upon heating. Although the overall vesiculation style could be affected by volatile content within B11_T1_1 and other shrivelling samples, this has no major impact on the porosity change as obsidians were heated. The lack of a volatile effect was expected due to previous experiments showing that volatile contents this similar and low show similar response when experimentally heated (Eichelberger and Westrich 1981; Toramaru 1989; Herbert and Andrew 2002), noting again that although there is some variability in Cordón Caulle volatile contents, they are consistently low compared to obsidian samples globally (Fig. 2.5). Although this lack of a volatile effect on the secondary vesiculation in Cordón Caulle samples was expected, small changes in volatile contents can cause differences in secondary vesiculation within suites of obsidian with high volatile contents (0.75-1.25 wt. \% $\mathrm{H}_{2} \mathrm{O}$ ) (Forte and Castro 2019), none of our samples showed systematic dependence of secondary vesiculation on volatile content.

\subsection{Percolation and permeability thresholds}

The most common feature observed in the secondary vesiculation data is the development of porosity plateaux, at different porosities depending on the initial textures. Each texture had a maximum plateau, although at different porosity values for each. These plateaux are likely due to the development of a permeability threshold $\left(P_{m}\right)$ within each texture (Rust and Cashman 2004; Cashman and Sparks 2013; Wadsworth et al. 2014). The permeability threshold is the point when void spaces within a rock are sufficiently connected to create a permeable pathway for the melt to outgas without any further increase in porosity. This threshold is closely related to the percolation threshold $\left(P_{c}\right)$, which is the porosity at which the individual bubbles begin to interact and coalesce (Rust and Cashman 2004; Shea et al. 2010; Wadsworth et al. 2020). $P_{c}$ differs within homogenous obsidians and clastogenic obsidians. Due to the sintered origin of clastogenic obsidians, these textural domains only have a $P_{c} \approx 0.03 \phi$ (Fig. 5.2 B) (Rust and Cashman 2004; Wadsworth et al. 2014; Wadsworth et al. 2016). The reason the $P_{c}$ for clastogenic obsidians is so low is due to their formation by sintering particles together, with pore spaces originally being at inter-particle spaces, making it easier to maintain connected pathways during sintering-driven densification (Wadsworth et al. 2014; Wadsworth et al. 2016; Gardner et al. 2018). Homogenous obsidians do not have 
these pre-existing inter-particle voids, allowing them to vesiculate to a higher porosity prior to extensive bubble interaction. This results in the samples having a higher, yet more variable $P_{c}$ within measured samples of between $0.2-0.7$ \$ (Fig. 5.2 A, D) (Rust and Cashman 2004; Shea et al. 2010; Wadsworth et al. 2014; Wadsworth et al. 2016; Gardner et al. 2018). Each obsidian texture observed and measured has a different $P_{c}$ and apparent $P_{m}$ (Fig. 5.2 A, B, D) whilst remaining relatively consistent within its specific textural group.

Although no permeability or connected porosity measurements were conducted on any of the samples or textures here, inferences are still able to be made on the affect that these porosities will have once they reach the apparent $P_{m}$, and their $P_{c}$ (Fig. 5.2) (Cheadle et al. 2004; Rust and Cashman 2004; Gardner et al. 2018). Isolated homogenous obsidians within samples have the highest porosity before they reach their apparent $P_{m}$ of $\sim 0.67$. This is higher than vesiculated bands within homogenous obsidians which reaches the apparent $\mathrm{P}_{\mathrm{m}}$ at $a$ porosity of $\sim 0.41$, and clastogenic obsidians which reach their apparent $P_{m} \sim 0.19$. The respective $P_{c}$ will also differ, although these are unseen, due to the variation of apparent $P_{m}$, with the higher an apparent $P_{m}$ is the higher the $P_{c}$ for that texture will have to have been (Rintoul 2000; Cheadle et al. 2004; Rust and Cashman 2004; Wadsworth et al. 2014; Schipper et al. 2021).

These trends within the structures of each independent textures ultimate effect on $\mathrm{P}_{\mathrm{m}}$ and $\mathrm{P}_{\mathrm{c}}$ can be observed by comparing the natural and heated sample scans (Fig. 5.3). The clastogenic samples preferentially vesiculate at pre-existing weaknesses within the clast that are remnant from their formation (Gardner et al. 2017; Gardner et al. 2018; Gardner et al. 2019), with samples showing the vesiculation occurring along cracks, likely left from the welding of these particles and accentuated by the stress generating by the growth of the isolated homogenous obsidian (Fig. 5.3 A), which typically intersect forming a permeable pathway at a very low porosity (Gardner et al. 2017; Gardner et al. 2018; Gardner et al. 2019). 


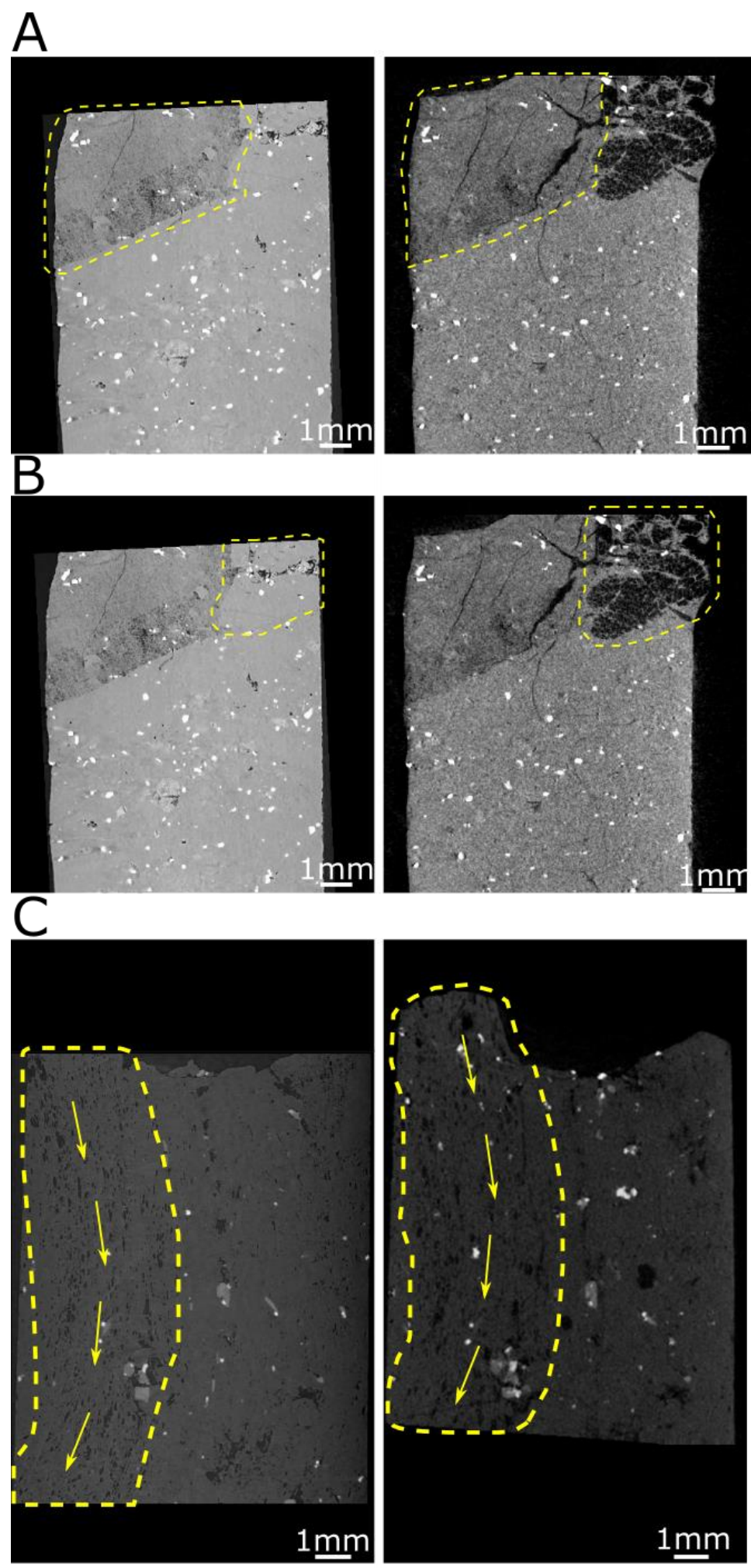

Figure 5.3 Differences in secondary vesiculation in response to pre-existing textures and structures. A region of clastogenic obsidian (yellow dashed circle) of B18_T2 with pre-existing cracks within the texture which vesiculate once heated and are likely accentuated by the growth of the isolated homogenous obsidian. B isolated homogenous obsidian (yellow dashed circle) of B18_T2 with very few spherical bubbles prior to heating spread throughout the volume. $C$ vesiculated band within homogenous obsidian (yellow dashed circle) of B11_T1_1, with yellow arrows showing the apparent direction of shear experienced during earlier primary vesiculation, the fabric of which is retained during heating. 
Vesiculated bands within homogenous obsidian display an apparent $\mathrm{P}_{\mathrm{m}}$ which is relatively low compared to that in homogenous obsidians, and presumably a $\mathrm{P}_{\mathrm{c}}$ that is also low because of this, but still higher than clastogenic obsidians (Cheadle et al. 2004; Rust and Cashman 2004). This low $\mathrm{P}_{\mathrm{m}}$ is likely due to the sheared orientation of the pre-existing bubble structures within this texture with many bubbles already interacting and with melt films visible between the bubbles (Fig. $5.3 \mathrm{C}$ ). This means that as the bubbles begin to grow as the sample is heated, the bubbles will begin to interact and coalesce, and due to this preferred orientation of growth these bubbles become interconnected and reach the $P_{c}$ at a lower total porosity, and consequently foam to a lesser extent during heating (Cheadle et al. 2004; Rust and Cashman 2004; Wadsworth et al. 2014; Colombier et al. 2020; Schipper et al. 2021).

Isolated homogenous obsidian has no apparent pre-existing structural weaknesses nor preferred orientation for vesiculation, and sub-spherical bubbles spread throughout them (Fig. 5.3 B). Due to the bubbles within the melt being small, isolated and spherical, the porosity at which they will begin to interact $\left(P_{c}\right)$ (in the absence of any further bubble nucleation) will need to be high, and permeable pathways for the obsidian to outgas $\left(P_{m}\right)$ will not form until higher porosities are reached (Cheadle et al. 2004; Rust and Cashman 2004; Wadsworth et al. 2014).

The porosity at which each textural type of obsidian reaches the $\mathrm{P}_{c}$ and $\mathrm{P}_{\mathrm{m}}$ has major implications for the outgassing of both the sample and the melt (Cashman and Sparks 2013; Wadsworth et al. 2014). As a volatile is exsolved from the melt into a gas, this will expand and increase the area that is required to contain this volatile within either the melt or obsidian (Toramaru 1989; Prousevitch et al. 1993; Navon and Lyakhovsky 1998; Proussevitch and Sahagian 1998). Therefore, with increased porosity, the melt or obsidian that vesiculated will occupy more space. If the apparent $\mathrm{P}_{\mathrm{m}}$ of the texture is low, then essentially the texture will vesiculate to a lower extent prior to outgassing becoming effective, and vice versa for areas with higher apparent $P_{m}$ (Pistolesi et al. 2015; Schipper et al. 2015; Wadsworth et al. 2020; Schipper et al. 2021). This is also seen with the increase in volume of each sample (Fig. 4.4) where the textures which experienced more vesiculation have a larger volume increase than textures which do not (i.e. isolated homogenous obsidians and large homogenous obsidians respectively). 
This variable $\mathrm{P}_{\mathrm{m}}$ within different textures can have dramatic implications to outgassing, where foaming of a specific region can impact a pre-existing outgassing pathway whilst this foam is still impermeable, leading to gas overpressure and potentially an explosive eruption (Pistolesi et al. 2015; Schipper and White 2016; Schipper et al. 2021). However, this can have the converse affect and be able to outgas volatiles more easily due to the lower porosity before the sample reaches $P_{m}$. The foaming of a region in-turn blocking an outgassing pathway has been theorized to cause some transitions between effusive to explosive volcanism within volcanic eruptions at Cordón Caulle 2011-2012 (Pistolesi et al. 2015; Schipper et al. 2015; Saubin et al. 2016; Schipper et al. 2021), Chaitén 2008-2009 (Saubin et al. 2016; Paisley et al. 2019), and Volcán de Colima 2012 lava dome emplacement (Kendrick et al. 2016). Observations made in these experiments demonstrate this to be possible. There is also the possibility to generate alternate outgassing pathways during the expansion of samples, with samples like B16_AS18 (Fig. 5.1 C) showing the generation of cracks in regions adjacent to the foaming. These could potentially facilitate outgassing of this region, however it would likely require the growth of the texture to be restricted before cracking of surrounding textures occurs, as seen by the difference within B16_AS18 and B18_T2, and if these are adjacent to an outgassing pathway, they will likely favour growth into these regions (Fig. 5.1 C and $\mathbf{A}$ respectively).

\subsection{Differing vesiculation styles within a singular texture.}

As mentioned, there is no clear evidence that differing volatile contents systematically affected the degree of secondary vesiculation that occurred during the heating experiments (Fig. 5.2, Section 5.1), however, the effects of the volatile content on the vesiculation style could not be determined. Sample B11_T1_1, along with other non-scanned heated samples shrivelled during the heating experiments. These samples displayed similar textural trends to those of localised planar foaming (Fig. 5.1 E-H). Another sample, B21_AS23_L3, displays the same surprisingly low heated sample porosity data when compared to $\mathrm{P}_{\mathrm{m}}$, except this region experienced foaming and an increase in size through isolated spherical foaming (Fig. 5.2 A, D).

B21_AS23_L2 and B11_T1_1 vesiculated differently from one another, but due to both having a lower porosity than expected with respect to the apparent $P_{m}$ for that texture, will be 
investigated jointly. These samples come from isolated homogenous obsidian texture for B21_AS23_L3 (Fig. 5.4 B) and vesiculated band within homogenous obsidian texture for B11_T1_1 (Fig. 5.4 A). The internal structures present with the heated sample XCT scans show evidence of bubble collapse following growth and coalescence, due to the formation of effective outgassing pathway (cracks within left circle Fig. 5.4 A, crack in upper right circle Fig. 5.1 A, upper bubble in centre of circle Fig. 5.4 B). This lowers the overall internal pressure within the bubble network, which now being interconnected allows exsolved gases within isolated regions to effectively outgas (Wadsworth et al. 2014; Gardner et al. 2017; Colombier et al. 2020). This will result in a reduction of size and porosity as the gases are removed and surface tension acts to collapse the textures (Eichelberger and Westrich 1981; Eichelberger et al. 1986; Bagdassarov and Dingwell 1992; Kennedy et al. 2016). The alternate hypothesis would be that neither of these samples vesiculated to the $P_{m}$ and they are instead representative of the maximum porosities of the samples. This is unlikely due to the samples exhibiting permeable pathways from which the volatiles within the texture can outgas through, making it more likely these samples reached this $\mathrm{P}_{\mathrm{m}}$ before outgassing instead of this vesiculation being the maximum, as this would not fit with other heated porosity measurements taken (Rust and Cashman 2004; Cashman and Sparks 2013; Wadsworth et al. 2014; Gardner et al. 2017; Colombier et al. 2020; Schipper et al. 2021). Volatile outgassing through permeable pathways is also supported by evidence seen other studies, where once the permeability threshold is reached the sample will either outgas and/or sinter, which removes the exsolved volatiles from within the melt, or if exsolved volatiles cannot be removed the melt will fragment (Rust and Cashman 2004; Gardner et al. 2017; Gardner et al. 2018; Gardner et al. 2019; Schipper et al. 2021).

There is still an issue with this interpretation. Although the isolated homogenous obsidian within B21_AS23_L3 exhibits the same textural response as the vesiculated band within homogenous obsidian of B11_T1_1, and outgassing leading to a reduction in porosity at the apparent $\mathrm{P}_{\mathrm{m}}, \mathrm{B} 21 \_$AS23_L3 still expands as opposed to B11_T1_1 which shrivels (Fig. 5.4). Very few examples from our experiments demonstrate shrivelling of obsidian, with samples B13_T5_2 and B11_T1_1 both shrivelling, but with only the latter having both natural and heated XCT scans. Three specific similarities exist between these bombs that could potentially cause this shrivelling: (1) vesiculated bands with sheared texture are adjacent to large 
homogenous obsidian, (2) they have low volatile contents $(0.07 \pm 0.02$ and $0.09 \pm 0.02$ wt.\%

$\mathrm{H}_{2} \mathrm{O}$ respectively, table 4.2), (3) both samples are obsidian dominated composite bombs with few non-obsidian components (Fig. 5.1 E, F).
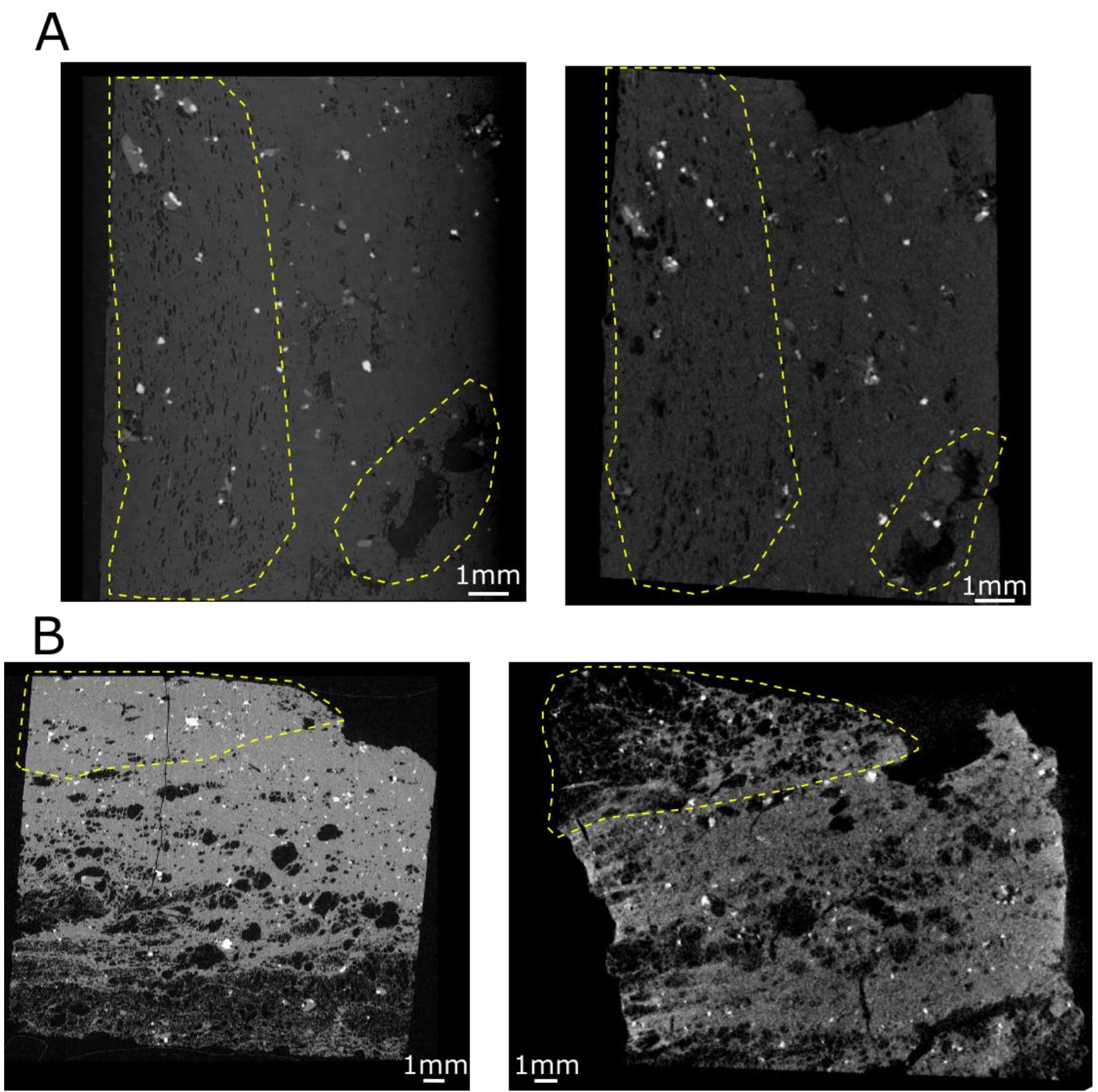

Figure 5.4 Coalescence and collapse of structures that decreases porosity. For both $\boldsymbol{A}$ and $\boldsymbol{B}$ the natural samples are displayed on the left and the heated sample are displayed on the right. $\boldsymbol{A}$ vesiculated band within homogenous obsidian within sample B11_T1_1 which highlights two regions (yellow dashed circles) which increase in porosity but decrease in size. For these we can see that each region has larger vesicles with these also being interconnected with a pathway to allow outgassing to occur. B isolated homogenous obsidian within sample B21_AS23_L3 highlighting the area which vesiculated (yellow dashed circle) but within the darker region in the upper left side of the heated sample (right), there is clear interconnected vesicles which can outgas, removing volatiles and reducing the overall porosity of the sample. 
Volatile content is unlikely to have caused this shrivelling, solely due to numerous other samples that have low volatile contents within the vesiculated bands within homogenous obsidian texture (Fig. 5.2), and their observed isotropic expansion. However, a combination of these could have made vesiculation occur preferentially along vesiculated bands within homogenous obsidians and led to this zone experiencing increased vesiculation but reduction in overall size (Fig. 5.2 A).

Each vesiculated band within homogenous obsidian that shrivelled had an observable sheared direction for bubble formation (Fig. 5.2 E, F, Fig. 5.3 C, Fig. 5.4 A) and was surrounded by large homogenous obsidian clasts. This potentially affected the time needed to form these interconnected and permeable pathways present within B11_T1_1 once heated, or vesiculation could have favoured this more porous region (Fig. $5.4 \mathrm{~A}$ ). That secondary vesiculation favoured the already-porous band within the homogenous obsidian is understandable, especially if the volatile content of the material is low. This is due to the large homogenous obsidian texture being one of the largest textures within each sample (Fig. 5.1) and having a relatively low porosity (Fig. 5.2 C). When this low porosity is combined with the large area of the large homogenous obsidian then volatiles will have to diffuse over large distances before reaching a bubble-melt interface so that bubble growth can occur (Eichelberger and Westrich 1981; Toramaru 1989; Prousevitch et al. 1993; Stevenson et al. 1997; Navon and Lyakhovsky 1998; Herbert and Andrew 2002). Conversely, the vesiculated band within the homogenous obsidian consist of a high porosity, with numerous pre-existing bubble structures making numerous interfaces which volatiles can diffuse towards, with growth of these regions being easier (Toramaru 1989; Prousevitch et al. 1993; Hurwitz and Navon 1994; Stevenson et al. 1997; Navon and Lyakhovsky 1998). This effect would likely be heightened if the 'melts' were at a lower supersaturation, due to the energy demands required to nucleate bubbles compared to growth and coalescence of pre-existing bubbles (Eichelberger and Westrich 1981; Eichelberger et al. 1986; Bagdassarov and Dingwell 1992; Toramaru 1995; Stevenson et al. 1997; Navon and Lyakhovsky 1998). The vesiculated band within the homogenous obsidian will be favoured due to the pre-existing melt-gas interfacial area (Fig. $5.3 \mathrm{C}$ ) as opposed to having to nucleate new bubbles or grow sparse bubbles within 
the large homogenous obsidian (Navon and Lyakhovsky 1998; Proussevitch and Sahagian 1998; Herbert and Andrew 2002; Polacci et al. 2009; Castro et al. 2012; Wallace et al. 2015).

Due to the scarcity of obsidian samples that shrivelled, with B11_T1_1 and B13_T5_2 being the only obsidian samples to exhibit this, and volatile contents being relatively uniform across erupted material, it cannot be solely a volatile content affect that causes this vesiculation type (Fig. 5.3, 5.4). Instead, the pre-existing internal textures favouring the growth and coalescence of the bubbles which is facilitated in these textures exacerbating growth and coalescence and potentially leading to shrivelling is more likely. This can explain why certain regions experience heightened vesiculation compared to other regions, and why these few samples may have shrivelled (Fig. 5.4). As this explanation requires fewer assumptions on the structure and behaviour of materials, and explaining most vesiculation seen within the samples, it is preferred. This latter explanation also explains why large homogenous obsidians exhibit significantly less vesiculation than other regions, irrespective of the initial porosity, due to the distance required to diffuse volatiles across, and other regions having higher meltgas interfacial areas (Navon and Lyakhovsky 1998; Proussevitch and Sahagian 1998; Herbert and Andrew 2002; Polacci et al. 2009; Castro et al. 2012; Wallace et al. 2015).

\subsection{Vesiculation processes in slightly supersaturated melt}

All Cordón Caulle erupted materials have low volatile contents ( $<0.35$ wt. $\% \mathrm{H}_{2} \mathrm{O}$ ), and extremely low variability in volatile contents compared to other erupted volcanic material such as Chaitén (Fig. 5.2, Fig. 2.5). This low volatile content and variability mean that heating of the samples at $900^{\circ} \mathrm{C}$ would only generate minor amounts of volatile supersaturation for all samples (Toramaru 1989; Stevenson et al. 1997; Navon and Lyakhovsky 1998; Polacci et al. 2009). Due to these minor amounts of supersaturation within the obsidians of samples, higher energy vesiculation processes such as nucleation is unexpected, with bubble growth and coalescence being much more likely processes to occur (Toramaru 1995; Proussevitch and Sahagian 1998; Castro et al. 2012).

Porosity data also confirm that bubble growth and coalescence are the likely dominant processes to occur during heating (Table 4.4). Within specific textural domains of the obsidian 104 
regions, an initial porosity of between 0.1-0.2 resulted in a higher degree of secondary vesiculation until the apparent $P_{m}$ was reached (Fig. 5.2). If nucleation was significant, then no significant increase would be observed with respective porosity and instead a more pronounced affect with respect to volatile content of the sample (Fig. 5.2) (Forte and Castro 2019). Specific textures that also had higher initial porosities, such as vesiculated bands within homogenous obsidians, appear to also accommodate most of the samples' overall vesiculation, likely due to exsolving volatiles having exploited these pre-existing bubble structures (Table 4.4).

The XCT scans also demonstrate the dominance of growth and coalescence within all textures apart from one, that being isolated homogenous obsidian (Fig. 5.3 and Fig. 5.4). Apart from isolated homogenous obsidian, these pre-existing bubble structures visibly expand in each texture, and within the sheared texture of vesiculated bands within homogenous obsidians they coalesce along these sheared directions (Fig. 5.3 C). Having growth and coalescence of these pre-existing bubble structure being the main control on the secondary vesiculation of these textures also explains why samples with porosities $<0.025$ show no discernible difference between natural and heated porosities as the initial porosity is so low that little pre-existing melt-gas interfacial area for volatile exsolution exists. Growth and coalescence at lower amounts of supersaturation is expected, as these can occur at saturation of the melt, but they do require pore space to be present prior to heating (Eichelberger et al. 1986; Toramaru 1989; Hurwitz and Navon 1994; Stevenson et al. 1997; Navon and Lyakhovsky 1998).

Isolated homogenous obsidians did not display this same apparent trend with extensive vesiculation, and porosity increase observed once heated (Fig. 5.2 A). Although growth of preexisting structures cannot be ruled out due to the large degree of vesiculation causing difficulties observing natural structures within the heated samples (Fig. 5.5). It is unlikely that growth caused this extent of vesiculation, especially as the initial porosities were all relatively low; however, this cannot be ruled out due to smaller structures within the scanned volumes being unable to be resolved, and some processes overprinted by the extreme vesiculation within this texture (Table 4.4, Fig. 5.5). Although these regions are texturally distinct, there is 105 
no definitive textural structure that explains the foaming of these regions more than others, suggesting that nucleation may play a role, especially with the trends within other samples (Fig. 5.2, Fig. 5.5) (Eichelberger et al. 1986; Toramaru 1989; Hurwitz and Navon 1994; Stevenson et al. 1997; Navon and Lyakhovsky 1998). The smaller size of the objects would result in a lower surface area which could facilitated higher vesiculation compared to other textural regions, and the lack of shearing allows for a higher porosity before the apparent $\mathrm{P}_{\mathrm{m}}$ is reached (Fig. 5.2, Fig. 5.4 B, and Fig. 5.5). Isolated homogenous obsidians could also be easier to foam due to samples being typical surrounded by space allowing for unconstrained growth (Navon and Lyakhovsky 1998; Proussevitch and Sahagian 1998; Martel and Schmidt 2003; Lavallée et al. 2015; Forte and Castro 2019). To fully determine why and how this region foamed, 4D XCT scans of a sub-micron definition would be required to be captured during the heating experiments to see whether there are bubble structures present and how these affected the foaming within isolated homogenous obsidians.

Within all the heated samples, each textural domain experienced differing degrees of secondary vesiculation. Almost all textures appeared to validate the hypothesis that the most dominant process was that of bubble growth and coalescence during the heating of the samples, which is as expected in only slightly supersaturated regions within a melt where significant nucleation of new bubbles is precluded (Navon and Lyakhovsky 1998; Proussevitch and Sahagian 1998; Lavallée et al. 2015). 

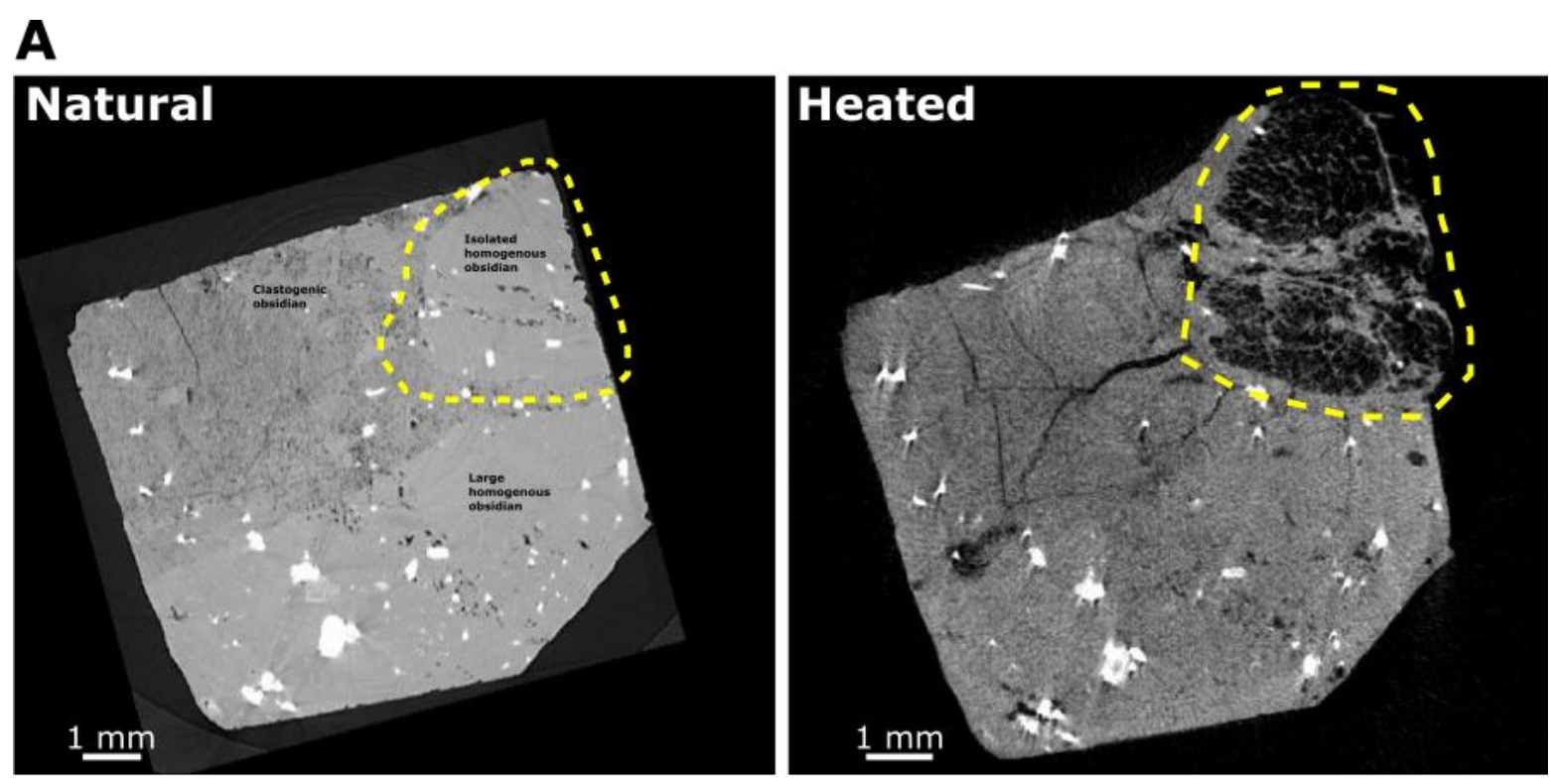

B
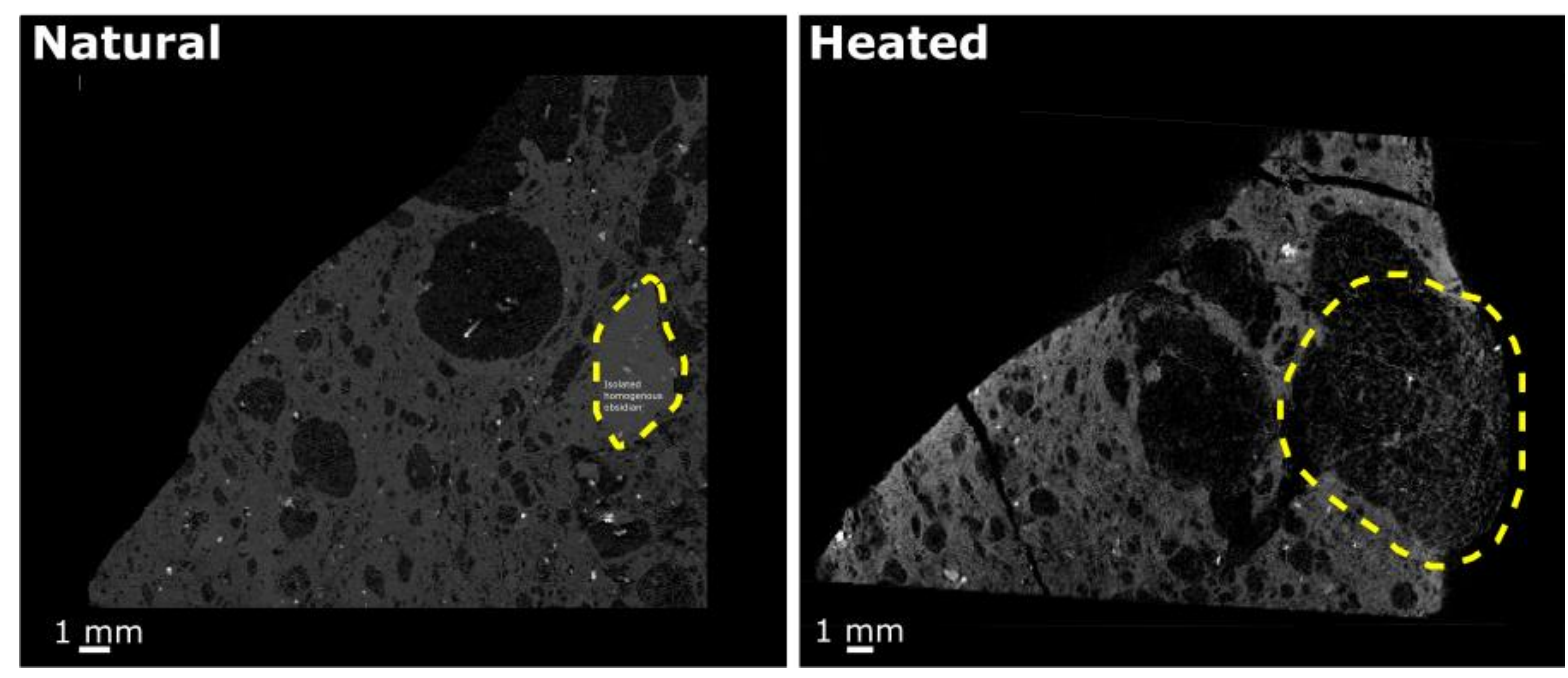

Figure 5.5 Spherical isolated foaming showing the structural reorganisation associated with this foaming shown in XCT slices. $\boldsymbol{A}$ is sample B11_T1_1 with the foamed region in both the natural and heated samples outlined in yellow. B sample B16_AS18_A1 with the foamed region in both the natural and heated samples outlined in yellow. 


\section{Chapter 6. Implications}

The experiments presented above provide clear evidence of secondary vesiculation in response to heating of texturally distinct regions. Clasts with similar textures experienced similar vesiculation across different composite bomb samples, irrespective of water content. With these consistent trends observed in obsidians, and certain obsidians representative of unvesiculated melt (as opposed to clastogenic obsidian), we can infer how the melt may react when subjected to the same conditions, and how this foaming may affect the eruption dynamics (Eichelberger and Westrich 1981; Toramaru 1989; Hurwitz and Navon 1994; Navon and Lyakhovsky 1998).

The first dominant trend observed within all samples and the majority of textures is that vesiculation is dependent on the pre-existing textural structures, with higher initial porosity samples vesiculating to greater extents, with certain textures showing an increase of 2.6 to 6 times the initial porosity when the initial porosity rises past 0.05 (large homogenous obsidians, Section 5.2) before reaching this plateaux value, within these slightly supersaturated samples with low initial volatile contents $\left(<0.35\right.$ wt. $\left.\% \mathrm{H}_{2} \mathrm{O}\right)$. Continued vesiculation of higher porosity regions occurs, even when other localities with pre-existing bubble structures were present (Eichelberger and Westrich 1981; Toramaru 1989; Hurwitz and Navon 1994; Navon and Lyakhovsky 1998; Proussevitch and Sahagian 1998; Herbert and Andrew 2002). The enhanced vesiculation at these larger structures can impact melt vesiculation tremendously, especially when either stalled or variable outgassing is occurring (Cheadle et al. 2004; Castro et al. 2014; Wadsworth et al. 2014; Schipper et al. 2015; Colombier et al. 2020; Schipper et al. 2021). If a region has a higher retained porosity due to prior degassing or ineffective outgassing, this region of the melt will vesiculate more if subsequently heated or decompressed (Fig. 6.1). This is especially true when such regions are only just volatile-supersaturated and will exacerbate pre-existing textures and/or textural heterogeneity. Although for this specific vesiculation to occur, a previously vesiculated melt needs to be either heated or decompressed allowing for volatile supersaturation and the melt must be unable to outgas the exsolved volatiles effectively (Toramaru 1989; Prousevitch et al. 1993; Navon and Lyakhovsky 1998; Castro et al. 2014; Schipper et al. 2015). This 108 
heterogeneity within different regions, potentially exacerbating gas overpressure within the melt, could be one possible explanation for explosive-effusive eruptions happening simultaneously, as occurred at Cordón Caulle (Pistolesi et al. 2015; Schipper et al. 2015; Schipper et al. 2021).

Additionally, a more direct inference from the composite bomb samples and obsidian foaming is the affect that in situ foaming can have on these eruptive dynamics. As shown, these obsidian clasts vesiculate within hand samples (Fig. 2.4) and are present within numerous composite bombs and tuffisites veins within the Cordón Caulle erupted material (Castro et al. 2014; Pistolesi et al. 2015; Schipper et al. 2015; Schipper et al. 2021). These obsidians can be heated by the heat carried during the outgassing of volatile gas and ash through permeable pathways adjacent to obsidian localities, if the temperature rises above $T_{g}$ (Rust and Cashman 2004; Wadsworth et al. 2020; Schipper et al. 2021). However, heating might be more likely to occur through; viscous heating as the melt shears across the conduit tuffisite, frictional heating due to faulting, or magma mixing due to these processes continuing to occur throughout the eruption process (Lavallée et al. 2015; Wallace et al. 2015; Forte and Castro 2019). As seen within heated obsidians in these experiments, not all regions foam uniformly within these samples with certain obsidian textures having different local percolation thresholds and apparent permeability thresholds depending on the texture and shearing direction of the bubble structures, with the latter also affecting the direction of the permeability of the sample (Fig. 5.2).

If these pyroclastic obsidian samples vesiculate within the conduit, the foamed samples can effectively stop outgassing from the conduit if regions that foam expand but remain impermeable (Fig. 6.1 B) (Wadsworth et al. 2014; Wadsworth et al. 2020; Schipper et al. 2021). This will therefore relate to the shearing direction and porosity of the percolation and permeability thresholds relative to the outgassing pathway. Higher porosity values of these will require the obsidian texture to reach a larger size while vesiculating before bubble structures become interconnected and generate permeable pathways to allow outgassing (Rust and Cashman 2004; Shea et al. 2010; Wadsworth et al. 2014; Schipper et al. 2021). Although each texture has an independent porosity where the percolation and permeability 109 
thresholds form, the overall permeability pathway through the obsidian and variable/heterogeneous texture will ultimately control outgassing (Cheadle et al. 2004; Rust and Cashman 2004; Colombier et al. 2020; Wadsworth et al. 2020).

The sample with the lowest porosity before reaching the percolation and permeability thresholds was the clastogenic obsidian, which experienced little to no increase in size throughout heating. However, this textural domain forms by the sintering of ash within an already permeable pathway (Gardner et al. 2017; Gardner et al. 2018; Gardner et al. 2019). This means that although this may develop permeable pathways within this sample at lower porosities, meaning the pathways will form quicker, the permeability of the obsidian is likely less than that of the pre-existing ash, with the resultant outgassing at this region being lower than in their initial, unsintered clastic state. This will produce gas overpressure due to the inability of this texture to remove volatiles to the same extent as the ash could prior to the melt solidifying (Martel and Schmidt 2003; Liu et al. 2005; Edmonds 2008).

There is also the potential of dense, homogenous obsidians being present in the melt within the conduit tuffisites (Schipper et al. 2013; Schipper et al. 2015; Whattam 2019; Schipper et al. 2021). Again, with outgassing pathways present and these obsidians located within or near these, there is the potential certain textures can foam in situ (Wadsworth et al. 2014; Wadsworth et al. 2020; Schipper et al. 2021). If this occurs, then the pre-existing textures become essential. If there is a sheared direction to the bubble formation, irrespective of the heating direction, vesiculation will occur along this prior sheared direction. This will result in the obsidian foaming, the percolation threshold and the permeability threshold forming parallel to the sheared direction, as seen during the experiments (Fig. 5.3). This can aid or hinder outgassing, depending on whether the sheared direction is parallel or perpendicular to the pre-existing permeable pathway within the conduit, with outgassing occurring in the former and gas overpressure being generated in the latter (Liu et al. 2005; Wadsworth et al. 2014; Edmonds and Woods 2018; Forte and Castro 2019; Wadsworth et al. 2020).

The last textural foaming observed during the heating experiments that may occur within the conduit would be dramatic vesiculation of a region with a specific pre-existing texture. This 
vesiculation generates a large increase in the size of the texture and obsidian itself with certain textures showing an increase in porosity 10 s of times the initial volume once heated (Table 4.4, B21_AS23_L2 Isolated homogenous obsidian). Isolated homogenous obsidians, which generated this large vesiculation observed, also have higher percolation and permeability threshold (Cheadle et al. 2004; Wadsworth et al. 2020; Schipper et al. 2021). This requires more space available for the vesiculation to occur to an extent before the permeability threshold is reached. As these textures foam, they generate stress on neighbouring regions, restricting/restructuring the conduits, and potentially affecting the outgassing ability of those regions, until the porosity is sufficiently high to cause this expanding region to become permeable (Cheadle et al. 2004; Wadsworth et al. 2020; Schipper et al. 2021). Also, the stress exerted on surrounding regions during this expansion may cause cracking of the texture if it remains dense, and there is no space to facilitate further expansion (Fig. 5.5 B). These cracks can potentially form a new permeable pathway, aiding in outgassing, and showing the variable nature of these processes. However, if obsidians are situated near an already existing outgassing pathway with space these can vesiculate into, it may generate an impermeable plug from the foaming of the obsidian. This formation of foamed obsidian plugs is one observed within numerous erupted Cordón Caulle composite bombs, with these blocking outgassing pathways, leading to potential gas overpressure and potentially the explosive-effusive eruption dynamics observed (Schipper et al. 2013; Castro et al. 2014; Schipper et al. 2015; Cassidy et al. 2018; Whattam 2019; Wadsworth et al. 2020; Schipper et al. 2021).

Additionally, there is potential for obsidians to undergo sintering, densification, and volatile resorption as they foam (Rust and Cashman 2004; Wadsworth et al. 2014; Gardner et al. 2017; Gardner et al. 2018; Gardner et al. 2019; Schipper et al. 2021). Although this was not fully observed during the heating experiments, examples of outgassing causing a reduction in size were seen, likely the first step to densification. During the heating of the conduit, these obsidians will not be vesiculating in isolation, and pressure from neighbouring particles could be enacting on some of these obsidians (Bagdassarov and Dingwell 1992; Rintoul 2000; Rust and Cashman 2004; Wadsworth et al. 2020; Schipper et al. 2021). Therefore, once the 
obsidian has vesiculated to the permeability threshold it will begin to outgas, and the pressure enacting on the melt will cause a reduction and densification, reducing the permeability. If this occurs for long enough, then this region of the textures will begin to sinter and amalgamate the exsolved volatiles back into the melt, forming a dense obsidian again (Wadsworth et al. 2014; Wadsworth et al. 2020; Schipper et al. 2021).

Within the context of Cordón Caulle, these vesiculation differences can explain most of the processes observed during the volcanic eruption. Along the periphery of the crater and conduit, the melt can outgas volatiles through permeable pathways present within the conduit walls, removing exsolved volatiles and decreasing the overall gas pressure within the melt (Fig. 6.1). The melt will not be able to remove all exsolved volatiles and still erupt, except in an effusive obsidian lava flow, seen during the Cordón Caulle eruption (Parejas et al. 2012; Castro et al. 2013; Schipper et al. 2013; Schipper et al. 2015). However, within the central region of the conduit, volatiles will remain exsolved within the melt and be unable to effectively outgas (Fig. 6.1). Due to the volatiles remaining exsolved in the melt, and the melt being of a slightly supersaturated nature, regions with pre-existing bubbles will experience preferential secondary vesiculation as shown by the experiments. However, due to fractures present within the upper conduit tuffisite region, outgassing through these permeable pathways can occur (Fig. 6.1) (Schipper et al. 2015; Whattam 2019; Wadsworth et al. 2020; Schipper et al. 2021). As the melt outgasses through these fractures, ash will be transported along with gas, with some of this ash being deposited on the periphery of the fracture during ascent, and becoming welded onto the walls of the fractures (Fig. 6.1 A) (Cashman and Sparks 2013; Wadsworth et al. 2014; Gardner et al. 2018). This ash can begin to sinter if heated high enough and/or enough pressure is exerted, lowering the effective outgassing from this fracture and potentially leading to enough gas overpressure for an eruption to occur (Fig. 6.1 A) (Gardner et al. 2017; Gardner et al. 2018; Gardner et al. 2019). However, a more dominant affect I would argue for is the foaming of obsidian pyroclasts within or near the outgassing fractures, with this expansion causing the outgassing pathway to become impermeable (Fig. 6.1 B). Even if these regions foamed to the point of achieving permeability, they could densify or form an impermeable layer on the outside causing no further outgassing and leading to gas 
overpressure (Ericson et al. 1975; Stevenson et al. 1997). To again allow outgassing to occur through these fractures, the blockages must be cleared, likely through an explosive expulsion of the clasts and conduit tuffisite surrounding the region, which will then be followed by passive outgassing (Fig. 6.1 B to A). As the eruption and heating continues, the system will be able to refill these fractures with ash material and peripheral obsidians will continue to foam, leading to blockage and a small explosive phase continuing until the melt is depleted (Eichelberger et al. 1986; Toramaru 1989; Stevenson et al. 1997; Navon and Lyakhovsky 1998; Edmonds 2008; Lavallée et al. 2015; Forte and Castro 2019). This explains the peripheral crater expulsion of an effusive lava flow whereas the central crater experiences phases of explosive volcanism, with this model being supported by heating experiments performed here and erupted product work conducted in previous studies (Castro et al. 2013; Schipper et al. 2013; Castro et al. 2014; Wadsworth et al. 2014; Pistolesi et al. 2015; Schipper et al. 2015; Gardner et al. 2018; Forte and Castro 2019; Paisley et al. 2019; Whattam 2019; Wadsworth et al. 2020).

Although textures themselves do not cause the vesiculation process within silicic melts, they can have a dramatic effect on localized foaming and potential outgassing of volatiles within the conduit, especially in low volatile melts. The internal textures within these melts favour regions of pre-existing bubble structures for foaming with secondary vesiculation from either regions of prior volatile exsolution within the melt or ineffective outgassing. Within obsidians in the upper regions of the conduit, if foamed they have the potential to block outgassing pathways leading to gas overpressure and affecting the eruption dynamics from effusive to explosive, as seen during the 2011-2012 Cordón Caulle volcanic eruption. Although this research was centred around silicic eruptions the same textural processes can be thought to occur within eruptions with lower silicate volumes as well, meaning the pre-existing internal textures can affect the eruptive dynamics within all volcanic eruptions. 


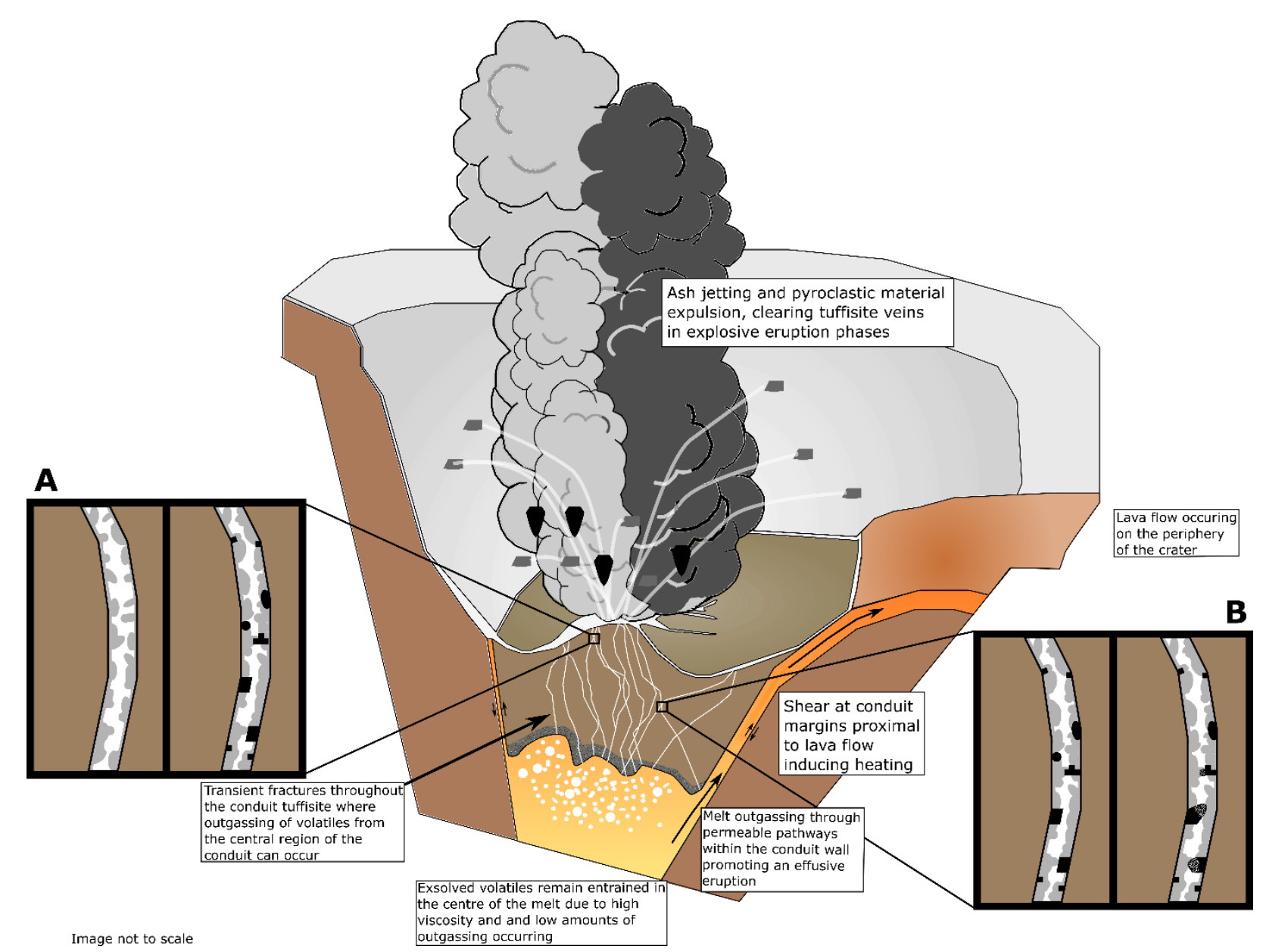

Figure 6.1 Cartoon cross-section from NW to SE of the Cordón Caulle 2011-2012 vent, with proposed effects of textures had on the eruption dynamics observed during the effusive-explosive hybrid eruption (Schipper et al. 2013; Gardner et al. 2017; Whattam 2019). Annotated boxes explain the process occurring at the regions proximal to their location. A zoomed in fracture where outgassing in the central conduit is occurring with the box of on the left demonstration depositing of ash during the outgassing process and the box on the right typifying sintering of this ash to produce clastogenic obsidians within the fractures. $B$ zoomed in fracture where outgassing is occurring within the central conduit with the left box showing obsidians adjacent to the fractured outgassing pathways near the top of the conduit and the right box shows these obsidians foaming, forming effective impermeable plugs resulting in gas overpressure and the explosive eruption illustrated at the top of this image. 


\section{Chapter 7. Conclusions and further work}

Ultimately, this thesis has shown, through the use of heating experiments on composite bomb samples and obsidian pyroclasts, that internal textural variations can affect the secondary vesiculation of silicic melts. Texturally similar regions behaved similarly to each other, with vesiculation styles and resultant porosities of heated textures almost identical to those from different samples. Within the slightly supersaturated melts, secondary vesiculation occurred preferentially within regions of pre-existing bubble structures with a rate change observed within one texture from 2.6 to 6 times the initial porosity once porosity was greater than 0.05 , showing the dominance of bubble growth and coalescence during secondary vesiculation. Different textures did display different maximum porosities which could relate to the development of an apparent permeability threshold with this being affected by; the sheared direction of pre-existing structures, initial volatile content, pre-existing weaknesses within the texture, dispersion of bubbles within the texture, and the porosity at which the percolation threshold was reached. Higher porosities prior to the permeability threshold being reached meant that the sample could vesiculate to a greater extent and reach a larger overall size prior to becoming permeable. These textures can also vesiculate in situ if heated above the glass transition temperature, resulting in the texture expanding but remaining essentially unchanged. If these obsidians are adjacent to a pre-existing outgassing pathway, then this pathway will be blocked by an impermeable foam, building gas overpressure and resulting in a localised explosive eruption. These experiments highlight two main trends: 1) slightly supersaturated melts focus vesiculation in regions with pre-existing bubble structures with the potential to exacerbate gas overpressure within the melt, 2) Obsidians within the upper conduit have the potential to foam in situ, forming impermeable plugs and removing effective outgassing pathways leading to gas overpressure. So, internal textures can impact eruptions drastically causing a switch from effusive venting to localised explosive ejection of volcanic bombs and explain why certain eruptions display hybrid effusive-explosive volcanism.

Future work should determine the volatile content of the samples which had experiments run for less time (P16_B16 and P16_B21) to fully determine whether the foaming behaviour of these samples were controlled by textural processes or volatile processes. Investigation of 116 
more dense obsidians which exhibit shrivelling within the composite bomb samples should be conducted to determine why these structures promoted shrivelled. Although inferences were made that these were likely textural influences, further constraints would be required to verify that this was valid. Samples with higher volatile content also require further examination to see whether there is a textural affect to their foaming or if the volatile content overprints these features once vesiculated and only slightly volatile supersaturated obsidians show this textural trend. Lastly, with the development of 4D XCT scanning and the ability to observe vesiculation changes at submicron levels during heating experiments, there will be opportunities to observe the vesiculation processes occurring in samples, to determine why there is preferential uptake of volatiles into larger structures, and to verify whether nucleation occurs within the isolated homogenous textures. Although this thesis has managed to determine that present internal structures affect and even promote secondary vesiculation, real time vesiculation observations would be able to resolve how these structures change throughout the heating process and why these structures are favoured through observation and potentially validate theories around vesiculation. 


\section{Chapter 8. Bibliography}

Bagdassarov NS, Dingwell DB (1992) A rheological investigation of vesicular rhyolite. Journal of Volcanology and Geothermal Research 50(3):307-322

Baker J, Guillard F, Marks B, Einav I (2018) X-ray rheography uncovers planar granular flows despite non-planar walls. Nature Communications 9(1):1-9

Bryan SE, Peate IU, Peate DW, Self S, Jerram DA, Mawby MR, Marsh JS, Miller JA (2010) The largest volcanic eruptions on Earth. Earth-Science Reviews 102(3):207-229

Cashman KV, Sparks RSJ (2013) How volcanoes work: A 25 year perspective. GSA Bulletin 125(5-6):664690

Cassidy M, Manga M, Cashman K, Bachmann O (2018) Controls on explosive-effusive volcanic eruption styles. Nature Communications 9(1):1-16

Castro J, Schipper C, Mueller S, Militzer A, Amigo A, Parejas C, Jacob D (2013) Storage and eruption of near-liquidus rhyolite magma at Cordón Caulle, Chile. Bulletin of Volcanology 75(4):1-17

Castro JM, Dingwell DB (2009) Rapid ascent of rhyolitic magma at Chaitén volcano, Chile. Nature 461(7265):780

Castro JM, Burgisser A, Schipper Cl, Mancini S (2012) Mechanisms of bubble coalescence in silicic magmas. Bulletin of Volcanology 74(10):2339-2352

Castro JM, Bindeman IN, Tuffen H, lan Schipper C (2014) Explosive origin of silicic lava: Textural and $\delta \mathrm{D}-\mathrm{H} 2 \mathrm{O}$ evidence for pyroclastic degassing during rhyolite effusion. Earth and Planetary Science Letters 405:52-61

Cheadle MJ, Elliott MT, McKenzie D (2004) Percolation threshold and permeability of crystallizing igneous rocks: The importance of textural equilibrium. Geology 32(9):757-760

Cnudde V, Masschaele B, Dierick M, Vlassenbroeck J, Van Hoorebeke L, Jacobs P (2006) Recent progress in X-ray CT as a geosciences tool. Applied Geochemistry 21(5):826-832

Colombier M, Wadsworth FB, Scheu B, Vasseur J, Dobson KJ, Cáceres F, Allabar A, Marone F, Schlepütz CM, Dingwell DB (2020) In situ observation of the percolation threshold in multiphase magma analogues. Bulletin of Volcanology 82(4):32

Desbois G, Urai JL, Kukla PA, Konstanty J, Baerle C (2011) High-resolution 3D fabric and porosity model in a tight gas sandstone reservoir:A new approach to investigate microstructures from $\mathrm{mm}$ - to $\mathrm{nm}$ scale combining argon beam cross-sectioning and SEM imaging. Journal of petroleum science \& engineering 78(2):243-257

Dobson PF, Epstein S, Stolper EM (1989) Hydrogen isotope fractionation between coexisting vapor and silicate glasses and melts at low pressure. Geochimica et cosmochimica acta 53(10):2723-2730

Edmonds M (2008) New geochemical insights into volcanic degassing. Philosophical Transactions of the Royal Society A: Mathematical, Physical and Engineering Sciences 366(1885):4559-4579

Edmonds M, Woods AW (2018) Exsolved volatiles in magma reservoirs. Journal of volcanology and geothermal research 368:13-30

Eichelberger J, Westrich H (1981) Magmatic volatiles in explosive rhyolitic eruptions. Geophysical research letters 8(7):757-760

Eichelberger JC, Westrich HR (1981) Magmatic volatiles in explosive rhyolitic eruptions. Geophysical Research Letters 8(7):757-760

Eichelberger JC, Carrigan CR, Westrich HR, Price RH (1986) Non-explosive silicic volcanism. Nature 323(6089):598-602

Ericson JE, Makishima A, Mackenzie JD, Berger R (1975) Chemical and physical properties of obsidian: a naturally occuring glass. Journal of Non-Crystalline Solids 17(1):129-142

Forte P, Castro JM (2019) H2O-content and temperature limit the explosive potential of rhyolite magma during Plinian eruptions. Earth and Planetary Science Letters 506:157-167 
Gardner JE, Llewellin EW, Watkins JM, Befus KS (2017) Formation of obsidian pyroclasts by sintering of ash particles in the volcanic conduit. Earth and Planetary Science Letters 459:252-263

Gardner JE, Wadsworth FB, Llewellin EW, Watkins JM, Coumans JP (2018) Experimental sintering of ash at conduit conditions and implications for the longevity of tuffisites. Bulletin of Volcanology 80(3):1-14

Gardner JE, Wadsworth FB, Llewellin EW, Watkins JM, Coumans JP (2019) Experimental constraints on the textures and origin of obsidian pyroclasts. Bulletin of Volcanology 81(4):22

Gonnermann HM, Manga M (2003) Explosive volcanism may not be an inevitable consequence of magma fragmentation. Nature 426(6965):432-435

Gonnermann HM (2015) Magma fragmentation. Annual Review of Earth and Planetary Sciences 43:431-458

Heenan TMM, Finegan DP, Tjaden B, Lu X, lacoviello F, Millichamp J, Brett DJL, Shearing PR (2018) 4D nano-tomography of electrochemical energy devices using lab-based X-ray imaging. Nano Energy 47:556-565

Herbert EH, Andrew WW (2002) The role of volatiles in magma chamber dynamics. Nature 420(6915):493-495

Hurwitz S, Navon O (1994) Bubble nucleation in rhyolitic melts: Experiments at high pressure, temperature, and water content. Earth and Planetary Science Letters 122(3):267-280

Jerram DA, Higgins MD (2007) 3D Analysis of Rock Textures: Quantifying Igneous Microstructures. Elements 3(4):239-245

Kendrick JE, Lavallée Y, Varley NR, Wadsworth FB, Lamb OD, Vasseur J (2016) Blowing Off Steam: Tuffisite Formation As a Regulator for Lava Dome Eruptions. Frontiers in Earth Science 4(41):1-15

Kennedy BM, Wadsworth FB, Vasseur J, Schipper Cl, Jellinek AM, von Aulock FW, Hess K-U, Russell JK, Lavallée $Y$, Nichols AR (2016) Surface tension driven processes densify and retain permeability in magma and lava. Earth and Planetary Science Letters 433:116-124

Ketcham RA, Carlson WD (2001) Acquisition, optimization and interpretation of X-ray computed tomographic imagery: applications to the geosciences. Computers \& Geosciences 27(4):381-400

Kress V (1997) Magma mixing as a source for Pinatubo sulphur. Nature 389(6651):591-593

Lavallée Y, Dingwell DB, Johnson JB, Cimarelli C, Hornby AJ, Kendrick JE, von Aulock FW, Kennedy BM, Andrews BJ, Wadsworth FB, Rhodes E, Chinga $G$ (2015) Thermal vesiculation during volcanic eruptions. Nature 528(7583):544-547

Liu Y, Zhang $\mathrm{Y}$, Behrens $\mathrm{H}$ (2005) Solubility of $\mathrm{H} 2 \mathrm{O}$ in rhyolitic melts at low pressures and a new empirical model for mixed $\mathrm{H} 2 \mathrm{O}-\mathrm{CO} 2$ solubility in rhyolitic melts. Journal of Volcanology and Geothermal Research 143(1-3):219-235 
Major JJ, Lara LE (2013) Overview of Chaitén Volcano, Chile, and its 2008-2009 eruption. Andean Geology 40(2):196-215

Martel C, Schmidt BC (2003) Decompression experiments as an insight into ascent rates of silicic magmas. Contributions to Mineralogy and Petrology 144(4):397-415

Maxar Technolgies, Google maps (2021) 2011-2012 Cordón Caulle lava flow. In: Google, Google maps Mees F, Swennen R, Van Geet M, Jacobs P (2003) Applications of X-ray computed tomography in the geosciences. Geological Society, London, Special Publications 215(1):1-6

Navon O, Lyakhovsky V (1998) Vesiculation processes in silicic magmas. Geological Society, London, Special Publications 145(1):27-50

Newhall CG, Self S (1982) The volcanic explosivity index (VEI) an estimate of explosive magnitude for historical volcanism. Journal of Geophysical Research: Oceans 87(C2):1231-1238

Newman S, Stolper EM, Epstein S (1986) Measurement of water in rhyolitic glasses; calibration of an infrared spectroscopic technique. American mineralogist 71(11-12):1527-1541

Newman S, Lowenstern JB (2002) VOLATILECALC: A silicate melt-H2O-CO2 solution model written in Visual Basic for excel. Computers \& Geosciences 28(5):597-604

Nichols AR, Wysoczanski R (2007) Using micro-FTIR spectroscopy to measure volatile contents in small and unexposed inclusions hosted in olivine crystals. Chemical Geology 242(3-4):371-384

Paisley R, Berlo K, Ghaleb B, Tuffen H (2019) Geochemical constraints on the role of tuffisite veins in degassing at the 2008-09 Chaitén and 2011-12 Cordón Caulle rhyolite eruptions. Journal of Volcanology and Geothermal Research 380:80-93

Paisley R, Berlo K, Whattam J, Schipper Cl, Tuffen H (2019) Degassing-induced chemical heterogeneity at the 2011-2012 Cordón Caulle eruption. Volcanica 2(2):211-237

Pallister JS, Hoblitt RP, Reyes AG (1992) A basalt trigger for the 1991 eruptions of Pinatubo volcano? Nature 356(6368):426-428

Pankhurst MJ, Dobson KJ, Morgan DJ, Loughlin SC, Thordarson T, Lee PD, Courtois L (2014) Monitoring the Magmas Fuelling Volcanic Eruptions in Near-real-time Using X-ray Micro-computed Tomography. Journal of Petrology 55(3):671-684

Parejas CS, Lara L, Bertin D, Amigo A, Orozco G (2012) The 2011-2012 eruption of Cordón Caulle volcano (Southern Andes): Evolution, crisis management and current hazards. In: EGU General Assembly Conference Abstracts. p 9382

Pistolesi M, Cioni R, Bonadonna C, Elissondo M, Baumann V, Bertagnini A, Chiari L, Gonzales R, Rosi $M$, Francalanci L (2015) Complex dynamics of small-moderate volcanic events: the example of the 2011 rhyolitic Cordón Caulle eruption, Chile. Bulletin of Volcanology 77(1):3 
Polacci M, Baker DR, Mancini L, Favretto S, Hill RJ (2009) Vesiculation in magmas from Stromboli and implications for normal Strombolian activity and paroxysmal explosions in basaltic systems. Journal of Geophysical Research: Solid Earth 114(B1)

Prousevitch A, Sahagian D, Anderson A (1993) Dynamics of diffusive bubble growth in magmas: Isothermal case. Journal of Geophysical Research: Solid Earth 98(B12):22283-22307

Proussevitch AA, Sahagian DL, Kutolin VA (1993) Stability of foams in silicate melts. Journal of Volcanology and Geothermal Research 59(1-2):161-178

Proussevitch AA, Sahagian DL (1998) Dynamics and energetics of bubble growth in magmas: Analytical formulation and numerical modeling. Journal of Geophysical Research: Solid Earth 103(B8):1822318251

Rintoul MD (2000) Precise determination of the void percolation threshold for two distributions of overlapping spheres. Physical Review E 62(1):68-72

Rust AC, Cashman KV (2004) Permeability of vesicular silicic magma: inertial and hysteresis effects. Earth and Planetary Science Letters 228(1):93-107

Sánchez MC, Sarrionandia F, Arostegui J, Larrondo E, Ibarguchi JIG (2009) Development of spheroidal composite bombs by welding of juvenile spinning and isotropic droplets inside a mafic eruption column. Journal of Volcanology and Geothermal Research 186(3):265-279

Saubin E, Tuffen H, Gurioli L, Owen J, Castro JM, Berlo K, McGowan EM, Schipper Cl, Wehbe K (2016) Conduit Dynamics in Transitional Rhyolitic Activity Recorded by Tuffisite Vein Textures from the 20082009 Chaitén Eruption. Frontiers in Earth Science 4:59-75

Schipper $\mathrm{Cl}$, Castro JM, Tuffen H, James MR, How P (2013) Shallow vent architecture during hybrid explosive-effusive activity at Cordón Caulle (Chile, 2011-12): Evidence from direct observations and pyroclast textures. Journal of Volcanology and Geothermal Research 262(C):25-37

Schipper Cl, Castro JM, Tuffen H, Wadsworth FB, Chappell D, Pantoja AE, Simpson MP, Le Ru EC (2015) Cristobalite in the 2011-2012 Cordón Caulle eruption (Chile). Bulletin of Volcanology 77(5):1-19

Schipper Cl, White JDL (2016) Magma-slurry interaction in Surtseyan eruptions. Geology 44(3):195198

Schipper Cl, Castro JM, Kennedy BM, Christenson BW, Aiuppa A, Alloway B, Forte P, Seropian G, Tuffen $\mathrm{H}$ (2019) Halogen (Cl, F) release during explosive, effusive, and intrusive phases of the 2011 rhyolitic eruption at Cordón Caulle volcano (Chile). Volcanica 2(1):73-90

Schipper Cl, Castro JM, Kennedy BM, Tuffen H, Whattam J, Wadsworth FB, Paisley R, Fitzgerald RH, Rhodes E, Schaefer LN, Ashwell PA, Forte P, Seropian G, Alloway BV (2021) Silicic conduits as supersized tuffisites: Clastogenic influences on shifting eruption styles at Cordón Caulle volcano (Chile). Bulletin of Volcanology 83(2):11 
Shea T, Houghton BF, Gurioli L, Cashman KV, Hammer JE, Hobden BJ (2010) Textural studies of vesicles in volcanic rocks: An integrated methodology. Journal of Volcanology and Geothermal Research 190(3):271-289

Sparks R (2003) Dynamics of magma degassing. Geological Society, London, Special Publications 213(1):5-22

Stevenson RJ, Bagdassarov NS, Romano C (1997) Vesiculation processes in a water-rich calc-alkaline obsidian. Earth and Planetary Science Letters 146(3):555-571

Toramaru A (1989) Vesiculation process and bubble size distributions in ascending magmas with constant velocities. Journal of Geophysical Research: Solid Earth 94(B12):17523-17542

Toramaru A (1995) Numerical study of nucleation and growth of bubbles in viscous magmas. Journal of Geophysical Research: Solid Earth 100(B2):1913-1931

Tuffen H, James MR, Castro JM, Schipper Cl (2013) Exceptional mobility of an advancing rhyolitic obsidian flow at Cordón Caulle volcano in Chile. Nature communications 4:2709

Ulke AG, Brizuela MMT, Raga GB, Baumgardner D (2016) Aerosol properties and meteorological conditions in the city of Buenos Aires, Argentina, during the resuspension of volcanic ash from the Puyehue-Cordon Caulle eruption. Natural hazards and earth system sciences 16(9):2159-2175

von Aulock FW, Kennedy BM, Schipper Cl, Castro J, Martin D, Oze C, Watkins JM, Wallace PJ, Puskar L, Bégué $F$ (2014) Advances in Fourier transform infrared spectroscopy of natural glasses: From sample preparation to data analysis. Lithos 206:52-64

Wadsworth FB, Vasseur J, von Aulock FW, Hess K-U, Scheu B, Lavallée Y, Dingwell DB (2014) Nonisothermal viscous sintering of volcanic ash. Journal of Geophysical Research: Solid Earth 119(12):8792-8804

Wadsworth FB, Vasseur J, Llewellin EW, Schauroth J, Dobson KJ, Scheu B, Dingwell DB (2016) Sintering of viscous droplets under surface tension. Proceedings of the Royal Society A: Mathematical, Physical and Engineering Sciences 472(2188):20150780

Wadsworth FB, Vasseur J, Scheu B, Kendrick JE, Lavallée Y, Dingwell DB (2016) Universal scaling of fluid permeability during volcanic welding and sediment diagenesis. Geology 44(3):219-222

Wadsworth FB, Llewellin EW, Vasseur J, Gardner JE, Tuffen H (2020) Explosive-effusive volcanic eruption transitions caused by sintering. Science Advances 6(39):7940-7963

Wadsworth FB, Llewellin EW, Vasseur J, Gardner JE, Tuffen H (2020) Explosive-effusive volcanic eruption transitions caused by sintering. Science Advances 6(39):eaba7940

Wallace PJ (2005) Volatiles in subduction zone magmas: concentrations and fluxes based on melt inclusion and volcanic gas data. Journal of volcanology and Geothermal Research 140(1-3):217-240

Wallace PJ, Plank T, Edmonds M, Hauri EH (2015) Chapter 7 - Volatiles in Magmas. In: Sigurdsson H (ed) The Encyclopedia of Volcanoes (Second Edition). Academic Press, Amsterdam, pp 163-183

122 
Whattam J (2019) Under the surface: Textural analysis of complex, multi-component Vulcanian bombs produced during effusive-explosive phase of the 2011-2012 Cordón Caulle eruption, Chile. In: Unpublished MSc Victoria University of Wellington,

Zandomeneghi D, Voltolini M, Mancini L, Brun F, Dreossi D, Polacci M (2010) Quantitative analysis of $X$-ray microtomography images of geomaterials: Application to volcanic rocks. Geosphere 6(6):793804

Zhang Y, Ni H, Chen Y (2010) Diffusion Data in Silicate Melts. Reviews in Mineralogy and Geochemistry 72(1):311-408 


\section{Appendix 1: All Data Collected During Heating Experiments of Samples}

Table begins on next page to allow for all data to be displayed effectively within. 


\begin{tabular}{|c|c|c|c|c|c|c|c|c|c|c|c|c|c|c|c|}
\hline Sample & Lat/Long & $\begin{array}{l}\text { Composite } \\
\text { bomb type }\end{array}$ & $\begin{array}{l}\text { Description } \\
\text { of sample }\end{array}$ & Subsample & $\begin{array}{l}\text { Thin } \\
\text { section } \\
\text { created for } \\
\text { subsample } \\
\text { (X) }\end{array}$ & $\begin{array}{l}\text { Cuts to } \\
\text { subsamples }\end{array}$ & $\begin{array}{l}\text { Experiment } \\
\text { number }\end{array}$ & \begin{tabular}{|l|} 
Date \\
(dd/mm/yy)
\end{tabular} & $\begin{array}{l}\text { Temperature } \\
\left({ }^{\circ} \mathrm{C}\right)\end{array}$ & $\begin{array}{l}\text { Time } \\
\text { heated }\end{array}$ & $\begin{array}{l}\text { Photographs } \\
\text { of } \\
\text { experiments }\end{array}$ & $\begin{array}{l}\mathrm{CT} \\
\text { scans } \\
\text { Natural } \\
(\mathrm{X})\end{array}$ & $\begin{array}{l}\text { CT } \\
\text { scans } \\
\text { Heated } \\
(\mathrm{X})\end{array}$ & $\begin{array}{lr}\text { Size } & \text { natural } \\
\text { sample } & \left(h^{*} w^{*} d,\right. \\
m m) & \end{array}$ & $\begin{array}{lr}\text { Size } & \text { heated } \\
\text { sample } & \left(h^{*} w^{*} d,\right. \\
m m) & \end{array}$ \\
\hline \multirow[t]{7}{*}{ Unknown } & \multirow[t]{7}{*}{$?$} & \multirow{7}{*}{$\begin{array}{l}\text { Matrix } \\
\text { dominated }\end{array}$} & \multirow{7}{*}{$\begin{array}{l}\text { Fine matrix } \\
\text { within the } \\
\text { sample with } \\
\text { obsidian } \\
\text { veins } \\
\text { running } \\
\text { through it. }\end{array}$} & \multirow[t]{7}{*}{ Extra AS03 } & & $1 \mathrm{~A}$ & 003 & 09/07/20 & $860 \pm 5^{\circ} \mathrm{C}$ & $10 \mathrm{mins}$ & $x$ & & & $23 * 10 * 9$ & --- \\
\hline & & & & & & $2 B$ & 004 & $09 / 07 / 20$ & $920 \pm 10^{\circ} \mathrm{C}$ & $10 \mathrm{mins}$ & $x$ & & & --- & --- \\
\hline & & & & & & $2 \mathrm{C}$ & 010 & $09 / 07 / 20$ & $894 \pm 2^{\circ} \mathrm{C}$ & $10 \mathrm{mins}$ & $x$ & & & --- & --- \\
\hline & & & & & & $\overline{M L 2}$ & 009 & $09 / 07 / 20$ & $920 \pm 10^{\circ} \mathrm{C}$ & $10 \mathrm{mins}$ & $x$ & & & --- & --- \\
\hline & & & & & & ML3 & 008 & $09 / 07 / 20$ & $920 \pm 10^{\circ} \mathrm{C}$ & $\begin{array}{l}2 \text { mins } \\
35 \text { secs }\end{array}$ & $x$ & & & --- & --- \\
\hline & & & & & & MU1 & 012 & $09 / 07 / 20$ & $830 \pm 10^{\circ} \mathrm{C}$ & $15 \mathrm{mins}$ & $x$ & & & --- & --- \\
\hline & & & & & & Broken & 013 & $09 / 07 / 20$ & $822 \pm 2^{\circ} \mathrm{C}$ & $15 \mathrm{mins}$ & $x$ & & & --- & --- \\
\hline \multirow[t]{8}{*}{ P16_B07 } & \multirow{8}{*}{$\begin{array}{l}40.512 \mathrm{~S} \\
72.156 \\
W\end{array}$} & \multirow{8}{*}{$\begin{array}{l}\text { Pumice } \\
\text { dominated }\end{array}$} & \multirow{8}{*}{$\begin{array}{l}\text { Low-density } \\
\text { pumice } \\
\text { clasts of } \\
\text { variable size } \\
\text { wielded } \\
\text { together } \\
\text { with a fine } \\
\text { pink matrix } \\
\text { with } \\
\text { sporadic } \\
\text { obsidian } \\
\text { clasts to } \\
\sim 5 \mathrm{~cm} . \quad \text { a }\end{array}$} & \multirow[t]{8}{*}{ B07_AS19 } & \multirow[t]{8}{*}{$x$} & $1 \mathrm{~A}$ & 040 & $16 / 07 / 20$ & $891 \pm 3^{\circ} \mathrm{C}$ & $15 \mathrm{mins}$ & $\mathrm{x}$ & $\mathrm{x}$ & & $26.8 * 19.52^{*---}$ & $26.0 * 16.1 * 11.3$ \\
\hline & & & & & & $1 \mathrm{~B}$ & 041 & $16 / 07 / 20$ & $889 \pm 4^{\circ} \mathrm{C}$ & $15 \mathrm{mins}$ & $x$ & $x$ & $x$ & $26.8^{*} 15.9^{*} 11.9$ & $25.8 * 18.9 * 12.0$ \\
\hline & & & & & & $2 \mathrm{~A}$ & 039 & $16 / 07 / 20$ & $880 \pm 5^{\circ} \mathrm{C}$ & $15 \operatorname{mins}$ & $\mathrm{x}$ & $x$ & & $27.9 * 16.1 * 11.3$ & $26.8 * 16.0 * 11.7$ \\
\hline & & & & & & $2 B$ & 042 & $16 / 07 / 20$ & $900 \pm 10^{\circ} \mathrm{C}$ & $15 \mathrm{mins}$ & $\mathrm{x}$ & $\mathrm{x}$ & & $28.14 * 15.9 * 11.9$ & $27.4 * 15.4 * 11.7$ \\
\hline & & & & & & $3 \mathrm{~A}$ & 038 & $16 / 07 / 20$ & $889 \pm 5^{\circ} \mathrm{C}$ & $15 \mathrm{mins}$ & $\mathrm{x}$ & $\mathrm{x}$ & & $26.9 * 14.9 * 12.2$ & $25.6 * 15.8 * 12.2$ \\
\hline & & & & & & $3 B$ & 043 & $16 / 07 / 20$ & $880 \pm 3^{\circ} \mathrm{C}$ & $15 \mathrm{mins}$ & $x$ & $x$ & & $29.6 * 14.8 * 11.2$ & $28.2 * 16.2 * 11.3$ \\
\hline & & & & & & $4 \mathrm{~A}$ & 037 & $16 / 07 / 20$ & $878 \pm 5^{\circ} \mathrm{C}$ & $15 \mathrm{mins}$ & $\mathrm{x}$ & $\mathrm{x}$ & & $31.5 * 25.2 * 13.7$ & $31.4 * 25.7 * 13.6$ \\
\hline & & & & & & 4B & 044 & $17 / 07 / 20$ & $875 \pm 8^{\circ} \mathrm{C}$ & $15 \mathrm{mins}$ & $x$ & $x$ & & $30.9 * 27.2 * 10.3$ & $31.2 * 27.5 * 13.6$ \\
\hline \multirow[t]{10}{*}{ P16_B09 } & \multirow{10}{*}{$\begin{array}{l}40.511 \mathrm{~S} \\
72.153 \\
W\end{array}$} & \multirow{10}{*}{$\begin{array}{l}\text { Dense } \\
\text { obsidian } \\
\text { dominated }\end{array}$} & \multirow{10}{*}{$\begin{array}{l}\text { High-density } \\
\text { obsidian } \\
\text { bomb, with } \\
\text { an } \\
\text { occasional } \\
\text { low-density } \\
\text { orange } \\
\text { matrix } \\
\text { separating } \\
\text { obsidians. }\end{array}$} & \multirow[t]{7}{*}{ B09_AS06 } & \multirow[t]{7}{*}{$x$} & A1 & 007 & $09 / 07 / 20$ & Unrecorded & $10 \mathrm{mins}$ & & $\mathrm{x}$ & & $19.5 * 2.25 * 29.5$ & --- \\
\hline & & & & & & $\mathrm{A} 2$ & 034 & $16 / 07 / 20$ & $891 \pm 3^{\circ} \mathrm{C}$ & $15 \mathrm{mins}$ & $x$ & $x$ & & $17.4 * 14.2 * 9.1$ & $19.6 * 12.6 * 9.7$ \\
\hline & & & & & & B1 & 033 & $16 / 07 / 20$ & $886 \pm 3^{\circ} \mathrm{C}$ & $15 \mathrm{mins}$ & & $x$ & & $19.4 * 10.9 * 9.9$ & $20.8^{*} 11.7^{*} 10.6$ \\
\hline & & & & & & $\mathrm{B} 2$ & 032 & $16 / 07 / 20$ & $900 \pm 10^{\circ} \mathrm{C}$ & $15 \mathrm{mins}$ & $\mathrm{x}$ & $x$ & & $19.4^{*} 11.0^{*} 8.1$ & $20.7 * 12.7 * 9.4$ \\
\hline & & & & & & B3 & 021 & $14 / 07 / 20$ & $888 \pm 3^{\circ} \mathrm{C}$ & $15 \mathrm{mins}$ & $x$ & $x$ & & $19.4 * 9.1 * 11.0$ & $19.6 * 9.6 * 11.2$ \\
\hline & & & & & & $\mathrm{C} 1$ & 018 & $13 / 07 / 20$ & $873 \pm 3^{\circ} \mathrm{C}$ & $\begin{array}{l}15 \text { mins } \\
20 \text { secs }\end{array}$ & $x$ & $x$ & & $19.8 * 9.1 * 14.3$ & $20.3^{*} 9.4^{*} 15.1$ \\
\hline & & & & & & $\mathrm{C} 2$ & 019 & $13 / 07 / 20$ & $874 \pm 3^{\circ} \mathrm{C}$ & $15 \mathrm{mins}$ & $x$ & $x$ & & $20.0 * 15.7 * 19.5$ & $20.8 * 16.0 * 16.2$ \\
\hline & & & & B09_AS07 & $x$ & $\mathrm{M} 2 \mathrm{~A}$ & 014 & $13 / 07 / 20$ & $900 \pm 10^{\circ} \mathrm{C}$ & $10 \mathrm{mins}$ & $x$ & $x$ & & $21 * 17 * 9$ & $22 * 17 * 1$ \\
\hline & & & & \multirow[t]{2}{*}{ B09_T5 } & & 1 & 058 & $17 / 07 / 20$ & $886 \pm 5^{\circ} \mathrm{C}$ & $\begin{array}{l}15 \\
\text { minutes }\end{array}$ & $x$ & $x$ & & $11.7 * 8.4 * 8.5$ & $12.9 * 9.4 * 9.3$ \\
\hline & & & & & & 3 & 059 & $17 / 07 / 20$ & $880 \pm 5^{\circ} \mathrm{C}$ & $\begin{array}{l}15 \\
\text { minutes }\end{array}$ & & $\mathrm{x}$ & & $6.7 * 8.7 * 8.7$ & $9.3 * 9.6 * 9.4$ \\
\hline P16_B10 & $40.512 \mathrm{~S}$ & & & B10_AS01 & $x$ & A1 & 026 & $15 / 07 / 20$ & $876 \pm 3^{\circ} \mathrm{C}$ & $15 \mathrm{mins}$ & $x$ & $x$ & & $21.7^{*} 14.2^{*} 6.6$ & $22.0 * 14.6 * 7.1$ \\
\hline
\end{tabular}




\begin{tabular}{|c|c|c|c|c|c|c|c|c|c|c|c|c|c|c|c|}
\hline & \multirow{4}{*}{$\begin{array}{l}72.150 \\
W\end{array}$} & \multirow{4}{*}{$\begin{array}{l}\text { Dense } \\
\text { obsidian } \\
\text { dominated }\end{array}$} & \multirow{4}{*}{$\begin{array}{l}\text { High-density } \\
\text { obsidian } \\
\text { dominated } \\
\text { bomb with } \\
\text { lithics } \\
\text { present } \\
\text { throughout } \\
\text { but no clear } \\
\text { matrix. }\end{array}$} & & & B1 & 022 & $14 / 07 / 20$ & $886 \pm 4^{\circ} \mathrm{C}$ & 15 mins & $x$ & $\mathrm{x}$ & $\mathrm{x}$ & $21.8^{*} 12.6 * 6.6$ & $23.3^{*} 13.7^{*} 7.5$ \\
\hline & & & & & & B2 & 027 & $16 / 07 / 20$ & $885 \pm 3^{\circ} \mathrm{C}$ & $15 \mathrm{mins}$ & $x$ & $x$ & & --- & $22.5 * 8.5 * 8.6$ \\
\hline & & & & \multirow[t]{2}{*}{ B10_T5 } & & $1 / 2 \_1$ & 064 & $17 / 07 / 20$ & $880 \pm 5^{\circ} \mathrm{C}$ & $\begin{array}{l}10 \\
\text { minutes }\end{array}$ & $x$ & $x$ & & $21.6 * 9.0 * 8.5$ & $22.2 * 9.5 * 9.2$ \\
\hline & & & & & & $1 / 2{ }^{2}$ & 063 & $17 / 07 / 20$ & $863 \pm 10^{\circ} \mathrm{C}$ & $\begin{array}{l}10 \\
\text { minutes }\end{array}$ & $x$ & $x$ & & --- & $22.9 * 10.5 * 10.2$ \\
\hline P16_B11 & $\begin{array}{l}40.512 \mathrm{~S} \\
72.150 \\
W\end{array}$ & $\begin{array}{l}\text { Dense } \\
\text { obsidian } \\
\text { dominated }\end{array}$ & $\begin{array}{l}\text { High-density } \\
\text { obsidian } \\
\text { composite } \\
\text { bomb with } \\
\text { banded } \\
\text { internal } \\
\text { textures. }\end{array}$ & B11_T1_1 & & 1 & 057 & $17 / 07 / 20$ & $885 \pm 6^{\circ} \mathrm{C}$ & $\begin{array}{l}15 \\
\text { minutes }\end{array}$ & $x$ & $x$ & $x$ & $16.2 * 9.8 * 8.1$ & $16.2 * 10.0 * 8.0$ \\
\hline \multirow[t]{3}{*}{ P16_B13 } & \multirow{3}{*}{$\begin{array}{l}40.512 \mathrm{~S} \\
72.149 \\
W\end{array}$} & \multirow{3}{*}{$\begin{array}{l}\text { Dense } \\
\text { obsidian } \\
\text { dominated }\end{array}$} & \multirow{3}{*}{$\begin{array}{l}\text { High-density } \\
\text { obsidian } \\
\text { composite } \\
\text { bomb with } \\
\text { lava like } \\
\text { lithics. }\end{array}$} & \multirow[t]{2}{*}{ B13_AS02 } & \multirow[t]{2}{*}{$x$} & 1 & 066 & $17 / 07 / 20$ & $876 \pm 4^{\circ} \mathrm{C}$ & $\begin{array}{l}15 \\
\text { minutes }\end{array}$ & $x$ & $x$ & & $22.9 * 13.8 * 9.05$ & $23.8 * 13.6 * 9.03$ \\
\hline & & & & & & 2 & 067 & $17 / 07 / 20$ & $880 \pm 4^{\circ} \mathrm{C}$ & $\begin{array}{l}15 \\
\text { minutes }\end{array}$ & $x$ & $x$ & & $18.2 * 8.8 * 8.0$ & $18.09 * 8.8 * 7.9$ \\
\hline & & & & B13_T5 & & $1 / 2$ & 065 & $17 / 07 / 20$ & $880 \pm 4^{\circ} \mathrm{C}$ & $\begin{array}{l}10 \\
\text { minutes }\end{array}$ & $x$ & $x$ & & $21.8 * 9.6 * 9.1$ & $17.2 * 10.2 * 9.4$ \\
\hline P16_B14 & $\begin{array}{l}0.512 \mathrm{~S} \\
72.149 \\
W\end{array}$ & $\begin{array}{l}\text { Dense } \\
\text { obsidian } \\
\text { dominated }\end{array}$ & $\begin{array}{l}\text { High-density } \\
\text { obsidian } \\
\text { composite } \\
\text { bomb }\end{array}$ & B14_AS17 & $x$ & 1 & 001 & 09/07/20 & $840 \pm 3^{\circ} \mathrm{C}$ & $20 \mathrm{mins}$ & $x$ & & & $12 * 12.5 * 12$ & --- \\
\hline \multirow[t]{6}{*}{ P16_B16 } & \multirow{6}{*}{$\begin{array}{l}40.510 \mathrm{~S} \\
72.155 \\
W\end{array}$} & \multirow[t]{6}{*}{$\begin{array}{l}\text { Matrix } \\
\text { dominated }\end{array}$} & \multirow{6}{*}{$\begin{array}{l}\text { Matrix } \\
\text { dominated } \\
\text { with } \\
\text { numerous } \\
\text { in-situ } \\
\text { foaming as } \\
\text { well as } \\
\text { obsidian, } \\
\text { lithic and } \\
\text { pumice } \\
\text { clasts within }\end{array}$} & \multirow[t]{6}{*}{ B16_AS18 } & \multirow[t]{6}{*}{$x$} & A1 & 051 & $17 / 07 / 20$ & $879 \pm 4^{\circ} \mathrm{C}$ & $\begin{array}{l}10 \\
\text { minutes }\end{array}$ & $x$ & $x$ & & $22.4 * 20.0 * 17.2$ & $25.3^{*} 23.8^{*} 20.8$ \\
\hline & & & & & & $\mathrm{A} 2$ & 053 & $17 / 07 / 20$ & $888 \pm 4^{\circ} \mathrm{C}$ & $\begin{array}{l}3 \\
\text { minutes }\end{array}$ & $x$ & $x$ & & $25.7^{*} 17.3^{*} 14.8$ & $26.7 * 19.9 * 17.2$ \\
\hline & & & & & & B1 & 054 & $17 / 07 / 20$ & $876 \pm 7^{\circ} \mathrm{C}$ & $\begin{array}{l}2 \\
\text { minutes }\end{array}$ & $x$ & $x$ & & $19.2 * 18.4 * 17.7$ & $19.4 * 18.7 * 17.0$ \\
\hline & & & & & & B2 & 052 & $17 / 07 / 20$ & $890 \pm 10^{\circ} \mathrm{C}$ & $\begin{array}{l}3 \\
\text { minutes }\end{array}$ & $x$ & $\bar{x}$ & & $24.7 * 18.0 * 13.8$ & $26.0 * 17.4 * 14.3$ \\
\hline & & & & & & B3 & 055 & $17 / 07 / 20$ & $900 \pm 10^{\circ} \mathrm{C}$ & $\begin{array}{l}10 \\
\text { minutes }\end{array}$ & $x$ & $x$ & & $24.3 * 18.1 * 9.1$ & $25.1 * 19.5 * 9.7$ \\
\hline & & & & & & B4 & 056 & $17 / 07 / 20$ & $860 \pm 8^{\circ} \mathrm{C}$ & $\begin{array}{l}2 \\
\text { minutes }\end{array}$ & $x$ & $x$ & & $23.9 * 17.9 * 14.5$ & $234.2^{*} 17.8^{*} 15.1$ \\
\hline \multirow[t]{2}{*}{ P16_B17 } & \multirow{2}{*}{$\begin{array}{l}40.519 \mathrm{~S} \\
72.166 \\
\mathrm{~W}\end{array}$} & \multirow[t]{2}{*}{$\begin{array}{l}\text { Matrix } \\
\text { dominated }\end{array}$} & \multirow{2}{*}{$\begin{array}{l}\text { Matrix } \\
\text { dominated } \\
\text { composite } \\
\text { that does } \\
\text { contain } \\
\text { some glassy } \\
\text { regions }\end{array}$} & \multirow[t]{2}{*}{ B17_AS10 } & \multirow[t]{2}{*}{$x$} & 1 & 002 & 09/07/20 & $900 \pm 10^{\circ} \mathrm{C}$ & $15 \mathrm{mins}$ & $x$ & $x$ & & --- & --- \\
\hline & & & & & & 0 & 035 & $16 / 07 / 20$ & $886 \pm 3^{\circ} \mathrm{C}$ & 3 mins & & $x$ & & --- & --- \\
\hline \multirow[t]{2}{*}{ P16_B18 } & \multirow{2}{*}{$\begin{array}{l}40.519 \mathrm{~S} \\
72.166 \\
\mathrm{~W}\end{array}$} & \multirow[t]{2}{*}{$\begin{array}{l}\text { Obsidian } \\
\text { dominated }\end{array}$} & \multirow{2}{*}{$\begin{array}{l}\text { High-density } \\
\text { obsidian } \\
\text { composite } \\
\text { bomb with }\end{array}$} & B18_T2 & & $\mathrm{T} 2$ & 062 & $17 / 07 / 20$ & $878 \pm 3^{\circ} \mathrm{C}$ & $\begin{array}{l}10 \\
\text { minutes }\end{array}$ & $x$ & $x$ & $x$ & $16.3 * 8.7 * 8.0$ & $17.4 * 9.0 * 8.4$ \\
\hline & & & & B18_T5 & & 1 & 060 & 17/07/20 & $879 \pm 4^{\circ} \mathrm{C}$ & $\begin{array}{l}15 \\
\text { minutes }\end{array}$ & $x$ & $\mathrm{x}$ & $x$ & $20.1^{*} 9.4^{*} 8.0$ & $22.2 * 9.9 * 9.4$ \\
\hline
\end{tabular}




\section{$\stackrel{\sim}{N}$}

\begin{tabular}{|c|c|c|c|c|c|c|c|c|c|c|c|c|c|c|c|}
\hline & & & $\begin{array}{l}\text { thin matrix } \\
\text { within } \\
\text { obsidians }\end{array}$ & & & 2 & 061 & $17 / 07 / 20$ & $880 \pm 5^{\circ} \mathrm{C}$ & $\begin{array}{l}15 \\
\text { minutes }\end{array}$ & $x$ & $x$ & $x$ & $19.5 * 9.3 * 8.6$ & $21.8 * 12.5 * 11.5$ \\
\hline \multirow[t]{4}{*}{ P16_B20 } & \multirow{4}{*}{$\begin{array}{l}40.519 \mathrm{~S} \\
72.166 \\
W\end{array}$} & \multirow{4}{*}{$\begin{array}{l}\text { Matrix } \\
\text { dominated }\end{array}$} & \multirow{4}{*}{$\begin{array}{l}\text { Variable } \\
\text { sizes of } \\
\text { clasts. } \\
\text { Abundance } \\
\text { pumices> } \\
\text { obsidians > } \\
\text { lithics. Fine } \\
\text { pink matrix. }\end{array}$} & \multirow[t]{4}{*}{ B20_AS04 } & \multirow[t]{4}{*}{$\mathrm{x}$} & 1 & 015 & $13 / 07 / 20$ & $870 \pm 5^{\circ} \mathrm{C}$ & $10 \mathrm{mins}$ & $x$ & & & $28.3 * 9.8 * 11.8$ & $28.7 * 9.9 * 11.8$ \\
\hline & & & & & & 2 & 036 & $16 / 07 / 20$ & $890 \pm 3^{\circ} \mathrm{C}$ & $15 \mathrm{mins}$ & $x$ & $x$ & & $23.5 * 10.6 * 9.2$ & $23.2 * 10.9 * 9.5$ \\
\hline & & & & & & 3 & 017 & $13 / 07 / 20$ & $880 \pm 5^{\circ} \mathrm{C}$ & $10 \mathrm{mins}$ & $x$ & $x$ & & $21.4 * 11.2 * 13.0$ & $21.5 * 11.6 * 13.0$ \\
\hline & & & & & & 4 & 020 & $13 / 07 / 20$ & $867 \pm 4^{\circ} \mathrm{C}$ & 15 mins & $x$ & $x$ & & $24.0 * 13.9 * 12.5$ & $24.0 * 14.0 * 12.8$ \\
\hline \multirow[t]{16}{*}{ P16_B21 } & \multirow{16}{*}{$\begin{array}{l}40.520 \mathrm{~S} \\
72.166 \\
W\end{array}$} & \multirow{16}{*}{$\begin{array}{l}\text { Pumice } \\
\text { dominated }\end{array}$} & \multirow{16}{*}{$\begin{array}{l}\text { A composite } \\
\text { bomb } \\
\text { consisting of } \\
\text { banded } \\
\text { dense } \\
\text { obsidian and } \\
\text { foam (shown } \\
\text { as pumice). }\end{array}$} & \multirow[t]{8}{*}{ B21_AS16 } & & A & 025 & $15 / 07 / 20$ & $890 \pm 3^{\circ} \mathrm{C}$ & 15 mins & $x$ & $x$ & & $24.7 * 14.7 * 9.0$ & $54.8 * 14.7 * 8.9$ \\
\hline & & & & & & B1 & 048 & $17 / 07 / 20$ & $900 \pm 10^{\circ} \mathrm{C}$ & $\begin{array}{l}1 \\
\text { minute } \\
30 \\
\text { seconds }\end{array}$ & $x$ & $x$ & & $20.2 * 19.2^{*} 13.4$ & $28.1 * 25.0 * 20.1$ \\
\hline & & & & & & B2 & 049 & $17 / 07 / 20$ & $880 \pm 8^{\circ} \mathrm{C}$ & $\begin{array}{l}1 \\
\text { minute } \\
55 \\
\text { seconds }\end{array}$ & $x$ & $x$ & & ---- & $23.5 * 21.7 * 13.3$ \\
\hline & & & & & & $\mathrm{C} 1$ & 005 & $09 / 07 / 20$ & $900 \pm 4^{\circ} \mathrm{C}$ & 7 mins & $x$ & $x$ & & --- & --- \\
\hline & & & & & & C2 & 006 & $09 / 07 / 20$ & $900 \pm 4^{\circ} \mathrm{C}$ & $\begin{array}{l}2 \text { mins } \\
35 \text { secs }\end{array}$ & $x$ & $\mathrm{x}$ & & $16 * 13 * 6.5$ & --- \\
\hline & & & & & & $E$ & 050 & $17 / 07 / 20$ & $888 \pm 8^{\circ} \mathrm{C}$ & $\begin{array}{l}5 \\
\text { minutes }\end{array}$ & $x$ & $x$ & & $13.8 * 19.2 * 13.7$ & $13.6 * 19.2 * 13.2$ \\
\hline & & & & & & $F$ & 011 & $09 / 07 / 20$ & $845 \pm 2^{\circ} \mathrm{C}$ & $15 \mathrm{mins}$ & $x$ & $x$ & & --- & --- \\
\hline & & & & & & G & 029 & $16 / 07 / 20$ & $883 \pm 5^{\circ} \mathrm{C}$ & $2 \mathrm{mins}$ & $x$ & $x$ & & $22.3 * 18.9 * 6.6$ & $28.1 * 20.4 * 7.5$ \\
\hline & & & & \multirow[t]{6}{*}{ B21_AS23 } & & $\mathrm{L} 1$ & 028 & $16 / 07 / 20$ & $900 \pm 10^{\circ} \mathrm{C}$ & $2 \mathrm{mins}$ & $x$ & $x$ & & $22.7 * 19.9 * 4.8$ & Deformed \\
\hline & & & & & & $\mathrm{U} 1$ & 023 & $15 / 07 / 20$ & $890 \pm 4^{\circ} \mathrm{C}$ & $\begin{array}{l}1 \quad \min \\
56 \text { secs }\end{array}$ & $x$ & $x$ & & $22.7^{*} 17.9^{*} 13.0$ & $24.3 * 19.2 * 13.1$ \\
\hline & & & & & & L2 & 016 & $13 / 07 / 20$ & $880 \pm 5^{\circ} \mathrm{C}$ & $\begin{array}{l}2 \text { mins } \\
58 \text { secs }\end{array}$ & $x$ & $x$ & $x$ & $23.6^{*} 18.3^{*} 9.9$ & $33.4 * 19.7^{*} 11.5$ \\
\hline & & & & & & $\mathrm{U} 2$ & 030 & $16 / 07 / 20$ & $883 \pm 5^{\circ} \mathrm{C}$ & $2 \mathrm{mins}$ & $x$ & $x$ & $x$ & $23.1 * 19.5 * 10.7$ & $28.4 * 23.0 * 11.7$ \\
\hline & & & & & & L3 & 031 & $16 / 07 / 20$ & $890 \pm 10^{\circ} \mathrm{C}$ & $\begin{array}{l}1 \quad \min \\
30 \text { secs }\end{array}$ & $x$ & $x$ & & $23.8^{*} 9.5^{*} 8.8$ & $29.2 * 10.5 * 12.3$ \\
\hline & & & & & & U3 & 024 & $15 / 07 / 20$ & $871 \pm 5^{\circ} \mathrm{C}$ & $\begin{array}{l}1 \quad \min \\
45 \text { secs }\end{array}$ & $x$ & $\mathrm{x}$ & & --- & --- \\
\hline & & & & \multirow[t]{2}{*}{ B21_AS24 } & & $1 \mathrm{AP}$ & 045 & $17 / 07 / 20$ & $894 \pm 5^{\circ} \mathrm{C}$ & $5 \mathrm{mins}$ & $x$ & $x$ & & $24.7 * 21.4 * 13.9$ & $24.4 * 21.5 * 13.6$ \\
\hline & & & & & & $1 \mathrm{BP}$ & 047 & $17 / 07 / 20$ & $890 \pm 5^{\circ} \mathrm{C}$ & $10 \mathrm{mins}$ & $x$ & $x$ & & $24.5 * 16.4 * 14.4$ & $24.8 * 17.0 * 13.5$ \\
\hline
\end{tabular}




\section{Appendix 2: FTIR measured and averaged data}

The FTIR data of just the measured water absorbance of the samples is attached electronically and the averaged data for each sample measured. 